\title{
Negotiating Citizenship and the Entrepreneurial Self: Funding, Income Assistance, Surveillance and Resistance in the Advanced Liberal Society
}

\author{
by \\ Marisa Barnhart, H.B.A. \\ A Thesis submitted to the Faculty of Graduate Studies and Research \\ in partial fulfillment of the requirements for the degree of \\ Master of Social Work \\ School of Social Work \\ Carleton University \\ Ottawa, Ontario \\ (C) Copyright \\ 2006, Marisa Barnhart
}




$\begin{array}{ll}\begin{array}{l}\text { Library and } \\ \text { Archives Canada }\end{array} & \begin{array}{l}\text { Bibliothèque et } \\ \text { Archives Canada }\end{array} \\ \begin{array}{l}\text { Published Heritage } \\ \text { Branch }\end{array} & \begin{array}{l}\text { Direction du } \\ \text { Patrimoine de l'édition }\end{array} \\ \begin{array}{l}\text { 395 Wellington Street } \\ \text { Ottawa ON K1A ON4 }\end{array} & \begin{array}{l}\text { 395, rue Wellington } \\ \text { Ottawa ON K1A ON4 } \\ \text { Canada }\end{array}\end{array}$

Your file Votre référence ISBN: 978-0-494-23365-8 Our file Notre référence ISBN: $978-0-494-23365-8$

NOTICE:

The author has granted a nonexclusive license allowing Library and Archives Canada to reproduce, publish, archive, preserve, conserve, communicate to the public by telecommunication or on the Internet, loan, distribute and sell theses worldwide, for commercial or noncommercial purposes, in microform, paper, electronic and/or any other formats.

The author retains copyright ownership and moral rights in this thesis. Neither the thesis nor substantial extracts from it may be printed or otherwise reproduced without the author's permission.
AVIS:

L'auteur a accordé une licence non exclusive permettant à la Bibliothèque et Archives Canada de reproduire, publier, archiver, sauvegarder, conserver, transmettre au public par télécommunication ou par l'Internet, prêter, distribuer et vendre des thèses partout dans le monde, à des fins commerciales ou autres, sur support microforme, papier, électronique et/ou autres formats.

L'auteur conserve la propriété du droit d'auteur et des droits moraux qui protège cette thèse. $\mathrm{Ni}$ la thèse ni des extraits substantiels de celle-ci ne doivent être imprimés ou autrement reproduits sans son autorisation.
In compliance with the Canadian

Privacy Act some supporting forms may have been removed from this thesis.

While these forms may be included in the document page count, their removal does not represent any loss of content from the thesis.
Conformément à la loi canadienne sur la protection de la vie privée, quelques formulaires secondaires ont été enlevés de cette thèse.

Bien que ces formulaires aient inclus dans la pagination, il n'y aura aucun contenu manquant.

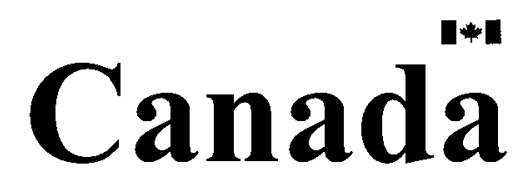




\begin{abstract}
This thesis attempts to address a gap in current literature on surveillance, resistance, funding and welfare. While there is a good deal of literature on the surveillance and restriction of resistance of people living on welfare and social service workers, there is very little, if any, literature that links these two trends in surveillance and resistance. This work seeks to advance our understandings of the impact of these trends on each group individually, as well as on the nature of our relationships with one another.

In particular, this project employs a governmentality perspective to investigate the ways in which people living on social assistance and people working in social service agencies take up notions of active citizenship and the entrepreneurial self, in the context of their funding and income arrangements. These constitutions of the self shape and are shaped by resistance and surveillance. In the spirit of post-structural and critical social work analytics, this project hopes to unpack some of the stories of a small group of participants in order to develop a deeper understanding of the many complex issues facing them with respect to income, funding, surveillance and resistance.
\end{abstract}




\section{ACKNOWLEDGEMENTS}

First, a warm thank you to all of the individuals who participated in this

project. Your thoughtful and passionate commentaries, and generous sharing of your experiences have made this a wonderful and enlightening experience for me. I gratefully take your stories with me in this and all of my future work.

A special thank you to Sarah Todd for the ongoing support and encouragement you offered to me throughout this process. I particularly benefited from your guidance and insight, and have learned much from you over the past couple of years. You always inspire me to always reach a bit further.

To Pat Evans for your patience and thoughtful feedback. Your immense and intuitive understanding of the qualitative research process was a life-saver, and helped guide me through some of the more difficult aspects of this project.

To my friends and family who have had to endure this process along with me, some with their own research and writing, and some who listened to my endless agonizing about the details, thank you for your support and encouragement (and occasional "tough love"). And to Catherine, for everything.

Thank you all so much! 


\section{Table of Contents}

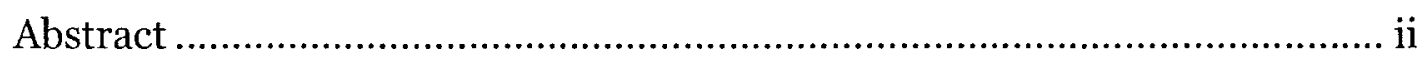

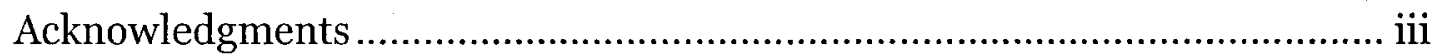

Introduction ...............................................................1

Theoretical Approach ................................................................. 3

Literature Review....................................................................... 5

Governmentality and Power.................................................. 9

Governmentality and Our Place as "Actors" ............................ 10

Governmentality and Self-Governance ................................... 13

Research Question ........................................................................ 16

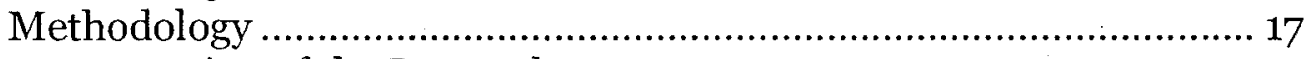

Design of the Research ........................................................... 17

Recruitment Procedure ...................................................... 18

The Participants................................................................... 20

Data Collection: Sources and Methods ………………........... 22

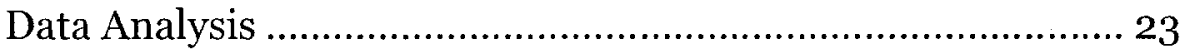

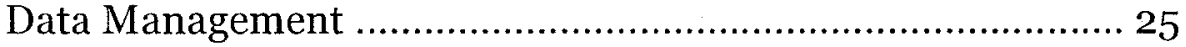

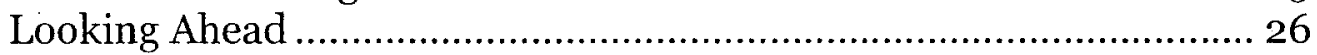

Chapter One: Social Service Agency Workers and Managers .......28

Workers' Perceptions of Funding Benefits,

Tensions and Limitations ....................................................... 30

Government Funding .......................................................... 31

Donations............................................................................ 33

Funding And Control .................................................................. 36

Too Close for Comfort......................................................... 36

Framing Accountability: Funders and Agencies ....................... 39

Accountability to the Agency: Obedience and

Technologies of the Self............................................... 40

Instability, Fear and Being Silenced ................................................... 43

Decentralizing Surveillance .......................................................... 48

Surveillance within the Agency …………………................. 50

Statistics as a Technique of Governmentality ........................... 52

Chapter Two: People Living on Social Assistance .......................57

Perceptions of People Living on Social Assistance:

Tensions, Benefits and Limitations ......................................... 58

Stigma, Shame, Prejudice and Self-Esteem ............................. 60

Visibility and Feeling Violated ................................................ 64

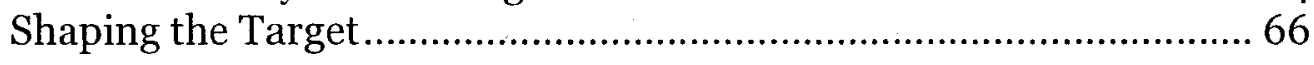




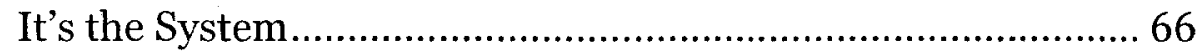

For-Profit Agencies ........................................................ 68

Agency Cuts............................................................. 70

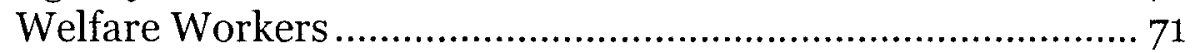

Funding and Control............................................................... 73

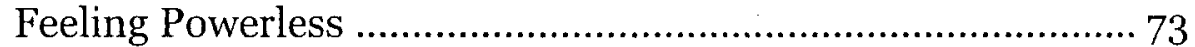

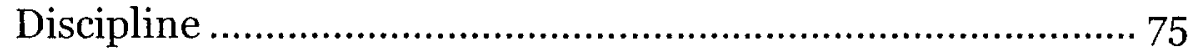

\section{Chapter Three: The Entrepreneurial Self and the Constitution of}

Active Citizenship .........................................................81

The Entrepreneurial Self and Enterprise Culture .............................. 86

The Entrepreneurial Self .................................................... 87

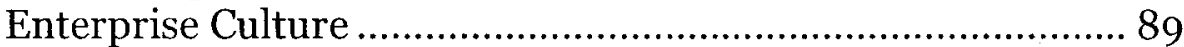

Responsibilizing the Self.................................................................... 93

Social Workers as Experts in Enterprise Culture................................ 95

Constituting Ourselves: Identities and Subjectivities......................... 99

Chapter Four: Resistance ..................................................106

Dividing Practices ......................................................................... 108

Official/Good Forms of Resistance ......................................... 109

Unofficial/Bad Forms of Resistance ...................................... 112

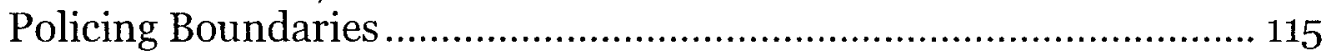

Professionalism................................................................ 117

Being Strategic and Following Rules....................................... 119

Value in Unofficial Resistance ........................................................ 124

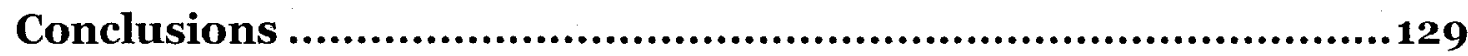

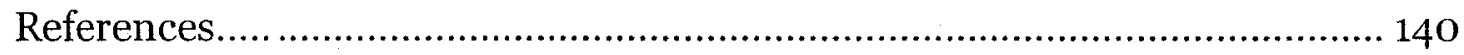

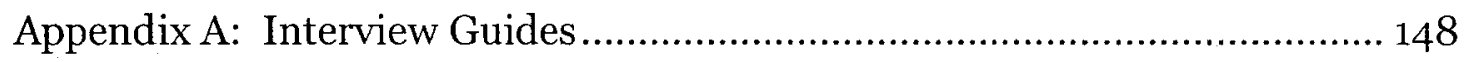

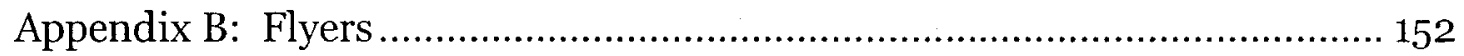

Appendix C: Information Letter and Informed Consent .............................. 153 


\section{APPENDICIES}

Appendix A: Interview Guide

Appendix B: Flyers

Appendix C: Information Letter and Informed Consent 


\section{INTRODUCTION}

In the last few decades a broad body of literature has been created to acknowledge the surveillance and restriction of welfare recipients and to a lesser degree social workers (Moffat, 1999; Gilliom, 2001; Mosher et al., 2004). Individuals interacting with social assistance systems often find themselves under the surveillance of the system which provides them with financial support, and this is a phenomenon experienced by social worker and recipient alike. Under the effect of the "panopticon," (Foucault, 1979) which is primarily enacted through computerized systems, but also the gaze of "accountability agents", the movements of workers and clients are watched, with workers playing the dual role of the watcher and the watched (Moffat, 1999). However, while we can speak of the effect of the panopticon, the reality of workers and recipients is best understood through techniques of governmentality, of which the reality of the panopticon is only a part. Here we can see the results of the "triangle" of political relations - governmentality, sovereignty and discipline (Foucault, 1991). This reality is ever-present in the lives of workers and those receiving assistance.

The effect of governmentality has serious impacts on the ability of clients and workers to engage in acts of resistance against the State mechanisms and system that regulate their lives. Concerns about having financial support "cut off' change the movements of clients and workers, and thus reshape their citizenship (Isin, 2002) and self-determination (Leonard, 1997). Discipline takes many forms, but in this case I will look primarily at the use of cut-offs and suspensions to control people receiving social assistance under the Ontario 
Welfare regime, and professional discipline and funding reductions that affect workers. An investigation of this discipline and regulation is particularly crucial, as it has intensified since 1995 (Ralph et al., 1997).

In general, this thesis draws on data from interviews with service providers and people receiving social services to explore the hypothesis that, in advanced liberal societies, funding and income models encourage subjects to conduct themselves so as to secure funding/income and, more often than not, the relationship between securing funding is intimately linked to the dynamics of securing an income. As such, this thesis seeks to advance our understanding of the power relationships and restrictions placed both upon individuals receiving social assistance and social service workers and/or managers who work for agencies that are funded by governments, corporations, and/or funding agencies. In addition, it seeks to examine the similarities and differences in the ways in which their "funding arrangements" restrict their abilities to resist and fight oppressive systems.

I am particularly interested in looking at the ways in which folks who are constructed as dependent are restricted (or feel restricted) by the realities of their "funding arrangements" and sources of income (i.e. are afraid to speak out against those organizations from whom they are receiving financial support for fear of getting "cut off"). When we encounter similarities in the manifestations of these restrictions/relationships between recipients and "funders", how can we use this information/analysis to inform the ways in which social workers manage and construct our relationships with the people who come to us seeking help, recognizing that there is still a complex power dynamic in that relationship? 
This thesis is intended to address a gap in current literature on surveillance, resistance, funding and welfare. While there is a good deal of literature on the surveillance and restriction of resistance of people receiving welfare and social service workers, there is very little, if any, literature that links these two trends in surveillance and resistance. This work seeks to advance our understandings of the impact of these trends on each group individually, as well as on the nature of our relationships with one another. Through the methodology described below, this research seeks to solidify social work as a practice of resistance.

\section{Theoretical Approach}

A post-structural and critical social work frame informs this study (Fook, 2002; Healy, 2000; Rossiter, 2005a; Rossiter, 2005b). I explore the ways in which these theories make visible the social control of people receiving social assistance and social service workers. Foucault's work, particularly related to his discussion of governmentality (Foucault, 1991), is a major source of thinking about the ways in which techniques of governmentality, including surveillance, impact the lives of these particular social service workers and people receiving social assistance. I focus particularly on Rose's concept of the entrepreneurial self (1996) as a technique of governmentality which is specifically applicable to the experiences of participants in this project. Critical social work, influenced both by structural and post-structural philosophies, offers a way into thinking about power, domination and discourse, that will inform the ways in which we 
deconstruct and reconstruct those experiences, and engage in acts of resistance (Fook, 2002; Hick \& Pozzutto, 2005). Additionally, the work of Deleuze and Guattari is useful in attending to the ways in which power operates as a web-like network, decentralizing surveillance and resistance (1987). I found Deleuze's discussion of the control society is particularly useful when investigating the themes I observed emerging from my discussions with participants.

One of the critiques of Foucauldian analysis is that it often feels overdetermined, eliminating the possibility for actors to behave outside of the relations that the theorists argue are central to the social organization of our societies. While I think there is value to this critique, I would argue that there is a possibility to use Foucault's analytic frameworks and still see openings for subjects to resist or to take up and accommodate relations to different degrees, depending upon their social location, and individual agency.

I have selected these theories because they offer a way into thinking about the complexities of people's lives, and challenge traditional notions of structural oppression. While we can certainly think about the lives of the poor as influenced by meta-narratives of oppression and resistance, taken together poststructuralism and critical social work offer a more nuanced look into the experiences of these individuals and the power relations that impact their lives (Leonard, 1997; Fook, 2002). Moreover, these theoretical frameworks allow notions of agency to be visible; oppression does not simply present as a function of structural inequities, but instead becomes a daily practice which we resist and reproduce at multiple sites (Healy, 1999). 


\section{Literature Review}

Much work has been done on the surveillance of people living on social assistance and on the regulation of social work agencies through funding. Connections between the surveillance of people receiving social assistance and the surveillance of social service workers are not represented in the current literature. Instead, these trends are treated as independent, and linkages are not made between them. This project pulls out themes in the two bodies of literature investigating these trends, and incorporates them into an analysis of the interconnections between both of these types of experiences.

The literature investigating the surveillance of individuals receiving social assistance, and their subsequent resistance, is diverse, and originates from a number of disciplines. Historical, political, social work and gendered analyses (Piven and Cloward, 1993; Gilliom, 2001; Parenti, 2003; Moffat, 1999; Little, 1998; Mosher et al., 2004) all provide context for looking at the surveillance and resistance of poor people and social workers. Additionally, a critical look at the construction of dependency facilitates an analysis of the ways in which surveillance gets justified in specific political contexts (Fraser and Gordon, 1994). In particular, the literature is most compelling when it looks not only at the ways in which the movements of individuals are monitored, passively and actively, but also the ways in which people become involved in social movements to resist such surveillance and engage in everyday forms of resistance (Gilliom, 2001, Piven and Cloward, 1993).

Gilliom (2001) in particular connects the concepts of surveillance and resistance in the lives of low-income mothers. He investigates the ways in which 
these mothers are under the gaze of the "panopticon" on a daily basis but also looks at their movements of everyday resistance (99) to subvert their watchers. For example, with workers regularly monitoring the bank accounts of people living on social assistance, people living on social assistance, in turn, are careful about what types of transactions appear on their accounts, and often use cash to obscure their daily financial activities and protect themselves from surveillance. While these may not be traditional forms of political action, they are nonetheless movements that frustrate the social services system that acts as an oppressive and policing force in the lives of these women, and other individuals engaging with the social services system (100). Moffat also incorporates this analysis of the everyday practices of the welfare office (Moffat, 1999). This critique extends the analysis of Piven and Cloward, which looks more broadly at traditional and collectivist movements of poor people to work against the State (Piven and Cloward, 1979). Gilliom, and others who engage in this sort of everyday analysis provide a language with which to discuss those important moments of the "everyday" (Smith, 1987) in which people are subjected to, and resist, movements by other actors and systems.

The literature surrounding the regulation of social workers and social service agencies is broad, and also ranges across disciplines. Currently, with the "marketization" of the social services, there is an ongoing debate raging as to the impact that different modes of funding have upon the ability for agencies and charities to engage in democracy-building and civil society (Alexander et al., 1999). Particularly with the ongoing threat of government intervention, and the increase of private funding into agencies via private-public partnerships, and 
notions of corporate citizenship (Dobbin, 1998), much of the literature questions the ability for agencies to maintain their autonomy and advocate for their clients in meaningful ways which are not compromised by funding requirements (Alexander et al., 1999; McFarlane \& Roach, 1999). Concerns around "mission drift," "mission creep" (Loconte, 1997; McFarlane and Roach, 1999) and goal displacement (Froelich, 1999), troubles those who are committed to agencies and workers as active participants in a strong democratic system. To these researchers, there is an ever-present danger that agencies and workers will not be able to advocate for their clients and engage meaningfully in a civil society if they are constantly wary of procuring funding for the next year/project/initiative. Moves of agencies/workers begin to reflect funding constraints, and the surveillance begins to shape their everyday actions and resistance. These concerns mirror those of people receiving social assistance, where fears of being cut-off also impact their lives and everyday resistance.

When we examine this literature, it becomes clear that such writings facilitate a destabilization of the identity of the activist social worker, and bring to the fore the notion of social services as a tool of surveillance (Healy, 1999). In this way, we can see that even social workers coming from a structural social work perspective facilitate the ongoing surveillance of the lives of people receiving social assistance. This picture is complicated by the fact that social workers are also under the effect of governmentality, and in particular their subjectivities are constituted as active self-governing citizens, mobilized particularly to the benefit of the advanced liberal state (Rose, 1999; Dean, 1999). The texture of the problem is made even clearer by Moffat's investigation of the 
ways in which workers are both surveilled in the workplace, and engage in a surveillance role with respect to people seeking help (1999). This problematizes any movements by workers to engage in emancipatory practice, but these actions nonetheless remain important, particularly given the ways in which social service workers experience surveillance in their own work/lives. What this literature can do is help us to understand the ways in which activities are complex, and try to move around and with the complexities to construct meaningful practice.

To begin this discussion, I will first turn to the reason that I have chosen a governmentality perspective to investigate these trends as opposed to a structural social work approach. The structural approach to social work is rooted in an analysis of state power and resistance to state power, and it is this understanding that many of the participants in this project articulated when speaking about power and resistance. Pioneered by Maurice Moreau in the mid-1970s, structural social work relies on "the major radical themes of Marxism, feminism, radical humanism and radical structuralism" (Mullaly, 1997:105) for its root theories. Ideologically influenced by theories reliant on critiques of capitalism and state power, structural social work has recently faced challenges by the post-structural critical framework of Foucault and his contemporaries. In particular, the concept of "governmentality" offers a new way of thinking about power and resistance, and challenges social work to think beyond traditional notions of power. By shifting the analysis from a focus on state power, to an understanding of power as more complex and diffuse, governmentality perspectives challenge social workers committed to social justice to rethink the ways in which they are implicated in 
power relations and practices. Perspectives on governmentality have enriched the political foundation that I have gained from structural analysis, and it is for this reason that I have chosen to further pursue this type of analysis in this project.

\section{Governmentality and Power}

The concept of governmentality, proposed by Foucault, offers a challenge to an analysis that is rooted in notions of centralized power held by the State. Foucault conceptualizes power differently, seeing it not as a centralized force to be held, but rather inherent in every space and transaction. Power, in this model, is diffuse, molecular and capillary (Fraser, 1989). Not only is power conceptualized as decentralized, but it is also seen as "productive rather than prohibitive" (Fraser, 1989:18). This means that power has a creative energy produced through power relations; it does not just take away, as one might consider is the role of the State, it does not just regulate individuals/citizens through legislation and punitive measures, but also in subtle ways disciplines people to regulate themselves. This view of power complicates the way in which we analyze and discuss power and resistance. Foucault suggests that "where there is power there is resistance," although there is no central point of power that can be consciously and explicitly resisted (1978:95). In this way, an object (in this case, the State) does not hold power; power is not something to be seized in a manner befitting Marxist revolution. Instead, one begins an analysis by dissecting power relations and its many techniques and manifestations, and then can, at that point, move to a view of the State as a benefactor of power 
relations. This perspective complicates the way in which we view and construct resistance. Fraser suggests, "this suffices to rule out those types of liberation politics that presuppose that power is essentially repressive" (1989:18). This reframing of resistance and sites of resistance issues a challenge to structural oppositional politics by suggesting a different understanding of power and resistance, one that we all reproduce and resist.

For Foucault, government is power relations codified; he speaks of the "art of government" and the "tactics of government" (1991:99). By government, he does not solely refer to the State; he also incorporates other units of power relations (for example, the family) in this definition. When power relations become "managerial" (books, texts, experts, statistics, calculations, "how to" manuals), when knowledge begins to proliferate and become codified, this is all part of governmentalization (Foucault, 1991).

Governmentality and our Place as "Actors"

One of the strengths of a governmentality perspective in social work in particular, and to notions of state power in specific, is the ways in which it frames our practices and movements. Governmentality adjusts its lens to focus on practices and techniques of power, and does not place actors as central to its analysis. What this assertion suggests is that subjects are constantly participating in practices of governance, be they of self-governance or the governance of others (Dean, 1999:12). The concept of power is shifted to an understanding in which we all become embedded and engaged in power relations; no one person is excused from these power relations by their individual commitments to personal 
or community liberation. This understanding implicates us in processes in which every movement becomes dangerous; even our movements against so-called oppression becomes complicated by our engagement (Cruikshank, 1999).

Foucault suggests, "no simple lines could be drawn between reformers and reactionaries, between those "on the side of power" and those "on the side of resistance" (Rainbow and Rose, 1994:ix). We are all in the uncomfortable place of being implicated in the technologies of governance and power. This insight challenges notions of state power, which emphasizes the agency of particular actors, and places them in opposition to one another, whereby power is exchanged and potentially seized by one or another. In structural social work power is almost treated as a commodity, an ever-expanding commodity perhaps, but one which is important in obtaining to create political change. The commodity of centralized power is ideally seized from elite power holders by and for "the people." In a governmentality perspective, this picture becomes more complicated as the understanding of power is not linear or simple, and power, itself, is interwoven with resistance.

This notion of power as diffuse implicates us in the practices of power, and additionally implicates us in our own governance. The structural perspective in social work is primarily concerned with personal liberation and empowerment, whereby clients become empowered individuals enabled to confront centralized power, with an eye to the political consequences of such liberation:

The process of empowerment has been likened to a dialogical relationship in which those becoming empowered engage in a staged process of changing consciousness in relation to their social world, and their ability to act within it" (Fook \& Morley, 2005:69). 
In her work, Cruikshank problematizes the processes of self-esteem and selfgovernance. This offers an interesting angle from which to consider structural and empowerment practice, two influential strains of social work, which are focused on building self-esteem, and helping people to learn self-discipline and governance. Using a governmentality perspective, we constitute ourselves as governable by taking up the goal of self-esteem and thereby fulfilling our social responsibilities and roles as citizens; we act upon ourselves by participating as active citizens so governments do not have this obligation (Cruikshank, 1996). This analysis is consistent with her arguments in Will to Empower, where she argues, among other things, that these types of discourses -- empowerment, democracy, and self-esteem -- are at once enabling and constraining (Cruikshank, 1999). They are not good or bad, but are inherently political; they at once contain the possibilities of both domination and freedom (Cruikshank, 1999).

Where the challenge to structural social work, and therefore theories of state power, exist is that the project of self-esteem and personal liberation is not coordinated through a top-down modality of centralized power. There are no grand conspiracies to use an ideology of self-esteem to dupe the masses into governing themselves, this is not a technology engineered from above, but the effect is that we monitor our actions in such a way that we place ourselves under surveillance (Cruikshank, 1996:234). This has the handy effect of creating "welladjusted", "socially responsible citizens" who are easy to govern. What becomes complicated about this analysis is that this modality of power does not provide a solid entry point or centralized point at which to direct one's resistance. As 
Cruikshank suggests, "if you look for a face...you will be disappointed, because in the strategic field of welfare everyone is accountable but there are no bodies" (Cruikshank, 1999:117). Where structural social work would resist government state power by a coordinated and explicit performance of resistance, governmentality perspectives might approach this situation differently. Although an analysis from a governmentality perspective would not necessarily provide a model of resistance, Fraser suggests that Foucault "calls in no uncertain terms for resistance to domination" (Fraser, 1989:29). A solid analysis of state power as centralized and visible allows a measure of comfort and security in protest, speaking out, and challenging power. Perhaps, however, it is useful to be a little bit less comfortable with our place in power relations.

\section{Governmentality and Self-Governance}

The issues that Cruikshank and Foucault bring to the picture are the problematics of social work notions of empowerment, both related to casework and community development. While structural social workers might see themselves as radical agents empowering clients to fight against the state, such simple notions of good and bad are confounded in a governmentality perspective. This perspective suggests that every moment between the social worker and "client" is about discipline. Even a so-called empowering moment where a client voluntarily comes for help with a particular issue, and the social worker explores with her some options where the client has ultimate choice over the direction, this situation, by facilitating a space for the building of self-esteem, has both liberatory and constraining effects. Governmentality, and this new 
understanding of power, then, has implications for the ways in which we think about helping, relationships, and moments of collaborative work. We are forced to see ourselves as part of a picture, not as heroes, but in relation to "all those many transactions where our own concerns with our own lives have also become the concern with others - not just explicitly political agencies, but also all those other authorities (religious, medical, commercial, therapeutic) who whisper in our ears and advise us how to act and who to be" (Rainbow and Rose, 1994:xi). We are all being worked upon and surveilled at all times; we are embedded in these power relations. In the case of social workers, this reality is further complicated by the fact that we also have to concern ourselves with the ways in which we whisper in the ears of others and participate in multiple and complex sets of power relations.

Related to these concepts is Rose's notion of the entrepreneurial self, which is one who is continuously engaged in maximizing his or her potential (1999). The entrepreneurial self does not just apply to economic capitalization of the self. It is also applied to the ways in which subjects maintain their bodies, their homes, their education and other areas of their lives. Rose argues that active entrepreneurial citizens ensure that they take full advantage of their freedom by participating actively in civic life through the "proper channels" (1999). These are concepts that I take up with respect to the experiences relayed by participants in the data.

Some scholars suggest that the structural perspective can benefit from post-structuralist/postmodern perspectives (Leonard, 1997; Fook, 2002). I would further suggest that a view to governmentality complicates our 
understanding of power/knowledge, and opens up possibilities in terms of understanding power as capillary and sites of power and resistance happening at multiple sites and in tandem. Critical social work, influenced both by structural and post-structural philosophies, offers a way into thinking about power, domination and discourse, that will inform the ways in which we deconstruct and reconstruct these experiences, and engage in acts of resistance (Fook, 2002; Hick \& Pozzutto, 2005). Power relations are often fluid, but there are certainly asymmetries in power. Technologies of power/domination "determine the conduct of individuals and submit them to certain ends or domination" while technologies of the self encourage individuals to take up certain practices to transform themselves (Foucault, 1988:18). In this context, groups/actors have some room to maneouver and there may be possibilities for resistance/movement. Complete domination is rare; and, in times of crisis, opportunities for resistance open up and move (Rose and Miller, 1992).

Often, as a result of multiple commitments to challenging injustice and oppression, critical social workers often try to "use Foucault's work to support non-Foucauldian purposes," and try to pair post-structuralism with a liberatory humanist project (McBeath and Webb, 2005:171). I have tried to avoid this move throughout my own analysis, while at the same time attempting to not minimize asymmetries in power relations. Moreover, some scholars accuse critical social work theorists of "not [looking] deeply at the genealogies of conduct and of power and/or knowledge within the domain of social work agencies... [instead grabbing] at a mechanistic 'black-box' account of the institutional ground of operation of social work upon a subjugated population - the client" 
(McBeath and Webb, 2005:173). In this project, I have tried to address this concern by looking at how we are all implicated in the techniques of governmentality, and while we cannot escape power relations or redeem our practice, we can hope to analyze and understand them.

\section{Research Question}

To guide my research, early in the process I developed the following questions: How are people receiving social assistance and social workers policed? How do their sources of income and funding place them under surveillance? How does that surveillance shape their relationships with one another and respective forms of resistance? These questions evolved as the project unfolded. Eventually, my attention began to turn towards how constitutions of active citizenship and the entrepreneurial self, as discussed by Nikolas Rose, helped to make sense of the data presented in the interviews. As I will discuss, specifically in Chapter 3, I believe Rose's theories to be particularly useful in interpreting the ways in which participants living on social assistance and working in social service agencies negotiate their daily lives with respect to funding and income arrangements. While this may appear as a departure from the initial questions, I see the literature on active citizenship and the entrepreneurial self providing useful analytic insight to the ubiquitous and nuanced ways in which regulation works beyond policing and surveillance; enacted through one's ability to self regulate before, or at the same time as, being policed and/or surveilled by institutional relations. 
The concrete nature of participant's experiences, provide a helpful site to consider how abstract and theoretical concepts like the entrepreneurial self and active citizenship might play out in people's lives. I argue that funding models are, in part, shaped to exploit and encourage an active constitution of the self. With respect to participants working in social service agencies, the aim can be articulated in an example offered by Elizabeth (one of the social service workers participating in this project) in her interview. That is, workers will conduct themselves in such a way that when their project's funding comes up for renewal on the City Council's agenda, they will be able to secure maximum funding. In this scenario, workers are not only policed by funding requirements and regulations, they also police themselves to obtain maximum capital with which to provide essential services. Therefore, the initial research questions around surveillance and how people working in social service agencies and people living on social assistance are policed is enhanced by further analysis into how they actively pursue and participate in their own surveillance.

\section{Methodology}

\section{Design of the Research}

This study is qualitative in nature, as I am interested in helping to bring to the fore voices that are typically repressed by the very surveillance and fear that is the topic of this study. My interviewing process is consistent with feminist research principles (Kirby \& McKenna, 1989; Reinharz, 1992). For instance, interviews, while having an interview guide, consisted of fairly broad questions to ensure that the voices of the participants came through and were heard without 
too much direction from me as the researcher. Given that people living in poverty and people working with individuals living in poverty are often in a position where their experiences and perspectives are ignored, it is important that I was as non-directive as possible when facilitating the interviews. I found that interviews were fairly free-flowing, and the participants and I found ourselves going "off-topic" constantly, exploring issues of interest to them (Riordon, 2004).

Additionally, I was primarily interested in hearing from participants about their experiences with surveillance, resistance and relationships. For this reason, while some questions seemed to have little to do, specifically, with these subjects, they were broadly constructed to allow for participants to define for themselves what resistance looks like, and were therefore in control of defining and labeling their own experiences (see Appendix A). This technique was useful in eliciting responses that I did not expect, but also was useful in developing a more holistic understanding of surveillance, governance and resistance in people's lives. Order and wording was often modified during the interviews to preserve flow and comfort during the process, and participants were given the opportunity to pass on questions that they would prefer not to answer. Most participants answered all of the questions asked, and only one participant chose to pass on one question.

\section{Recruitment Procedure}

To conduct this study, I interviewed six people receiving social assistance and four social service workers/managers who work for agencies that are funded by governments, corporations and/or funding agencies. The participants were all 
drawn from one city in Ontario. This group of people is not a representative sample, but instead provides an in-depth look at the ways in which these specific participants, under the effect of governmentality, relate to their situations. One effect of participants self-selecting was that they already had a sense of some of the ways in which surveillance impacted their lives and their work, and were able to speak to this experience.

To recruit participants, I used a combination of active advertising, wordof-mouth and snowball recruitment. I placed posters and pamphlets in organizations that are accessed by people receiving social assistance, letting participants self-select to participate in the research process. I also spoke with social service workers both to invite their participation in the research as well as to pass on my contact information, pamphlet (Appendix B) and information letter (Appendix C) to anyone receiving social assistance who they think would be interested in participating in the research. Given that sometimes people receiving social assistance also struggle with literacy issues, it was important that information about the project circulate by word of mouth, and this is the reason for asking social service workers to pass on the information. All participation was voluntary, and anyone suggesting the project to anyone else was doing so for informational purposes only. Most participants indicated that they had seen my poster up in an agency, or grabbed my pamphlet from a display in the community. Most social service agency workers were recruited more actively through networking, as I found they were generally more hesitant to volunteer.

My suspicion is that in this small community, people working in social service agencies were nervous of having their identities exposed and being 
sanctioned for their participation. Additionally, since recruitment was based on self-selection, people who felt particularly affected by their funding or income arrangements were more likely to come forward. Frontline workers seemed to be less likely to see themselves as affected personally by funding arrangements and therefore were less likely to see their participation as relevant. Managers, on the other hand, are involved in the day-to-day procurement and maintenance of funding and consequently seemed to see more reason to participate. Additionally, managers might have been less fearful of reprisal than frontline workers, and therefore were more likely to come forward. In the end, the participants in this project were largely managers and social service recipients and there was far less participation from workers, than from recipients. The limited the data that I was able to collect from the perspective of people who are affected by social service funding relations and accounts for my heavy use of the data secured from interviews with Elizabeth and Michael.

\section{The Participants}

I spoke with ten participants, four of whom work in social service agencies, and six of whom are living on social assistance. While I actively recruited both groups, sixteen people living on social assistance contacted me and out of this, six participated in interviews. Only four people working for social service agencies agreed to participate. While there was not a great deal of racial and gender diversity in either participant group, there was some variation with respect to age and length of time on social assistance or working in social services. 
Most of the participants living on social assistance with whom I spoke were between 35-50 years old. Most of them were single women; Mark was the only man in the group, and he was considerably younger than the rest of the participants with an age range between 20-30 years old. Sarah had school age children and Pamela had adult children.

There was some diversity with respect to time on welfare within the group. Robin and Pamela have been on welfare for less than one year. Pamela is currently homeless and Robin is in the process of applying for Ontario Disability Support Program (ODSP) benefits. Lindsay has been living on and off welfare for less than five years. Mark has been living on and off welfare for 5 to 10 years. Rebecca has been living on welfare for 10 to 15 years, and is currently in the process of applying for ODSP. Sarah has been living on and off welfare for 15 to 20 years, but she "took herself off assistance voluntarily" three months ago.

The group of participants working in social service agencies had similar patterns of gender diversity with more women than men participating. Elizabeth, Michael and Marie were all 45 to 55 years of age, and have all been working in social service agencies for 10 to 20 years. All were in various levels of management in their agencies. Julia was the only younger person in this group. She was between 25 to 35 years of age and she has been working as a frontline worker for just a few years. 


\section{Data Collection: Sources and Methods}

Most interviews took place in a private room at a local community facility. A few participants opted to meet me at their places of work, and one interview took place over the phone.

Interviews ran approximately 60-90 minutes and followed an interview guide (Appendix A). I transcribed half of the interviews, and hired a private contractor to transcribe the rest of the interviews. The transcripts were used as the basis of analysis. The participant's name was not on the tape and therefore remained anonymous. Permission was obtained for the audio-taping and notetaking during the interview. Only one participant chose not to have the interview audio-taped. Given potential literacy issues with low-income populations, all permission (i.e. letter of information/consent form) was also undertaken verbally. All participants were given copies of their transcripts and were offered the opportunity to remove anything with which they were not comfortable or that did not accurately represent their opinions.

With the completion of the thesis defense, participants will be supplied with a summary of the findings and interpretations of the research. As there may be literacy issues with some of the people that I interview, I will be available to sit down with them and discuss the findings and interpretations with them, to ensure that all of the people involved in the study have an opportunity to engage with the final product.

Interviews were scheduled at the convenience of participants to acknowledge the valuable time and wisdom that they have offered to the process, particularly considering the complicated and hectic lives of poor people and 
social service workers. Finally, if participants were interested, I offered some information about local resources including the contact information for local social, advocacy and anti-poverty services (Kirby \& McKenna, 1989). In these ways, every effort was made to minimize the possible economic, social, emotional and psychological risks in participating in the research.

\section{Data Analysis}

To analyze the interviews, I did 3 readings. I used open coding for the first reading to look for general themes, and more focused codings for the second and final readings to examine the finer aspects of the transcripts including language and more subtle themes. I did go back to the transcripts a few more times to look at select passages. In my readings, I typically looked for key words that might illustrate participants' feelings about their funding and income arrangements. Words that jumped off the page for me related to un/fairness, surviving, being productive, feeling watched, being careful, being professional, and putting on a good face. As in the interviews, I tried to follow the directions that participants were inclined to take me, but I was also guided by my own perceptions about what might be useful. Because of my own understandings of funding, income, surveillance and resistance, my lens on the issues certainly influenced what seemed the most interesting and useful in the transcripts, and while I tried to modify this somewhat, since I am also embedded in the power relations participants were speaking of, my use of the data was not neutral or objective.

The interviews varied greatly in length with some as short as half of an hour and some as long as an hour and a half. For this reason, some of the longer 
interviews, in particular Michael and Elizabeth, offered more data to work with than others. Also, since my interviews with them were longer than both Marie and Julia's, which ran half an hour each, I was able to develop more rapport with Michael and Elizabeth, which seemed to help them to share more risky insights with me. Additionally, Marie did not allow the interview to be taped, which limited my ability to access and analyze her precise words throughout the coding and analysis process. Thus, my final text relies quite heavily on the data that I was able to secure from my discussions with Elizabeth and Michael.

Also contributing to the overall analysis was the ways in which the people working in social service agencies were located in their agencies. Julia was the only worker not occupying a managerial role and I believe that this affected the way that she spoke about funding. Whereas Elizabeth, Michael and Marie spoke very directly about the ways in which funding affects their day-to-day operations and conduct, Julia spoke less about this and more about the ways in which her position in the agency affects her daily work. Therefore while Julia's daily work is textured by the complexities of funding and income strings, her statements relating to these issues were less direct and therefore less likely to capture my attention on the first few rounds of coding. While my recruitment strategy did not take into account the ways in which different agency worker roles might affect perspectives on funding and income, there certainly seemed to be some variation in this small group, and this might be an interesting direction for future research.

Finally, with respect to the different treatment of workers and people living on social assistance, as someone cognizant of the relations of power and also someone who is sees herself reflected in the roles of the participants who 
were working in social service agencies, my tendency was to be more sympathetic to people living on social assistance than to people working in social service agencies. This is partially because I aim to be critical of my own practice, and my own complicity in the relations of power and the ways in which social workers often occupy a social control function in their work. This lens plays into the ways in which I read and treated the interviews, and although I tried to offer a systematic treatment of both sets of interviews, it is useful to acknowledge that this tendency more than likely influenced my readings of the interviews and the ways that certain passages and not others leapt off the page for me.

\section{Data Management}

The identities of participants remained anonymous. Given the nature of the project, only confidentiality of participants' identities was guaranteed, however, any statements that could put participants at risk were kept confidential. A few participants suggested that they would not mind if their identities were disclosed, but did not specifically suggest that they would like to be identified. Transcripts were numbered, and participants are only identified by pseudonym in the final paper. Transcripts have been kept in a locked filing cabinet, and data was coded so as to preserve the anonymity of the participants (Kirby \& McKenna, 1989). I am the only person who knows the participants by name. The data will be shredded at the conclusion of a successful defense. Participants were made aware of this, both in the initial recruitment of the participants and at the beginning and end of the interview when the information letter and consent portion is discussed. 
As a result of the efforts to secure anonymity, there are few risks associated with this thesis. To secure anonymity, the city in which the interviews took place is not revealed in the final product. Additionally, participants selfselected and were offered the opportunity to opt-out of the process at any time to reduce the risks associated with participating in this research project.

\section{Looking Ahead}

In the following chapters I will begin to explore the ways in which funding and income, and concomitant surveillance and governance, shape the way that participants take up subjectivities consistent with active citizenship and the entrepreneurial self. I will further explore the ways in which these subjectivities both open up and constrain possibilities for resistance.

In chapters one and two I look at both participant groups individually in an effort to outline some major themes. My exploration of how workers, particularly managers, at social service agencies negotiate their funders takes place in the following chapter. Particularly, I will attend to the ways in which the intimacy of a funder, the notion of accountability and the desire for statistics, regulates workers. At the same time, I argue, workers regulate themselves to fall within the parameters set by funders. In chapter 2, my attention shifts to people receiving social assistance and the relations of power specific to their engagement with the welfare system. Here I investigate the techniques associated with discipline, surveillance and the in/visibility related to income assistance and control. These chapters are meant to provide some foundation and separate analysis of the two groups before launching into a more analytical discussion 
about how the themes can be understood in terms of the entrepreneurial self in the enterprise society and possibilities for resistance.

This is the focus of chapter three where I turn my gaze to the specific technique of the entrepreneurial self. This technique expressly relates to the ways in which participants working for social service agencies and people living on social assistance take up subjectivities associated with active citizenship and continuous capitalization of the self. The complexities of this technique and others which manifest in the lives of participants are contextualized with respect to resistance in chapter four. In this chapter, I investigate how individuals can erect boundaries around their resistant practices, particularly with respect to "official" and "unofficial" resistance. In the final chapter of the work, I offer a summation of the project, review the findings and possible directions for future research. 


\section{CHAPTER ONE: \\ SOCIAL SERVICE AGENCY WORKERS \\ AND MANAGERS}

One of the issues I struggled with throughout the construction of this thesis was how to weave together the issues facing workers and the issues facing people receiving social assistance. This confusion resulted in my putting a chapter together, pulling it apart, putting it back together and then pulling it apart once again. Finally I decided that the best way to approach some similarities in the techniques of governance that I saw shaping the lives of both workers and people receiving social assistance was to separate these roles and talk about them individually. What I found was that although we can take a governmentality approach to the ways in which workers and people living on social assistance are produced within power relations, the ways in which that governmentality is productive is somewhat different as a result of different constraints and techniques operating in their lives. Consequently, while we can see some connections in terms of the ways in which people feel disciplined or regulated, and the ways in which people modify their lives to meet the demands of the advanced liberal society, people still operate in different ways, and are differentially affected by various elements, such as stigma. Governmentality theory does not necessarily take this into account in readily useful ways. Increasingly, it became clear that treating the participants as one uniform subject would not take into account the layers of meaning shaping people's lives. In this chapter, and the one that follows, I investigate these trends separately, while examining some common themes. 
Workers in social service agencies are not removed from the tendency to tell ourselves stories to help make sense of our place in the interlocking spaces of oppression, surveillance, and resistance. ${ }^{1}$ In making sense of our place in the world, in our search for meaning in our work (Camielleri, 1999), we often rely upon notions of progress, necessity, charity and social justice. Writers such as Swanson and Lundy (1999; 2004) suggest that social justice approaches to antipoverty work and charity model approaches to the same work are different and separate phenomena. However, in discussion with workers from various agencies and perspectives, it seems that these two ways of engaging in one's work are, more often than not, muddled. They are more interwoven than set in opposition. Notions of helping and charity work are often articulated alongside notions of fairness, justice and equality. Workers constitute their subjectivities as activists/non-activists at different points in their speech. These intersections make for interesting, albeit difficult to negotiate and occasionally conflicting, perspectives on work, engagement and politics. One of the difficulties with negotiating charity and social justice is the rhetoric that asserts they are separate and apart from one another. In service providers' talk about donor relations, government funding, and negotiating advocacy and service within these contexts, notions of social justice and charity models of work are amalgamated in the messy context of day-to-day practice. In this chapter, I will focus on unpacking how social service workers participating in this project speak of negotiating the daily tensions associated with funding, advocacy, surveillance and multiple sites and constructions of resistance and acquiescence. I will return to many of these

\footnotetext{
${ }^{1}$ I include myself in this practice, and in the category of "worker in a social service agency."
} 
conversations in chapter three, where I will think about them in terms of how workers manage themselves so as to maximize their funding and opportunities by taking up entrepreneurial selves.

\section{Workers' Perceptions of Funding Benefits, Tensions and Limitations}

Before launching into an analysis of workers' speech and negotiation of funding, I will introduce some of the broad and general ways in which workers discussed the ways they perceive funding benefits, tensions and limitations. Government funding, funding from other non-profit agencies such as the United Way, corporate partnerships, and donations, both individual and corporate, are just a part of the day-to-day conduct of business, according to workers. In their talk, agency workers did not see a way around obtaining funding through these organizations, all of them suggesting that the funding their agencies receive "pays the bills," (Julia) albeit, "it is never high enough to meet the need," but nevertheless “completely enables the programs" (Elizabeth). Having one's financial needs met, however, does not come cheap. Workers identified a number of challenges with the receipt of funding, not just associated with the inadequate amount received. They also identified the concerns they had regarding the political realities of being funded, and the costs in terms of autonomy and ability to engage in advocacy. These concerns were raised with all types of funding, but seemed to be particularly present when negotiating municipality-based dollars. 


\section{Government Funding}

Participants working for social service agencies (PWSSA) identified government funding and the strings attached to government funding as one of the more problematic relationships in which they were required to engage. Elizabeth noted:

In terms of specifics, as you know, the way that services are funded ebbs and flows with the political will of the day, and I've been around long enough now to see it happen three times in three different ways, and it's heartbreaking to see the momentum that can be broken down...

Here Elizabeth describes how political will shapes funding priorities and the administration of that funding. This reality can be particularly threatening for agencies because it means that financial stability is in jeopardy, particularly in moments of political change and upheaval. Another participant, Michael, suggested the same sort of manifestation of political implications on their funding relationships, but he focuses on the problems that emerge with the changing faces of the funder's decision makers:

But the downside of the funding is that the municipality controls the purse strings, even though the province substantially covers the cost, because again it's a joint thing...and it's at the whim of the [city] staff. So if the department has a good leader, it's good. But since I've been here there have been four different leaders, and experiences under each one has been completely different - negative, positive and otherwise. So that's really hard when you're trying to operate consistently, and that person changes and the control issue comes into play... And then the relationship feels, regardless of how positive the staff relationship might be, you're still the poor cousin, even though you're the one providing the service. So it feels like we're always begging for money, even though they should be begging us to do the service... [but] it's about relationships, so we try to approach it from an amicable perspective.

Michael highlights a number of issues in this passage. First, he discusses the difficulty of planning and undertaking the day-to-day work in his agency when 
funding is inconsistent. Moreover, this instability makes it very difficult to operate consistently, particularly with respect to long-term planning and capital projects. Additionally, Michael begins to touch on the role of relationships and intimacy in regulation. His references to poverty and the unbreakable link of family blood are rich. Family blood, in particular, speaks to the intimacy of the relationship between funders and agencies within this community, and communities like it. Many of this project's participants highlighted the experience of intimacy with funders, particularly with respect to municipal and community funding. Having close ties with one's funder, for example being located in the same community, or having both a funding and an administrative relationship with one's funder makes it more difficult to resist perceived capricious or unfair decisions. This is not only true because funding is more precarious, but also because it is typically more difficult to resist when there is a personal relationship with the funder, when each party can see the humanity in the other. Additionally, close relationships draw upon feelings of partnership, which, while sounding neutral, can depoliticize decisions that have regulatory effects. While partnerships sound consensual and equal, in reality the power relations between partners can be quite unbalanced. Such inequality is often ignored as parties are drawn into constructing a consensus and it becomes difficult to resist and oppose in this relationship, thus speaking to the complexities of local control and funding (Kinsman, 1997: 227).

Michael and Elizabeth also spoke at length about the challenges facing their agencies with respect to the relationship between their agencies' funding and the political will of the day. Workers' perception that funding is determined 
by political will seemed to influence feelings of hesitancy when speaking out against results that they deemed unfair or unjust. Workers were wary about resisting when there was a risk of losing funding, support or in the case of one agency even autonomy from their funder. Even when they expressed some concerns with respect to the impact of funding structures on agency stability or autonomy, workers often identified that speaking out, or challenging a government funder on their policies, might hurt their ability to survive financially:

[with respect to being stifled, there's also] the politics that follow people, and also the fact that if you throw sand in the face of your funder too many times they may decide that you're too much trouble. And that's very real. (Elizabeth)

This perception shapes the ways in which agencies and their workers constitute their subjectivities, as well as their modes and techniques of resistance. I will explore issues of funding insecurity and intimacy with funders in greater depth towards the end of this chapter.

\section{Donations}

Surprisingly, donations came up as less troublesome for agencies, during the interviews. Agency workers seemed to note that there are "less strings attached" to donations. This reality was not simply because donations did not make up a substantial proportion of agency funding. Even when donations were essential to continue day-to-day operations, some workers found that the dynamics associated with negotiating relationship with donors were much more manageable than dealing with government agencies. Michael suggested: 
...donations... they're funds that we need to operate day to day. So there is a certain humility and dependence that goes with that...it's spread across the map. So it's not like if somebody pulls out their funding you're totally screwed. We don't get huge donations but generally we have a lot of people giving. So it helps that you have that kind of stability, and you don't have someone trying to control what you do because they're holding the purse strings... But yet again they can't control you because of their donations, they just don't have that kind of power. So you're not being driven by a large firm that gives you X amount of dollars and you don't agree with them, or it's not a casino giving us money, thankfully. That would really jeopardize what we believe, because things like that aren't really, um, the most positive for the community. So that part's really cool.

Michael highlights some key issues with respect to private dollars, typically generated by fundraising drives, and regular private giving. Recent research by the Canadian Council on Social Development (CCSD) has found that private funding in the form of donations can be useful for organizations as they are often unrestricted. While government funding makes up the better part of revenues for social service agencies, roughly $60 \%$, private dollars offer flexibility that government grants and contributions do not (Scott, 2003). Michael illustrates that even though a great deal of his agency's funding comes from transfer payments from the provincial and municipal governments (in a per diem grant that is directly related to service numbers), the agency is also reliant on donations which, as a result of not being concentrated with one donor, are more flexible than government grants. Michael's sense of humility with respect to donations, stands in contrast to a feeling of being a poor cousin to the government funder earlier in the interview. These two sentiments, juxtaposed with one another, offer a complicated look at funder relations. Whereas government grants are viewed by Michael as an entitlement, a responsibility of government, private donations are viewed as a gift relationship which (in this case individual citizens) 
offer support to the agency in generosity. The nature of this gift relationship might shift if the donor was a large multinational corporation, but potentially not since connections are often not made between the lobby efforts of corporations to reduce the welfare state, and their meager donations to social service agencies. The "myth of the good corporate citizen" still holds the public imagination today (Dobbin, 1997), despite the reality that the good citizenship of the corporation is often very much tied to efforts to "maximize positive corporate exposure" and increase customer loyalty (Scott, 2003:25).

Additionally, some participants working for social service agencies identified that since individual donors are often members of the community particularly committed to the cause of the agency, they often find it easier to convince donors that their operations and programs are worthwhile. Because the donations were often smaller in size but spread out over a larger group of people, no single person controls the purse strings of agencies, which allows them to take more risks if necessary.

Occasionally, however, some PWSSAs noted that the anonymous face of government makes it easier to agitate for more funding, especially when the board of directors is made up of donors and supporters:

What's difficult is to make long-term commitments to programs because all of the funding is very tenuous at best... there's a lack of stability in the funding... It's much better when you can yell at the government or something. The board of directors doesn't really like it when I yell. (Laughs). Been there, done that, paid the price. Okay I'll take another pay cut. (Michael)

Although some PWSSAs expressed concerns regarding offending donors and community members, and discussed moves that their agency and workers made 
to ensure ongoing support from donors, most participants found the donor/agency relationship to be easier to negotiate, manage and felt more secure in taking steps to further their advocacy with respect to their cause.

\section{Funding and Control}

Most PWSSAs expressed frustration in the level of control they perceived that their funders had over their agency's activities. This control and discipline is exercised in both subtle and overt ways. Participants told stories of funders telling them not to go to the media about an issue, being directed by Boards not to take action against an injustice because it might threaten their funding, and more generally, being discouraged to speak out on anything without approval from various individuals/bodies, and being monitored by other community agencies and organizations. These measures were often constructed as empowering/encouraging agencies to be accountable, although workers identified that funders themselves often acted in unaccountable ways. Although some participants broadly identified these themes, in the following sections I will draw exclusively on Elizabeth's experiences regarding funding and control to offer texture to the ways in which intimacy and local funding control impact her and her agency.

\section{Too Close for Comfort}

In this section, I explore some terrain I have already touched upon, but I would like to provide more texture to it. A number of workers suggested that the closer to home the funding body is, the more difficult it is to feel secure and 
autonomous in agency operations. Workers suggested that they felt "watched" more often and more intensely by municipal and community funders. Elizabeth discussed her frustration with municipal downloading, especially as it affects the autonomy and stability of community agencies:

When the Feds funded the [support fund] and the funding ran out, you could scream blue murder. You could knock down [the MP's] door, you could carry placards, you could do anything you wanted because it's at an arms length from you, because the funding is coming through on behalf of the entire nation... In the old days when we were funded by the province, we could have a battle with anyone locally, and we could butt heads, but it didn't affect our ability to exist. It didn't affect our ability to do the important work that we spent so long building up doing, that we could see... So I can't emphasize enough the importance of maintaining those relationships at whatever cost.

Here, Elizabeth speaks about the tensions of maintaining relationships with funders and partners when funding is administered locally. She outlines how negotiating relationships (and even fighting a battle locally) was not as difficult when funding was administered at an arms-length from the community agency. In this way, surprisingly, it is of little benefit to have a funder that is a part of the community. It seems that local funding bodies and local funding arrangements have the potential to seriously damage the ability of agencies to engage in advocacy. While this might be a result of municipal funders feeling more vulnerable than provincial or federal funding agencies, or a lack of experience on the part of staff and councillors, or even just the experience in this particular community, it is interesting that at a time where community advocates often agitate for more community control over services and resources, there are challenges that accompany these arrangements:

So if the theory was that, on the local level, people would be more connected in their planning, in their service delivery, I don't see it 
happening. It's worse, way worse. I haven't had occasion to speak to or meet with either director of either [community agency] in the last year. They meet with the city, nobody else as far as I know. Neither of them sit on [the municipal committee that deals with our common issue]. I don't know about provincial conferences on the issue that we work on here, when they're being held, so... I haven't seen the culmination of these cycles, if it ever ends or if it just keeps cycling. (Elizabeth)

Here Elizabeth speaks directly to the idea that local control is the idyllic, left-wing answer to the problems of centralized state control (Rice and Prince, 2000). Unfortunately, despite the rhetoric of the possibilities of local control, the reality has not met expectations. Not only does negotiating with funders closer to home make agency workers feel more closely surveilled, it also does not seem to bring the benefits associated with having more local arrangements or community control over funding. Some participants working for social service agencies expressed frustration over these new arrangements. What downloading responsibilities to the municipal government has achieved is the possibility of closer, more efficient management techniques, with more points of intersection in the network of power. Here again we see the contradictions between the idealized, romanticized hope for local control and its realities. State control is typically imagined as dangerous because it is impersonal, but conversely this research demonstrates that in many ways, for these participants, intimacy is depoliticizing. Particularly notable are Elizabeth's comments, which indicate that when funding bodies are "too close for comfort" she feels unable to hide in the anonymity that the city has provided people within the modern state and, as a result, feels heavily surveilled. 
Framing Accountability: Funders and Agencies

A number of participants identified that there are many funders that are simply not accountable by their own standards. Accountability is often conflated with becoming "state-like" in organizational structure, orientation and behaviour through accounting practices and reporting procedures (Anheier, Toepler and Sokolowski, 1997). Often it takes the shape, to the benefit of neo-liberal governance, of a business and a (as much as possible) comprehensive bureaucracy (Alexander, Nank and Stivers, 1999). Elizabeth expressed frustration with the double standard that the funding body seemed to take with her agency, and her inability to fight back:

So what enables [the funder] to have that power? ... If [the manager of the funder] told [the other agencies they fund] not to come to the meeting, they didn't come... So on the bigger level what is all that? All that is an erosion of accountability. [This committee] is supposed to be representing the community as a whole to City Council...So how does staff of an organization refuse to support a committee of that organization? How does that happen? How do people get away with that? But it does... It happens because we're too afraid to go over his or her head, you wouldn't dare. The theory is that you can go to your City Council that everyone can; well as a small not-for-profit or even a good-sized not-for-profit you won't be doing that more than once or twice. And they will have to take a side -either your side or the side of their staff person. Once they do that the relationship is irrevocably broken down.

Here Elizabeth illustrates that it is difficult for her to hold her funder, the City, to account because she is afraid that it will hurt her relationship with her funder. She discusses how the funder is instructing other agencies not to attend a community meeting, and she considers this to be a questionable practice for which there is no mechanism to hold them to account. Therefore, while the relationship between government and non-profit organizations is supposedly influenced by "traditional public sector values of accountability, stability, 
responsiveness to clients and community and serving the public interest" (Scott, 2003:8) she seems skeptical that these expectations were located on both sides of the relationship. Elizabeth and her agency co-workers dealt with dealt with their funder controlling their ability to speak with their elected officials by regulating their own practices. At other points in the interview, Elizabeth suggested that she was willing to make concessions in terms of political agitation to maintain relationships and funding so that her agency continues its ability to provide services to clients. To her, continuity and stability of service is directly linked to her accountability to her clients. The other participants working for social service agencies articulated similar sentiments regarding accountability. They were generally supportive of funders who placed emphasis on accountability, efficiency and innovation, but were frustrated that such expectations were not also hoisted upon funding bodies themselves (Scott, 2003).

Accountability to the Agency: Obedience and Technologies of the Self

Agency workers also spoke of the challenges of working within a context of governance in which they monitor themselves. Foucault speaks of technologies of the self and the mode of the confessional as bound up together in a particular constitution of the self. Here he explains obedience and deference:

Here, obedience is complete control of behavior by the master, not a final autonomous state. It is the sacrifice of the self, of the subject's own will. This is the new technology of the self. The monk must have permission of his director to do anything, even die. Everything he does without permission is stealing; there is not a single moment when the monk can be autonomous. Even when he becomes the director himself, he must retain the spirit of obedience. He must keep the spirit of obedience as a permanent sacrifice of the complete control of his behavior by the master. The self must constitute itself through obedience (Foucault, 1982:165). 
In conversation with agency workers, I was struck with the consistent deference to the authority of the board of directors and/or management. When asked if they would speak out against something that was unfair, all of the participants working for social service agencies said, at one time or another, that they would have to request the permission of the board before taking any action. While we can think about this deference as structurally instituted, this explanation is incomplete. Foucault's conception of the technologies of the self "which permit individuals to affect by their own means, or with the help of others, certain number of operations on their own bodies and souls, thoughts, conduct, and a way of being, so as to transform themselves in order to attain a certain state of happiness, purity, wisdom, perfection, or immortality" (Foucault, 1982) offer us a way to think about how agency workers conduct themselves in obedience to authority. These theories offer a way into thinking about the interplay between the structural relations that shape one's ability to act autonomously and how workers who we imagine to be relatively autonomous workers, often holding high positions of authority, place themselves in positions where they seem to have little control over their movements. I suggest that this relinquishing of control is an apparition because, in fact, since these techniques are taken up "freely" by workers as the constitution of their selves, they are "controlling" their own conduct. They have other options, though clearly they are not without severe consequences:

But if [the ED] doesn't want it to go public, or if the board doesn't want to go anywhere, that's their right, then obviously it won't. Or it will and you won't do it again, you won't be around. I have a feeling that if you went to the press you won't get a chance to do it again. (Elizabeth) 
There are multiple ways to understand this statement. First, Elizabeth speaks about going to the media without permission, and what types of consequences might be associated with such an action. As a result, we can think about mitigating one's risk in terms of maintaining employment. Therefore part of the reason she asks permission and is obedient is to maintain her employment. Second, we can think about this statement and others like it revealing a commitment to doing one's duty, to obeying orders, to performing optimally at one's job (Arendt, 1963). Most often, both of these desires and fears are at play. In fact, they serve to reinforce one another. Earlier in the conversation Elizabeth stated:

I think people understand that they can't make a public statement without the blessing of the organization or board. You can't go to the press. That's done by the ED or the President of Board. It would be chaos if you did it any other way.

The optimal place of employment is not one that is in chaos. Chaos is fearful and dangerous because it cannot be tightly managed and controlled, and controlling crisis is essential to understandings of the professional. What this worker discusses is acting in a responsible way that prevents chaos in one's organization. She speaks of knowing one's boundaries and responsibilities and conducting oneself accordingly. This constitution is consistent with a capitalization of the self, of being a "good" worker who does the best job that she can, which in this case means respecting the policies and roles within the organization. The worker is not simply repressed into a narrow responsible self; she also takes up these subjectivities in productively, behaving in ways that are consistent with professional and responsible conduct. Elizabeth later discusses that chaos 
threatens the stability of her agency, which thereby threatens services to clients. Maintaining essential services is a third way to understand obtaining the "blessing of the Board." Here Elizabeth seeks to act professionally and responsibly to maintain continuous and high quality services for clients, which is an important part of her professional ethic. In chapter three, I will discuss further how one can read this type of conduct as part of an entrepreneurial constitution of the self and what this interpretation means for the regulation of social service agencies.

Before I close this section, I do want to make clear that these workers are doing the best that they can - or imagine that they can - under the circumstances. As people working in the social services, they are under enormous amounts of stress, and negotiate regular demands and pressures from numerous points of contact. Often their conduct is demonstrative of the constrained circumstances in which they are acting, and not necessarily representative of their values. While the movements and deference of service providers can be understood in problematized ways, it is also difficult, if not impossible, to break these forms of conduct. I will explore some of the ways in which resistance is shaped and managed in chapter four, but I will also look at new understandings of resistance and some hopeful possibilities for engagement.

\section{Instability, Fear and Being Silenced}

One of the predominant themes identified by workers was a feeling of insecurity and fear, which resulted in workers feeling silenced by these constrictions and realities. Workers suggested that the cost of maintaining 
relationships that were necessary to continue receiving the level of funding to which they are accustomed (or even the cost of losing some but not all of their funding) is sacrificing some of the advocacy and activism that they would like to engage in as agencies and workers. Workers told stories of both subtle and overt coercion to keep quiet about what they perceived to be injustices. Two, in particular, identified their main funder as the reason for which they felt that they could not speak out against what they perceived to be within their mandate and purpose:

It was a funder. It was a political issue in terms of not wanting us to speak because it's supposed to look as though we're cohesive, when in fact we are individuals. To be fair we have less of that problem because we're an independent charity. We're not like a transfer agency, which tends to be fairly closely tied to a political body. Whether municipally, provincially, or federally. But it has happened... So the board has the ultimate say, in spite of the funders. So what happened in the case here was that we proceeded to say what we felt we needed to say, and to try to stay true to what we're here for, which is a bit frightening... [Researcher: And how did you feel about that?] I gulped. Although also angry, to be put in that position when again because I think we don't like to jump on a bandwagon, we like to have information and approach it from an amicable space. (Michael)

Michael imagines his agency as more at an arms length from government than a transfer agency, which receives direct funding grants from government, and has a specific intimate governance relationship with government funders. However, here again he outlines some themes of closeness and intimacy with one's funder. The personal nature of these relationships seems central to the weight of restriction, the perceived inability to resist, and the need for social niceties. It is sometimes easier to resist when we imagine ourselves to be unknown and anonymous. His comments speak to the ways in which local control has a double meaning, and this mirrors some of his and Elizabeth's comments with respect to 
the difficulty of negotiating close relationships with funders. I will investigate this in more depth later in this chapter. Here, however, his comments also demonstrate how agencies, anticipating this manner of regulation or reaction from the funder, take up their own regulation, choosing to act in particular ways to avoid sanctions. Elizabeth also spoke extensively of this experience and the ways in which her agency avoids confrontation and sanctions from one of its funders:

So because of the way funding is made available to municipalities [via the 80\% provincial:20\% municipal funding split], it makes it almost impossible for the people that are in charge of the management of those departments not to want to increase their funding base and therefore their staff levels and in my opinion their power in the municipality... all across the province [agencies like mine] are disappearing they're getting amalgamated, they're becoming municipal services... The municipality can do anything they want...The end result of downloading is that we're not independent from all of the other goals of the municipality, or all of the other... We couldn't possibly go to the [paper] and do a story about discretionary benefits and how they used to be allocated in certain way and now they're allocated this way, just as an example, we couldn't do that. If we did that we would not have any relationship whatsoever with our funder. And...that's not a good thing... So while certain organizations that are possibly more grassroots and might feel that we should do that sort of thing, they don't understand the reality of the fact that we wouldn't be here if we did those things.

Part of the concern of agencies is that whatever they say will be used against them the next time they request funding or the next time their budget is up for review. Additionally, it suggests that nonprofit survival strategies might be implicated in a decline in participation in civil society, as a result of nonprofits' reluctance to speak out against funders or the municipality to maintain relationships and funding (Alexander, Nank and Stivers, 1999). Although some people attribute the decline in civic participation by government funded agencies to rules restricting an agency's advocacy activities to 10 percent of its budget (Julia), 
implicit concerns about loss of funding also restrict agency's advocacy efforts. This perception mirrors concerns expressed by agencies across the country in the CCSD's Funding Matters report, where agencies discussed the constraints placed on them by funding bodies (Scott, 2003). This anxiety is not unfounded, since most of the PWSSAs interviewed have seen massive cuts to their budgets and operations in recent years, specifically in the late 1990 s and early 2000 s when the Conservative Party, led by former premier Mike Harris, was in power in Ontario.

On the other hand, the regulatory effects of this fear in response to what workers consider to be institutional power, shapes the ways in which workers act and the bounds they place on themselves. Workers expressed hesitancies in joining coalitions, particularly coalitions formed partially by organizations that had been confrontational with the workers interviewed, in the past:

...there's been some community advocacy, and it's easier for some groups to do that than others, even if they wanted to. Here in my organization I wouldn't be allowed to, we don't do direct action. Secondly, we might have to get in bed with some organizations that in the past have caused us some significant difficulty and we never know when we might do that again, much as we respect their work. Finally, our funders would have an absolute fit. (Elizabeth)

Elizabeth highlights here some concerns she has about coalition work and funder reactions to any type of direct action advocacy she and her agency might want to undertake. At the same time, she indicates that she understands that community advocacy (including direct action) can have a significant impact in shifting public policy. Throughout the interview she also indicated that her agency has, in the past, taken action to address imbalances in funding, particularly with respect to their support fund. In this way, there is a disjuncture in her negotiation of her 
wishes to engage in active resistance, while at the same time understanding the possible implications of any sort of activism.

Elizabeth also articulates some hesitancy with getting involved in community organizing. What is interesting about this statement is that she suggests multiple reasons for not getting involved, but later in our interview, she identifies that there are campaigns in which her agency has been involved. Throughout all of the interviews, it became clear that participants working for social service agencies (PWSSAs) endeavor to be as strategic as possible in negotiating tensions with respect to their funding, which shapes their daily reality and engagement. In the situation above, the participant is discussing a campaign that targeted one of her agency's main funders. It seems that the intimacy of the target of the advocacy can be just as risky as the issue at hand, the coalition partners, or the tactics used.

What struck me during the interviews was the extent to which workers identified the proximity of the funder to the agency as impacting their autonomy or ability to resist. Elizabeth noted:

The more arm's-length it is from the community it serves, the more independent and probably effective it is, and it can be in terms of implementing policy...But if you're silenced by the dependence on local authorities to continue to keep your doors open, and, you know, people would not like to hear it but that really is the end result...It seems like the closer you get to home, the less easy it is to do that. Perhaps the more precarious their positions are affects the way they interact. But I couldn't see going into a director of a municipality and demanding that they end a program that they said they were going to end, and then living to say it another day.

In the face of this fear and instability, workers govern themselves to manage risk, to themselves, to their professional reputations, and to their agencies. 
Surveillance and panoptic observation operates differently than previously conceptualized. I argue that subjects are instead constituted through a normalizing gaze of the disciplines, and are engaged in the productive exercise of power over the self (Foucault, 1979). Workers engage in techniques of selfpreservation, modifying their behaviour and their interactions with others in order, in their view, to minimize the effects of regulation from an external source. This means that workers are often careful what they say, particularly in the name of the agency, and the actions that they take that are out of the bounds of direct, individual advocacy, the types of activities that one might associate with activism. Additionally, there are a number of ways that participants work to maximize the effects of regulation, for example, seeing caution around what they say as symbols of professionalism, effectiveness, accountability, and playing like a friendly neighbour. In this way, direct control by the funding body is no longer necessary, and instead governance is productive of particular modes of being a "professional." Workers take up particular subjectivities and self-governance in the interest of the advanced liberal society, and discipline is only deployed when techniques of governmentality are not effective or efficient (Rose, 1999).

\section{Decentralizing Surveillance}

In the section entitled "Funding and Control," I examined, through Elizabeth's experiences, some of the ways in which agency workers are surveyed by their boards of directors. Agencies are not only monitored by their boards, their funders and the public at large, they are also monitored by external agencies, advocacy groups and organizations. Michael expressed his frustration 
at feeling watched not only by the main funder of his agency, but also other community groups, that probably themselves experience the same monitoring:

Just in terms of questioning our decision making for service delivery. Accusations about why we do what we do... people jump to conclusions that are unfair. So they will monitor our activities pertaining to a specific client or specific staff person. So I've had to jump in and say, I've looked into this and this person is being treated unfairly by you. So if it pertains to a funder or this other agency, telling them to back off, [the staff person] not acting unilaterally or outside of our mandate. (Michael)

This comment is interesting because it speaks to the isolating effects of monitoring and surveillance. Certainly the ability of agencies and advocacy organizations to be a watchdog for the interests of clients is important, but these types of moves can also build mistrust and the inability to work together for common goals. Many of the participants expressed frustration with not being able to work with certain groups, as much as they "respect their work" (Elizabeth) or have common interests.

What this statement also indicates is that surveillance is not centralized, but is, rather, networked. This understanding of surveillance as operating in a web-like, decentralized fashion, is borrowed from Deleuze and Guatteri's notions of rhizomes. Deleuze and Guattari speak of the notion that control is not centralized but rather is varied and fractured (1987). When watchdog agencies act of behalf of clients and survey shelters or housing agencies, they are not acting on behalf of the state, and the Social Services Department is not coordinating them. In fact, they may be watching social services concurrently. While their efforts are felt by agencies as part of a seemingly wider network of surveillance, funders or the state who might also be surveying the agencies, do not centrally coordinate their interests or actions. Therefore, they belong to a 
network of surveillance without a centralized structure. This surveillance shapes the moves of agencies in particular ways, inducing them to self-govern and regulate the conduct their actions and movement. Moreover, viewing these moves as part of a network of power helps us to understand that although groups may not be allied with one another, their actions taken together might have similar effects on the same subject, generating the disciplinary practices that subjects need to exercise power over themselves (Foucault, 1991; Hier, 2003).

Surveillance within the Agency

Some control and surveillance often takes the form of subtle discouragement of questioning policies and politics. Here, Julia discusses her experiences of being subtly silenced, with an undercurrent of ageism and sexism:

At [one agency] I used to get shut down if I tried to bring up issues internally. People would look at me like I was crazy, or a naïve little girl. But I was never instructed not to say anything publicly. Although I never tried to, I knew that I shouldn't do that, so they didn't have to instruct me, because I always knew that if I said certain things I'd be in big trouble.

Researcher: So it was subtle?

Participant: Yeah, yeah, very subtle. Never overtly I guess, would be the way to put it. But, yeah.

This subtle discouragement from questioning the agency or its public image was compounded by a fear that Julia's comments could be misconstrued as a position of the agency. While Julia had empathy for the agency's position and resultant staff treatment, she could not continue to work for the agency:

The other thing about the [agency] is such a huge agency that you really do have to be careful, just because if people hear you say something they think of that being the agency, instead of just a reflection on you and that could have negative consequences just because of how things could be twisted. And you know the [agency's] funders are the community, so you have to be careful about not offending them. So on the one hand I 
understand it but on the other hand I couldn't continue to work there because of it.

It is clear that many workers are encouraged by agencies, in many cases subtly, to take up particular understandings of proper engagement. As non-profit agencies look more and more like their for-profit and corporate counterparts, corporate ideologies begin to further influence non-profit notions of professional conduct (Fook, 2000; Frost, 2001). This understanding of the appropriate public image is essential in the ways that agencies "market" themselves, and gain public support, often through a shift in presentation, and sometimes even in demonstrative values (Cain, 1993; Cain, 1994). Using notions of professionalism and professional conduct, workers are encouraged to govern themselves in ways deemed appropriate and professional. Some of the participants discussed the desire to appear professional in their conduct and actions, and particularly identified that this was the behaviour expected from their agencies and their funders. This notion of professionalism, however, is not unproblematic. Typically it assumes tightly managed conduct in the interest of capitalizing on oneself (Rose, 1999). Professionalism requires a certain restriction of oneself. It means not "blowing up" when bearing witness to an injustice, carefully considering all sides of a conflict (Michael), and often not taking part in activities that might hurt one's reputation or the reputation of one's agency. Julia speaks directly to this when she notes that she "worries about [her] reputation professionally...[and she doesn't] want to speak out about issues because [she] gets too emotional about them." This new professional self is non-emotional, without passion, bureaucratic, masculine and apolitical (Ferguson, 1984). Therefore, notions of 
professionalism and techniques that reinscribe certain modes of conduct in an agency are used to govern and surveil workers, particularly when these techniques are used to mitigate risks to loss or shifts in funding, we can see that the funding shapes the realities of agencies with the use of multiform tactics and a web of influence (Foucault, 1991).

\section{Statistics as a Technique of Governmentality}

A few of the participants discussed having to produce statistics for the purposes of "being accountable" to funders. Often this reporting is onerous, and most participants complained of the staff resources it requires to deliver service statistics and progress reports regularly and accurately to funders. While the sheer time and resources required for such activities is challenging, the importance of statistics is key to the function of governmentality in the advanced liberal society. Foucault speaks of "multiform tactics" in his piece on Governmentality, and one important tactic is the use of statistics, which reveal that "population has its own regularities, its own rate" (Foucault, 1991:99). Moreover, these statistics can be used not only to govern through power/knowledge, but also to encourage workers in agencies to take up particular subjectivities. These technologies set particular "standards", and encourage perpetual reflection on the numbers. Agency and worker moves are often determined by funding realities, and reflections on statistics can rapidly revise an agency's direction, shape perspectives on client needs, and redirect priorities. Moreover, anxiety around funding losses and moves can quickly spread "advocacy chill." 
Participants working for social service agencies spoke of the importance of statistics to their work, particularly with respect to how they shape agency funding. They noted that the Ministry determines how statistics are collected, processed and what they mean in terms of funding and accountability. In addition to strict direction, the Ministry requires these statistics on a regular basis, and often the collection of statistics, and what they reveal, determine agency direction:

The Ministry is only concerned with statistics. Our funding and accountability is related to clear direction on what we have to do [from the Ministry]. (Marie)

And:

...in a lot of ways it just means that we have to be professional. Not that we wouldn't be but with decisions that we make we have to think, "is this going to impact our funding?" because the bottom line is that if it does, it impacts the clients...So we're always thinking about that kind of stuff. And the Ministry decides how we do our stats to make us accountable for how we spend our funds. (Julia)

These statements about the Ministry/funding/statistic/advocacy relationship seem to suggest a top down operation of power, and a straightforward relationship between the funder and the agency - the funder determines the terms of the relationship, sets out guidelines, measures, benchmarks, and timelines, then the agency complies. In this telling of the story, power seems to be operating in a linear, hierarchical way, and the effect of these mechanisms is for the agency and its workers to be compliant with Ministry demands. The shift to new funding mechanisms (from core funding to contract and program funding) also exacerbates these tensions and feelings of top-down control by 
funders. Certainly this narrative is one which is pervasive, and is one way that workers make sense of the demands placed upon them by funders.

As a result of this narrative, any help with the onerous delivery of statistics is welcome and appreciated. Elizabeth spoke highly of the generosity of one forprofit funder and their donation of a very expensive data tracking system that would help the agency produce statistics more efficiently:

The reporting required for these funds is crippling because every funder has its own reporting requirements, and this was taking us up to 3 days a month just in reporting. And we didn't keep very good records. We couldn't participate in social planning, because we do know a lot of stuff, but we couldn't extract it from our database. They came along with their professionalism, and their capacity, they became really involved with the work we do, and they provided all or more that we could have ever dreamed of. They had some self-interest in it because they are trying to sell the system to other centers, but for us they did it for nothing. And now we have a system that would have cost us [thousands of dollars]. And it is leaps and bounds over the 3 systems we had before. It improves our capacity to keep records immensely, and helps us to be accountable to the funders. So that was a novel experience. I mean they had to come in and learn our work, they had to translate that into programming codes, we had to test, implement, tweak, document. And that was all provided by a forprofit funder.

Elizabeth discusses the generosity of a for-profit funder who developed statistical software for her agency. While such support certainly seems generous, and may be coming from benign intentions, it also has the effect of further entrenching surveillance systems in the work of the agency. Additionally, the ability to process statistics more efficiently also helps agencies and workers to take up active subjectivities that reflect continually upon the numbers, what they mean in terms of trends, and what kinds of implications they have upon the practice of workers and the moves of the agency. Therefore, regardless of the intentions of the players involved, these movements result in the reinscription of certain 
modes of conduct, valuing certain stances over others, and finally shaping priorities in particular ways. With the application of statistics as a technique of governmentality, "strong-arm" tactics of funders become less important; instead agencies and workers govern their conduct by the numbers - creating more efficient processes, re-evaluating their policies, finding ways to do more with less. For example, if the statistics are showing that a particular pocket of the agency's target population is being underserved, workers will endeavour to shift their priorities to meet those demands. The funder no longer needs to direct the priorities; agencies will move their priorities on their own pre-emptively. This form of regulation changes the work, and meaningful work necessarily becomes that which is quantifiable. What it creates is workers and systems who are effective at the management and representation of data, particularly numerical data and this shapes daily practices - it not only shapes time, it also priorities and practices. Numbers and statistics can be thought of "fostering detachment from feeling, passions and tumults... Numeracy [is] an element in the ethical technologies that would...produce a certain kind of disciplined subjectivity" (Rose, 1999:225). In this way, funding and its associated techniques shape an active construction of the self, the details of which I will speak more about in chapter three.

In this chapter, I began to trace some of the key issues facing and shaping the conduct of participants working in social service agencies, and attempted to carve out some themes for further investigation in subsequent chapters. In particular, I focused on how the intimacy of the funders, their flexibility, their notion of accountability and their insatiable desire for statistics work to regulate 
workers. At the same time, I highlighted the ways in which workers regulate themselves not to challenge funders for fear that their services will but disrupted or lost. The ways in which people construct their subjectivities strikes at the heart of issues around capitalization of the self and modes and terrains of resistance. What I find most interesting about the reflections of participants during this project is the ways in which power operates in their lives. Participants working for social service agencies seem to take up subjectivities of professionalism, responsibility, accountability, service provision and depoliticized understandings of engaging in relationship with funders, to both minimize and maximize the effects of regulation from external sources. These moves both open up and restrict possibilities for resistance, and I will explore the complexities of these realities in the following chapters. In chapter 2 , I will focus specifically on the experiences of people living on social assistance, with particular attention to the ways in which funding and control operate in their lives. In chapters 3 and 4 I will map the intersections between the experiences of people living on social assistance and people working in social service agencies, with explicit attention to active citizenship and resistance. 


\section{CHAPTER TWO \\ PEOPLE LIVING ON SOCIAL.ASSISTANCE}

Like social service agency workers, people living on social assistance are confronted with multiple tensions with respect to their source of income. To illustrate a consistency in thematics, I have used a similar framework between the two groups for discussion, and will be looking specifically at the ways in which each group is constructed by the techniques of the advanced liberal society. Here I will use notions of discipline, control, surveillance and conduct to investigate the ways in which individuals accessing social assistance are encouraged to govern themselves using efficient methods. What is most striking about the relationship between the ways in which social service agency workers and people accessing social assistance negotiate challenges is not simply the ways in which the funding/income is monitored and constrained, but also the ways in which each participant is encouraged to constitute themselves as self governing subjects.

Throughout conversations with participants it became clear this group of people living on social assistance constitute their resistance in subversive ways, similar to people working in social service agencies, but with one crucial difference: they often named their resistance as a difference in values from the dictates of the social assistance office. The people living on social assistance named values such as "survival", honesty and protecting those individuals close to them as the justification for subversion. This is in contrast to social service agency workers who used language of professionalism, responsibility, helping and protecting services for clients. While most participants living on social 
assistance constructed the active self as a subject they value, they also situated care, familial ties and survival as values worth resisting for, and their resistance took the form of everyday movements to disrupt and fragment institutional values. Collectively, their movements constituted fragmented collectivities: their resistances and identities do not look like traditional social movements, but are potentially new and useful future modes of resistance (Gilliom, 1999). As Gilliom suggests, "everyday tactics of evasion, subterfuge, and concealment, then, may very well become a defining form of politics in the surveillance" (1999:101). For this reason, I will shift my focus in this chapter from simply a search for continuities between social service agency workers and people living on social assistance, to a more in-depth look at how the participants who were living on social assistance constituted their experiences and resistances. This shift will lead into a look at the different moves that both groups make to resist against perceived injustices, and will give us a way to think about useful possibilities for future social movements, be they traditional collective movements or newer, fragmented collectivities.

\section{Perceptions of People Living on Social Assistance: Tensions, Benefits and Limitations}

For people living on social assistance (PLSAs), welfare income is a necessary trouble. Most were relieved to have access to welfare in cases where otherwise they would have no income. Similar to social service agency workers, PLSAs considered their source of income to be a necessity, a bottom line arrangement. While it is not sufficient for paying the bills, the little bit of money 
coming in helps meet some basic needs (if not all of them). At the same time, because the income from welfare is so meager, many participants were angry that they were, even with benefits, unable to keep a roof over their heads, and one participant, Sarah, even took herself off welfare because she felt that the surveillance and discipline associated with being on Ontario Works far outweighed any little amount of income she received from them. More specifically, she found that piecemeal employment and $\$ 10$ haircuts here and there (she is a licensed hairdresser) provided more stability for her and her family than welfare.

Even though most people living on social assistance consider welfare to be a bottom line arrangement, and better than no income at all, most expressed anger at the strings, surveillance and stigma attached to receiving welfare. Participants expressed feeling violated by a system which they felt is only set up to help agencies and "the system," not them as people requiring support. Some common themes came out of our discussions of these experiences, and I will explore these in depth throughout this chapter. There are numerous studies outlining pitifully low welfare rates, and how these rates do not even approach the amount of money an individual or family would need to meet their basic needs (Hurtig, 1999; Lee, 2002; Oliphant and Slosser, 2003). This chapter does not focus on a quantitative look at poverty, or the particular poverty of individuals and families living on welfare. Instead I will examine the ways in which people living on welfare experience their daily negotiations with "the system," specifically with respect to the ways in which they understand their places within that system of power relations. 
Stigma, Shame, Prejudice and Self-Esteem

While a number of social service agency workers discussed the negative impacts of always feeling as though one is begging for money, the stigma associated with funding operates differently for people working in social service agencies than people living on social assistance. Social service agency workers do not face the same stigma regarding where they get their money, although they might experience some related stigma as a result of the work they do and the clients with whom they work (Lundy, 2004). Workers, however, can protect themselves from that stigma and shame with their education, employment and relative socio-economic position in a way that people accessing assistance cannot. PLSAs discussed feelings of shame when first having to turn to welfare:

Well, when I first realized that I was going to have to turn to social assistance to keep a roof over my head, I was appalled; I was ashamed, I was horrified. I, never before in my life, with the exception of employment insurance, had to turn to anyone for funding. I had been employed for most of my life, and the stigma surrounding it, I was biased as most other people are... So it's limited my social contacts because even my mother thinks I'm a loser because I'm on welfare, despite the fact that I worked from the time I was 18 on (Robin).

Often it is welfare workers who perpetuate this shame. Pamela spoke of the way in which her son was treated by a worker, “...one worker said to my son [who is also receiving assistance] that this is coming out of our pockets, out of taxpayers' pockets." Here she touches on shame of not being treated with dignity by a welfare worker ${ }^{1}$. A large part of why this is shaming is that accessing income assistance has shifted from a right of citizenship, albeit insecure, to an act of

\footnotetext{
${ }^{1}$ For the purposes of this project, welfare workers and workers in social service agencies are not the same type of worker. Welfare workers are people working at ODSP or Ontario Works. They are directly employed by government. Social service agency workers work for non-profit agencies funded partially by government, but are not government workers. I did not interview welfare workers for this project.
} 
charity. The welfare worker suggested that taxpayers are doing Pamela's son a favour by "supporting him." This comment shapes Pamela's son as a passive recipient of welfare, not a citizen who has a right to income assistance because he is either having difficulty obtaining wage labour, or is busy working in his community without receiving a wage. The language of dependence here removes Pamela's son's right to dignity and respect, which reinforces the shame and stigma of living on social assistance.

Lindsay expressed similar frustrations, suggesting that welfare workers often treat PLSAs as if they have little right to their feelings, "they say rude things to you... They don't care if they hurt your feelings or nothing." Her comment points to a theme that I will speak to more fully in chapter three, that social service agency workers come to discipline their "clients" into seeing themselves differently. By reinforcing a particular notion of productivity (one which is tied to wage labour, regardless of how pitiful the wages) welfare workers encourage people living on social assistance to take up subjectivities of the entrepreneurial self - one who values labour for a wage over other types of productive activities, for example contributing to one's community or caring for family members. Additionally, individuals do not simply have the obligation to undertake these notions of personhood, they have the freedom to do so - individuals have the freedom to pursue wage labour (regardless of potential barriers to doing so) and having been accorded the freedom to do so, they also have the responsibility to take up this understanding of the self. In this way, power relations between the welfare worker and the person receiving social assistance are not simply about disciplining individuals into taking up certain notions of the self, they are also 
productive - they create, shape and utilize human beings as subjects, autonomous subjects that can be shaped using certain "strategies, techniques and procedures of regulation" (Rose, 1996:152).

Welfare workers are not alone in perpetuating stereotypes about people, and using this technique to shape individuals living on social assistance. Sarah suggested that the political system plays a big part in perpetuating stereotypes about welfare:

That would have to be the other real hard hit I think that you hear from people that have never been on assistance and our government preach. That, well if we give them this money, they are just gonna spend it on drugs and alcohol. It's like, "excuse me buddy but can I take your blood please? I would like to test the levels of alcohol and drugs in your system. You're supposed to be representing our country." In that respect, it's just a completely ignorant comment to make. Yes, I do understand that there are abusers out there. But that goes in every aspect of life - right up the corporate government ladder. What about all these people that already robbed us of millions of dollars? 'What's happening to them? Nothing. You hear that it happens, but you don't hear what the fallout is. Which is completely bogus as well.

Here Sarah outlines her frustration with the system, and the reasons for which she decided to refuse income assistance even when she did not have an alternative source of income. Her anger with the system is not only related to the meager support or stigmatizing nature of accessing benefits, but also the hypocrisy displayed by those workers, politicians and citizens making and supporting oppressive policies. Her speech here mirrors some of her later talk and the talk of other participants around the value of honesty and congruence in their and others' conduct. What emerges in this excerpt and others like it is that participants are framing their values differently than those values imposed upon them by the "welfare system." Sarah suggests that everyone is capable, regardless 
of social location, of "abusing the system." While she values having to protect the system from "abusers out there," she notes that abusing the system is an equal opportunity activity, and everyone should face consequences for their actions. Later in the interview she suggests that if she were hired at the welfare office, she would be "clicking every button going" to give people as much money as they need. This perspective, as well as her choice to leave the welfare system even without an alternative source of income can be understood as a demonstration of her values of welfare as an entitlement (by wishing to ensure that people receive all the support they need), the importance of survival and independence by her own standards (by leaving the welfare system when it was not conducive to her survival and the survival of her family).

At the same time people living on social assistance also take up other expectations and constitutions encouraged by policies and the social service agency workers with whom they interact. Returning to Sarah, her choice to leave the welfare system in an act of independence and will to survive can also be constructed as consistent with the purported values of the welfare system. Although not demonstrated in practice, the welfare system, particularly Ontario Works, uses rhetoric of valuing and promoting independence and self-sufficiency in the individual (Swanson, 1999). These purported values are consistent with the "presupposition of the autonomous, choosing, free self as the value, ideal and objective underpinning and legitimating political activity [imbuing] the political mentalities of the modern West...” (Rose, 1996:151). Sarah's choice to be free from the welfare system, in an act of independence and resistance, is also a subjectivity encouraged in advanced liberalism. In this way, we can see multiple 
and competing interests working upon participants living on social assistance, which affect the ways in which individuals undertake resistant activities. This is not a system that we can get outside of; in Foucauldian notions of power even resistance is caught within these power relations. I will speak more to this theme in chapter four.

\section{Visibility and Feeling Violated}

In addition to the shame and stigma associated with receiving assistance, participants also spoke of feeling violated by the system. In particular, they found the constant inquisition, particularly when being asked for information during the intake to be invasive. The required relinquishment of that information and their rights to privacy is not seen as congruent with the income assistance they receive. "The intake interview is horrible. They ask you so many personal questions for the little amount of money." (Pamela)

And:

Participant: They needed my rent receipts, my bank information, why I left my last job, ID, urine sample. Just joking...

Researcher: How did you feel about them asking for this information?

Participant: Oh fine, but definitely a little bit violated at times. You have to jump through a lot of hoops to get 500 bucks... Everything they do is to make your life harder. I'm sure they have meetings where they sit around and say "how are we going to make it a displeasure for these people so that we don't have to keep handing out welfare?" (Mark)

These statements point to participants' frustration with what they see as the erosion of their privacy rights. People living on social assistance experience surveillance and degradation on a regular basis throughout their interaction with the welfare office. Mark was not alone in his comment about the urine sample 
requirement. Although urine samples are not required to secure welfare income in Ontario (although some governments have suggested this measure in reforms) Rebecca and Sarah also mentioned the fictional requirement of urine samples as a commentary on the extent of surveillance. Participants do not, however, challenge this erosion of rights by pointing to legalistic notions of privacy, dignity or independence; their frustration is not tied to an institutional rights-talk. Instead, their comments are directed at the unfairness of the system. While later in the interviews participants living on social assistance indicate in various ways that they resist against compulsory visibility in multiple ways, their discourse is often not tied to traditional notions of rights talk or collective action, which are typically associated with resistant subjectivities. Instead it takes the form of griping and everyday foot-shuffling (Gilliom, 1999). These realities are tied to notions of dependency, and the ways in which people accessing social assistance are constructed as dependent, and therefore required to be visible and "rightsless" (Gilliom, 1999). Additionally, since welfare is money that people are supposedly entitled to, it is a right of citizenship, that the experience is even more invasive than a bank loan communicates a lack of respect and trust. Thus the resistance outlined here is resistance against the reconceptualization of the subject. Becoming "rightsless" and visible (and invisible in certain ways, for example, in relations of power related to political processes) is not only a slight against one's income and survival, but also against the conception of the person living on welfare as a non-citizen. In a political culture which values the autonomous, free-choosing, self-regulating subject as citizen, notions of dependency are particularly dangerous to the citizenship of people living on 
social assistance - therefore rightslessness extends past losing the right to maintain a decent quality of life, and strikes at the heart of citizenship and participation. If a person is not seen to be productive by participating in wage labour relations, they lose entitlements to other markers of citizenship, including the right to privacy and in/visibility.

\section{Shaping the Target}

It's the System

Participants expressed frustration at a program that seems to work for agencies but not people using/needing services. They told stories of a system that has zero tolerance for quitting a job, even if doing so is the most rational decision:

And then the woman called and said we have a zero tolerance for quitting a job and you quit a job. We might look into doing something. So I got my mother to call in and say it was my car I don't want her using my car doing too much wear and tear on my car. So it was really my mother who covered me for that... But what's the bother of going out and working for two or three hundred dollars when they are going to take the money away? I mean -- they have to give a person incentive. (Lindsay)

Here Lindsay discusses the Ontario Works rule which decrees that a person cannot receive welfare after they have quit or been fired from paid employment. She also alludes to a policy which outlines for every dollar earned as a wage, a dollar is "clawed back" from her welfare cheque. She suggests that these rules do not work for people living on assistance because they create a "disincentive to work." Moreover, these types of policies make it difficult for people living on welfare to "get back on their feet," as it often costs money to get to and from work, purchase appropriate clothing for the workplace, and arrange childcare on the meager support available to people living on assistance. Participants also told 
stories of a system that perpetuates joblessness and does not provide real solutions to poverty and unemployment so that welfare workers can keep their jobs:

Instead of finding out things that will keep people off welfare forever, so they might have to spend that little bit of money at first to help keep people out of their dilemma, but in the end they will never have to come back, you see. You see what they're doing is they're just temporarily solving problems, but they're back all the time. You see they count on people being back all the time, because otherwise they'd be jobless... They've got it all figured out for themselves, not for us. (Mark)

The analysis participants offered about the welfare system targets both the "system" itself but also the individual players in that system. While participants acknowledged that "the system cheats the people" (Rebecca), they also acknowledged that systems are made up of people often making self-interested decisions - for example, expanding programs to keep social workers and social service workers employed, but that do not actually help people accessing those services. What is interesting about these statements is that people living on social assistance are suggesting that a push for increased funding and expanded social programs are not necessarily the best way to meet people's needs. These suggestions move us to consider new tactics and demands for change, and refocus efforts. While many advocacy groups and social service agencies often find themselves pushing for change in the form of greater and more autonomous funding, it is clear that these demands are not uncomplicated. In fact, individuals and groups pushing for increased funding and expanded programs need to question what really drives these goals, and if they need to be rethought in terms of a magic bullet answer to the injustices of neo-liberal government policies. 
For-Profit Agencies

It is not just social service agencies and the welfare system that participants targeted in their comments about what does not work for them, and the reasons for which they are living in poverty. Many of the participants suggested that for-profit corporations, with the help of government, exploit their poverty for profit. One participant, a young man frustrated and angry at the high unemployment rates and impossible job market in his town illustrated this situation beautifully:

You might as well be from another country...And that's the truth, it's either [one temporary work agency or another]; there's like 10 of them in this town. Anywhere where there's call centers, these places thrive. They're all interconnected. Oh well, this is a welfare town, we're going to go throw all our shit jobs in there... and they'll just love these $\$ 10$ an hour jobs. These Mexicans will just suck them up, they'll stand in line for hours. You know what I mean.

Researcher: So they basically go anywhere where there's a lot of poverty? Participant: Yeah, and set up shop. Because they know that they can just get rid of you. They know you have nowhere to complain to. They look at you like, "whatever buddy, you look like you're on welfare, and you don't have no one to back you up."... Because how can we fight for our jobs ourselves, and get capable work, which is 10 bucks an hour as an adult at least, and then they make it legal to [bring in temp agencies]. This ain't legal, man. [Temp agencies] get paid 14 bucks an hour from the employer. Why [don't employers] give welfare 14 bucks an hour and then [workers] get 12 and pay [welfare social workers] with the remaining money [for additional programs]? And then we won't even have to be government funded. (Mark)

This comment is rich with issues. Not only does Mark discuss his anger and frustration at being exploited, particularly with respect to these temporary work agencies (and it is important to note that because Mark is on Ontario Works, every time he gets fired from a job or has to quit because of dire work conditions, he is not eligible for benefits for a three month period) but he also targets the 
town's economic development strategy, which is to attract temporary work agencies and call centres to provide employment for its residents.

Additionally, Mark's comments are racialized and here he begins to connect - although not explicitly - some assumptions around racism, classism, and boundaries around those who do "shit labour" and "should" be grateful for it, and who, by virtue of their citizenship, should be granted good, well-paying, legitimate labour. People living on social assistance are denied their claim to citizenship: "because they know that they can just get rid of you, because they know even if you're going to complain, where are you going to complain to?... whatever buddy, you look like you're on welfare, and you don't have no one to back you up" (Mark). Having no one to support the poor was a reoccurring theme throughout the interviews, and relates back to notions of citizenship. Participants' comments suggested that they do not receive any support from their respective governments. In fact, in most cases, government was viewed as punitive and disciplinary undermining PLSAs claims to citizenship. In turn, participants receiving social assistance used less "rights talk," and did not speak much about spaces for collective organizing or movements based on collective identities (as rights talk often relies on imagined citizenships and communities of which the individual citizen can be a part.) In this way, PLSAs only spoke of certain types of engagement, but also opened up new possibilities for action and conceptions of resistance. I speak about this further in chapter four.

Finally, Mark does not attack the idea of activity and value tied to wagelabour. He is looking for a decent, respectable and stable job - he does not question the fundamental assumption or injustice of being tied to capitalist 
modes of production. Therefore, while he sees these companies as exploitative, they are deviant from the good companies and good jobs "out there." Overall, from his perspective, the system does not need to be changed, but some reforms need to be made. I will speak more about the active constitution of the self further in this chapter and in chapter three.

Agency Cuts

Cuts have not only affected agencies, but also the clients they serve. Mark expressed frustration that a service he used to use now offers fewer services, and has been unhelpful in his job search, "before they used to train you and teach you how to interview, and go to class. Now it's dwindled down to nothing." Additionally, some participants living on social assistance expressed that before the mid-1990s, there were more services and supports for people living in poverty. Pamela, who previously worked in the social services, discussed what the social services landscape currently looks like in her community:

I always worked in social services too. Enough though I was hearing these stories I still had faith that people would eventually get the help they needed... There is less money. There are fewer services. It's really fragmented. And people don't know how to access them. Unless you have somebody like I did like a CMHA worker to help navigate them.

In this climate, it is difficult to take risks to advocate for oneself, when both clients and service workers are having a difficult time staying afloat in their respective spheres. Additionally, there are multiple pressures on agencies to reduce advocacy efforts, which I explored in chapter two, therefore for some participants the target is the strain under which social services are operating. 
Welfare Workers

Despite the fact that they identified the "system as a whole" as a problem in their lives, most PLSAs expressed a great deal of frustration in having to deal with welfare workers. Story after story included welfare workers treating people receiving social assistance very poorly, especially with respect to decision making or respecting the difficulty people often face when receiving assistance. Most participants were angry with the way in which welfare workers treat them:

How do I feel about dealing with welfare workers? You can't deal with them. They are quick to dictate, and it's like they are inhuman. They don't seem to have any compassion. Or any understanding. I tell you if I was working in that office, I would be flicking every yes button going. And I don't care. If I could screw that whole system inside an hour, and pump out checks to people that desperately need them, and leave it in their hands for the next year to try to figure it out, well then that's what I would do. Because they are criminals. It's a government organized criminal agency. (Sarah)

While here Sarah imagines full-fledged resistance, at another moment in the interview she expresses empathy with the welfare workers because of the pressures they confront, particularly with respect to keeping their jobs. At this later point in the interview she suggests that the welfare workers are "happy just to have a job" and she does not blame them for their behaviour. These contradictions are interesting because they give a more complicated understanding of conflicted feelings towards workers to which other participants allude. Rebecca expresses a different, perhaps less conflicted, perspective on welfare workers:

These people do behave like Gestapo ladies some of them... and I just wish there was a test to see how do we get these sickos out. Where do they come from? 
Participants did not just identify lack of compassion and poor decisions as the reasons why they found workers to be difficult to deal with. They also identified what they considered to be ridiculous bureaucracy as part of the reason why they were angry about having to deal with the surveillance of the welfare office:

I didn't fill out the card right, you have to put nil, nil, nil, nil, nil in every box. This was really infuriating. I put nil and used quotation marks to denote nil for the rest of the boxes. They sent it back and made me write nil in every box. But you see again, because I expect this, I expect some pinhead who can't say that she clearly means this. No I expect someone who says (uses high nasal voice), "You have to fill in every box with N-I-L." So that could delay my money and get my landlord hassling me or something all for Nils in every box. I should have photocopied that one. But I use so much psychic energy just trying to live, that I can't hold onto that. But if I was feeling better, I would send that into MAD magazine or something. Or National Lampoon or something. But they didn't even call me for that, they just mailed it back with a post-it note on it. (Robin)

These kinds of engagements make it difficult to have compassion for welfare workers on the other side of the desk. They also locate power in individuals as well as in systems and structures. Participants living on social assistance, through their comments and observations, located power in relationships and agency with individuals as well as with systems. In tandem with other locations of power and power relations discussed in this chapter, some of the participants living on social assistance were shaping understandings of power in a way that, I believe, opens up new possibilities and targets for making change and shifting relations, in a way that is not possible when power is simply seen as located in an unjust structure: the welfare office. Instead of just naming a single location of power and oppression, for example locating injustice in oppressive welfare policies or in the business elite, participants indicate that there are a number of players in the perpetuation of injustice. Those of us working in social service 
agencies have much to learn from this understanding, particularly in including ourselves in power relations that produce and reproduce meanings of in/dependence, un/productivity, and non/citizenship. By shaping the "target" as multiple and complicated (and even including the constitution of our selves as the target), we begin to open up new spaces and terrains for understanding our own constructions and resistances. I will explore these ideas further in chapters three and four.

\section{Funding and Control}

Feeling Powerless

Like social service agency workers, people receiving social assistance felt powerless as a result of where they got their funding. Like social service agency workers, PLSAs indicated that they felt powerless and it was actually the workers and the "system" (the agency from which they receive the income, in this case, Ontario Works) that made them feel powerless:

You feel powerless on assistance. They make you feel powerless with constant threats. The way they manage everything. If you need something extra, like my other son he is on assistance and when the baby got sick they practically had to beg for money to take the bus to Toronto. Having to ask, and the attitude when you ask. It makes you feel like you are small...I think it is set up. They would never admit it but it is set up to make you feel ashamed. And I think that it's intentional. I think it's to discourage people from asking, prevent people from staying on assistance. Which I think is a good thing is some ways but the thing is you have to look at individual cases. (Pamela)

Here we can draw upon Arendt's notion of the complexity of the "law-abiding citizen." Because workers in bureaucracies are often just "doing their jobs", obeying orders and the law, they sometimes conceptualize themselves as not 
morally responsible for harmful consequences (Arendt, 1963). Likewise Pamela suggests, intentions of the workers aside, that the effects of institutional daily practices can be dehumanizing and even cruel.

One of these effects on Pamela, like most of the PLSAs I spoke with, felt that they would be targeted if they caused too much trouble, and this might threaten their benefits. Being labeled a troublemaker seemed particularly risky:

I feel like we don't have a voice. Because we are so powerless. We are all afraid because sometimes when you open your mouth, you get shut down...get labeled a troublemaker. (Pamela)

Getting labeled a troublemaker is not just an inconvenience or an uncomfortable feeling for people living on social assistance. Often being too active and causing "too much trouble" means that a person might find themselves under even more scrutiny from the welfare office. Being sent numerous cut-off letters, or having to check in even more frequently are real threats to participants - certainly those who pursue their appeal rights have experienced backlash in the past. Therefore, while people living on social assistance might want to "fight back" in overt ways and tip the relations of power in their favour for even a moment, these moves are sometimes too big a risk to take.

In this way, these feeling of powerlessness sometimes regulated participants' activities with respect to speaking out against something that they disagreed with:

Researcher: Do you ever wear buttons or anything like that? If it's a cause you agree with?

Participant: I am not really into that. I sort of question myself why. I am thinking the whole system is out for the rich. They don't care about the poor.

Researcher: ...Would you ever join the [local anti-poverty organization]?

Participant: I don't really see any point in that. 
Researcher: Why don't you see a point in it?

Participant: Because the whole system is ignoring the poor. My dad used to say to me, the poor are powerless. [Government people] only want to help the business people because they are ones who are the main taxpayers. They are all out to help the ones who are the main taxpayers. (Lindsay)

Lindsay expresses more than a fear of risk; she articulates a sense of complete hopelessness. Like social service agency workers, some people receiving social assistance stepped back from taking an active part in social justice campaigns as a result of feeling as though the risk was too great for such a small return. Instead of speaking out actively, many participants, both social service agency workers and people living on social assistance would often negotiate their resistances in different ways, moving to more "everyday" forms of resistance. For example, some participants spoke of not being completely honest in intake interviews, or not disclosing living with a partner, to qualify for assistance or to maintain their current level of assistance. While writing a letter of protest or attending a rally are typically seen as the "usual" forms of resistance against unjust welfare policies, these "everyday" moves of nondisclosure are also targeted at unfair welfare policies, they just take different forms.

\section{Discipline}

One of the prevailing risks of being labeled a troublemaker is to increase one's exposure to the disciplinary elements of welfare. One common theme running throughout the interviews, in both social service agency workers and people receiving social system, was the threat of discipline that ran through each of the interviews. Nearly every participant spoke of feeling watched and kept on 
guard with respect to their funding and their funding source. This issue came out throughout all of the interviews, but specific participants articulated such sentiments in particularly memorable ways. Mark suggested that such disciplining might be a way of keeping people off, or getting people off welfare. He states:

So it's a constantly pissing you off, and making you nervous, on guard, and you get so sick of it that you say to yourself, "fuck it, I just gotta get off." And that's the whole reason it works, but it only works short-term. They don't realize long-term. But that's what they want short-term, so it looks like it's being solved but it's not.

Others echoed these sentiments:

I don't say I want to know when you peed last as a joke. That's very true. And then the threats if you miss an appointment for this job researcher thing or whatever, you know. They just threaten to cut you off. I mean, it's ludicrous. If they spent more time trying to figure out how to help people rather than how to track people, [they would get more done]. And then if they still want to track people, go after the [guys] that aren't paying the money. (Sarah)

In these comments, participants indicate that the constant surveillance is tactical and unfair. The constant gaze of the panopticon in people's lives shapes the way that they conduct their conduct (Foucault, 1979). Additionally, participants indicated that these modes of surveillance and discipline do nothing to help people get off welfare (and into sustainable employment) in the long-term. What they do accomplish, however, is the constant fear of people on welfare, and the subsequent regulation of resistance. Participants indicated that one did not even have to face a decision or a cut off to feel regulated or disciplined:

I have never had to [fight a decision]. It's just like a constant threat. It's always hanging over your head. Like we can do this to you so you better smarten up. So luckily I was able to get the information they wanted. It's just the whole way that they do it. (Pamela) 
The disciplinary techniques shape participants' actions in particular ways. Participants shaped their conduct in ways congruent with the techniques and aims of governmentality in advanced liberalism. For example, people living on social assistance were particularly concerned about the ways in which their financial movements were being tracked, and therefore would act in ways that prevented them from being surveilled or at least minimize the negative impacts of surveillance:

So I'm pretty careful about what I use my bank card for now... So I won't even use my bank card at all because I know it's open to disclosure. I was really offended by all the rights I was signing away, but I understand too that it's for preventing fraud. Although, most of these people aren't committing fraud, it's just plain for survival... Yeah, I definitely feel big time big brothered... Not paranoid, but I am cautious about what I say to people. I'm not watching over my shoulder when I walk down the street, but I'm cautious about where I spend my money and what's going to show up on my bank account statement. (Robin)

And:

I was forced to use my credit card in an emergency situation and now I'm afraid they'll cut me off. (Lindsay)

Here, participants are "encouraged" to tightly regulate their financial activities. In an effort to carve out some autonomy in their ability to spend what little money they have to meet their needs, participants carefully control how they are monitored electronically and on paper. In this way, surveillance not only shapes their financial activities, but their financial activities shape the surveillance. As participants become more adept at hiding pockets of money and regulating what shows up on their bank statements, welfare workers become more adept at tracking down that spending and uncovering untracked spending. Fraud cheat 
lines are established and welfare workers study bank transactions intently for discrepancies (Parenti, 2003).

The impact of surveillance not only regulates the ways in which participants manage their financial affairs, but also how they experience their freedom: "big brother is watching me. I feel like they are controlling me. I feel like I am their property. I feel like - it's not freedom that's for sure." (Rebecca) This loss of freedom is particularly difficult given the reliance on the ideal of the free, autonomous individual in the advanced liberal society. This loss of freedom includes their access to privacy rights:

I haven't experienced [being monitored], but I'm very aware of it, and so I'm very careful about what I do... Yeah, I'm not walking around looking over my shoulder but I'm very aware of it. I went in to help out a friend sign his papers because he couldn't bear to go in by himself, and he says, "what am I signing, what am I signing?" and I say, "your life away; just keep signing." (Robin)

Not only are people living on social assistance expected to "sign their lives away" as an "eligibility requirement," they also learn how to tightly manage their own presentation:

But I don't know what they put in those OW files, and every time I call and talk to ODSP and OW I'm very, very careful about what I say. Because they can make a judgment call about whether or not I get disability based on something that I said during a conversation and I could have been out of my mind on my meds, having a psychotic day or something. I'm not psychotic but it could be anything. But every time I call I'm very careful of what I say. (Robin)

These quotations provide rich examples of advanced liberal governance techniques, leading to an understanding of how we negotiate the entrepreneurial self (Rose, 1996). Participants living on social assistance use multiple ways of understanding their experiences of discipline, and the ways in which it both 
shapes them, and the ways in which they shape it. Specifically in Robin's comments we can see the experience of discipline as encouraging her to take up a subjectivity that watches her bank accounts closely, uses a great deal of caution when speaking up for herself (or representing herself), and making decisions (in so far as she can) of when she will relinquish privacy rights and make inquiries about her file. Mark, Pamela, Robin, Sarah and Lindsay's experiences illustrate that it is not just the welfare system that is shaping the people who engage with it - people living on social assistance also shape the system. When PLSAs choose to be more careful, surveillance mechanisms expand to access the obscured information. This dance continues to expand and constrict the terrain for movement, leading to an ever-fluctuating experience and spaces for games of power. I will explore these new terrains and understandings in chapters three and four, through the concept of the entrepreneurial self and new spaces for resistance.

Many people, typically through their talk, place power squarely outside of themselves, in terms of who has control over their funding/income, in terms of feeling watched, in terms of how they are treated by "authorities." However, while people place this power outside of themselves, they also speak of an ethic, of wanting to be good, wanting to do the right thing. Therefore even though participants often place power outside themselves in terms of their talk, they also open up the opportunities to think about the ways in which we operate in power relations, and the ways in which we develop ourselves through understandings of how we interact with so-called, supposed "powerful people." This opens up the opportunity to think about the active self, because even in their talk people 
acknowledge that they are actively playing a part within this power relation, even if they do not necessarily use that language. What I find interesting, is the ways in which people think about power in this way, but also the ways that people open themselves up to possibilities of different understandings of power, and various ways of negotiating their lives with respect to the systems and the techniques that do affect them. The next chapter will focus on the manifestations of this active self, and the ways in which people negotiate their active selves in the interests of self-governance and the advanced liberal society. 


\section{CHAPTER THREE: \\ THE ENTREPRENEURIAL SELF AND \\ THE CONSTITUTION OF ACTIVE CITIZENSHIP}

In the previous chapters we looked at some negotiations and contradictions on the part of social service agency workers and people living on social assistance. To find a way through these negotiations and contradictions, Foucault's theories of discipline are enriched with the Deleuzian concept of Control Society and Nikolas Rose's notion of the entrepreneurial self, which relies upon an understanding of the ways in which governance operate in an advanced liberal society. I find that these concepts are particularly useful in exploring the ways in which people govern their conduct and take up subjectivities with a particular focus towards productivity. While I spoke generally about governmentality in previous chapters, in this chapter I will focus specifically on the entrepreneurial self as a technique of governmentality which merits further attention. I seek to take my analysis further and integrate the theoretical concepts of the entrepreneurial self, active citizenship, and resistance in the advanced liberal society.

Early in the research process, much of my focus was on the connections between funding and resistance between the two participant groups, with an eye to the ways in which people's subjectivities are mobilized. As I kept reviewing the transcripts, I realized that while looking at the disciplinary effects of funding and income systems was an invaluable starting point for analysis, it was not sufficient to understand the complexities of the different ways that people negotiate their positions. The more time I spent with the data, I realized that it would be helpful 
to further develop an analysis that provided the opportunity to think about resistance and subjectivities in a more interactive fashion.

What became increasingly clear to me is that people's subjectivities are mobilized to create certain effects. In an advanced liberal society, the purpose is not simply to have people receiving assistance so poor that they are desperate, and social service agencies so worried about grappling for funding that they stop talking and advocating because they are afraid that they will lose their funding. This type of discipline, which I explored in the first two chapters, is integral, but it does not explain the entire effect of contemporary governance. An important component of these practices is that subjectivities are also mobilized such that individuals are often trying to be better, trying to capitalize on themselves. Therefore a notion of the entrepreneurial self sits next to these notions of good and bad, and encourages us to take up entrepreneurial subjectivities.

For the purposes of this chapter, I am going to explore the entrepreneurial self as a technique of governmentality which operates as a universal mechanism. The analytic value of governmentality approaches is that they challenge the possibility of escape, asking us to disrupt our desire for innocence and instead consider, even for a moment, the possibility that we are all implicated in contemporary practices of self and other regulation. While this can feel deterministic, it offers the foundations from which we can imagine a collective resistance to those social relations which act upon and through all of us.

In speaking with people living on welfare one theme that kept recurring was a sense that participants were eager to convey that they want to work, they 
want to contribute, they want to produce, and in these ways they want to be "good citizens" (Cruikshank, 1999). Participants living on social assistance were, in this way, often capitalizing on themselves, making themselves better - whether that is by being good producers, good citizens, good workers if not for a wage. These are all qualities that the advanced liberal society demands.

The social service agency workers who participated in this study demonstrated a similar ethos; they were often trying to secure more funding with which they could develop and advance their services and stabilize their ability to operate in professional ways. The desire to secure more funding was not always about resistance and securing more autonomous resources in order to facilitate advocacy, but rather their subjectivities were constructed in a way that was useful for advanced liberal societies. They were acting as entrepreneurial citizens and as entrepreneurial agencies; they were efficiently delivering services and trying to grow and enhance themselves.

The connection, then, between the social service agencies and people living on social assistance is not necessarily just about their funding constraints, as previously imagined. A more nuanced connection is that their funding mobilizes them as entrepreneurial individuals. Both workers in social service agencies and people living on social assistance involved in this study were always capitalizing on themselves. In this way, the resistance is not solely tied to the funding or income, it is also tied to the fact that they think that they require those funds to maximize their potential. Therefore, often when participants resisted, their resistance was, in part, tied to securing further financial stability and support in order to capitalize on and maximize themselves. This is a theoretical 
capitalization/maximization; it can certainly be argued that the meager amount of income/funding that these individuals and agencies access is often not enough to meet necessities. However, that resistance can be tied to securing more financial resources with which to capitalize on oneself opens up the possibility to understand how regulation does not only work in repressive ways, it also is the mechanism through which subjects are produced and fashion themselves.

While participants, particularly workers, identified a fear that they would lose funding or income if they resisted, I would suggest while insecurity or the "bottom line" were foregrounded as important sentiments, the situation can be read as having some other important complexities. For workers in particular it seemed that the loss of funding was more tied to not being able to provide a particular service, not being able to perform to their fullest, and demonstrating an explicit concern that their service to the client would be threatened. In the first chapter we saw some contradictions around wanting to speak out against injustice, but not resisting because they might ultimately hurt the client. This might, in the end, result in an imagined harm to the client, for example, diminishing the relationship with the MPP making it difficult to request special consideration for expediting an appeal for disability supports in the future. Additionally, this ethos shapes decisions to affiliate with certain advocacy groups in coalition work:

In [this town], there are certain groups that have bad reputations, and although I wholeheartedly agree with those organizations, I worry about linking [our agency] to them. It could hurt our reputation. And if our reputation is hurt then the clients could suffer, so that's less around funding and more about reputation and being linked with certain types of advocacy/activism. (Julia) 
I would suggest that this entrepreneurial ethos (of delivering the best service to the client whatever the cost) is another important reason that workers subsume notions of agitating for social justice under providing a service. This may explain how they can get around "feeling bad" about not resisting, because if they are entrepreneurial, and their purpose, as entrepreneurs, is to provide the best service in the market for those needs/individuals, then it makes absolute sense that they will deliver that service and "maintain [those] relationships at whatever the cost" (Elizabeth). This is not to suggest that workers are being disingenuous, rather there are multiple desires and needs at stake in every one of our conversations. However, some are foregrounded, while others, such as the notion of self-improvement are obscured.

On the part of people living on welfare, it is interesting to consider this entrepreneurial spirit as tied to citizenship and the desire to contribute to society. Participants living on social assistance spoke a great deal about the responsibility of taking care of oneself, alluded frequently to the values they held when they were "taxpayers," and presented a number of alternatives to what they saw as an unjust system. Many of these changes were contingent on the moves of active citizens and active citizenship, relying upon notions of self-motivated workers. Much of their talk was centered around their contributions and potential contributions, indicating an active construction of the self. For example, Mark's solutions often revolved around innovative ways to help citizens maximize their productivity:

That's what really gets me, is that this money should be utilized better. You should give each welfare recipient a year to get on his feet. And what is it that you need? A driver's license, since you lost it. You got a fine you 
need to pay? Fine we'll do that, but after that you're own your own kid, and there's no reason you should need our help again. But they don't want to do that.

Mark is not alone in these sentiments. Most of the participants living on social assistance expressed a desire for similar solutions or supports for finding and maintaining wage labor. Like social service agency workers they were angry at unjust systems, but still demonstrated an entrepreneurial ethos located in the demands of the advanced liberal state. In the next section I will explore more indepth the theory of the entrepreneurial self and the enterprise culture.

\section{The Entrepreneurial Self and Enterprise Culture}

Social workers are often seen as governing the behaviours of others, or encouraging others to govern themselves through so-called "empowerment." In an advanced liberal society, certainly social workers are in a position through which they engage in the reproduction of the "entrepreneurial self" with respect to the individual in the welfare state. Moreover, social workers are an important part of the welfare state and its disciplinary function. Furthermore, in a neoliberal welfare state we can speak of perpetual training as a factor in workfare societies (Walters, 1997). Social service agencies and workers are often engaged in encouraging their "clients" to take up active constitutions of the self: a self which is self-supporting, self-reliant, and "actively participates" in society. Social workers have an "educator" function, and under the guise of "empowerment" and education help to shape clients in socially acceptable ways (Foucault et al., 1999; Margolin, 1997; Isin, 2002). Social workers are therefore implicated in techniques of risk-based targeting of services and peddlers of well-being and 
personal investment. While social workers take up these subjectivities to varying degrees, it is useful to investigate the ways in which these techniques are inherent in the realm of social work practice.

\section{The Entrepreneurial Self}

The entrepreneurial self is one that is active. It is a self that is always engaged in continuous calculating about, and acting upon, itself to improve upon itself (Rose, 1996:154). The activity upon itself, which Foucault terms 'technologies of the self' (Foucault, 1982), takes numerous forms including an endless learning and reflective approach to living and citizenship. This active citizenship is located in notions of enhancing the self's independence and freedom (Edwards, 2002:358), which is located in a particular subjectivity of citizenship (Isin, 2002). This self is shaped by a commitment to enterprise culture and capitalization of the self:

The new citizen is required to engage in a ceaseless work of training and retraining, skilling and reskilling, enhancement of credentials and preparation for a life of ceaseless job seeking: life is to become a continuous economic capitalization of the self (Rose 1999:161).

This subject is continually being improved upon, and takes steps to improve upon herself. Through working to achieve better health, better credentials and a better life, the worker governs and regulates herself in a way that constructs herself as a commodity - improving her "output" and "performance." Drummond refers to this as the "commodification of the self" (Drummond, 2003:61). The entrepreneurial self thereby invests in oneself, through privatized education and the investment decisions. She is always improving upon her performance, and 
securing the resources through which improvement becomes possible. In this form of governance, "responsibilized individuals are called upon to apply certain management, economic and actuarial techniques to themselves as subjects of a newly privatized welfare regime" (Peters, 2001:60). This work is ceaseless, leaving very little room for any other activity. As Drummond suggests, "to stand still and wonder is somehow to move backwards" (2003:61). In social work, as well as many other "professions", to be efficient, one must always engage in a progressive and linear movement.

The social worker is not exempt from this form of self-governance; none of us are. What makes the intersections of social work interesting in this case is not only do social workers construct their subjectivities with respect to the entrepreneurial self, engaging in a complex technology of the self, which commodifies and responsibilizes the self, they also play the role of expert in mobilizing other subjects to undertake the same form of self-governance. These individuals are social work clients, and potential social work clients. In other words, social workers are active in promoting others' activities, and in this promotion with individuals and groups they assist in constructing a discourse in which all of us must participate in this particular form of active and commodified subjectivity. We come to know ourselves as subjects through our ability to have others mobilize themselves (Margolin, 1997). This concept contributes to our understanding of the social worker functioning as both the watcher and the watched (Moffat, 1999) - in this scenario, the social worker is both the mobilizer and the mobilized. 
Enterprise Culture

Enterprise culture is one that depends on the mobilization of the entrepreneurial self, and promotes this mobilization. In the enterprise culture, the individual in the welfare state transfers from the "passive welfare consumer" to "entrepreneurial self" making private investment decisions to "improve her lot in life." In this way, the individual "contributes" to future prosperity in her life, and the prosperity of society (Peters, 2001). Enterprise culture relies on these constructions, and infuses every part of life - including health, community and education:

Enterprise culture has also been portrayed by its proponents as a set of values, behaviours and attitudes that emphasize innovation, self-reliance, initiative, flexibility and autonomy, in individuals and is seen to be equally applicable to all levels of institutions across both public and private domains (Hooper, 2001:2).

Education and training are key components in enterprise culture as mechanisms of personal investment. They are vehicles through which individuals work to promote their own interests, and develop themselves. Workfare is an example of this type of mobilization, and some participants living on social assistance, particularly Mark and Sarah, spoke to the need for training supports for people living on assistance.

Enterprise culture and the entrepreneurial self are taken up by "learning organizations" in techniques of governance. Learning organizations, represented by larger social service organizations such as Children's Aid Societies, often require their workers to take on lifelong learning strategies to manage themselves. Under the influence of these techniques, the worker is institutionalized "as an active, autonomous and continual learner, never "skilled" 
but continually needing to invest in their own human development and human capital"' (Reich, 2002:220). This technique is useful, as it encourages workers to be continuously working on themselves, governing themselves, often in the interest of the neo-liberal state. Workers are "enabled" to take responsibility for their actions, through their own empowerment and success within the organization. Therefore, it is clear that the social workers themselves are taking up an ethic of enterprise and self-governance by engaging in ongoing training and professional development. While the scope of the interviews for this project did not touch upon enterprise culture and continual training specifically (in fact, a number of the participants were not registered social workers, and therefore not required to undertake these types of requirements) this ethos permeates understandings of the competent professional worker, a concept to which many of the participants spoke directly.

This ethic is not only restricted to the workplace; the whole life, including health, leisure and family, is inscribed with the "ethos of enterprise" (Edwards and Nicoll, 2004:168). It is interesting to note that often continuing competence, professional development and lifelong learning programs include self-care, healthy living and stress management workshops to help social workers manage their personal lives, and, as a result, become more efficient in the workplace. It is clear here that the corporation's reach is further than simply the domain of the workplace. The entrepreneurial self in enterprise culture maximizes her potential everywhere, with an eye to efficiency and productivity in all moments of her life. Under this model, the state is required to formally intervene quite infrequently to 
regulate workers' behaviours, and their broader lives, as subjects work on and govern themselves.

This form of governance is also useful to organizations that are becoming themselves increasingly flexible and imbued with an ethos of enterprise. Not only does it allow the organization to "step back" in some respects from formally managing/governing its workers in an intensified manner; it also instills certain types of constructions of fulfillment in its workers. The worker begins to strive for the identity of the "multiskilled, flexible worker," which "is the desired identity for these flexible, restructuring, economically successful organizations" (Reich, 2002:227). By enabling a reduction in formal and intensive supervision and provision for regulation, and replacing it with "continuing competence" and learning standards for which the worker is most often privately responsible for in cost, the organization is able to reduce its costs and formal regulation, by instilling an ethos of personal investment. Again, while participants did not speak to these phenomena directly, they did allude to an ethos of productivity and professionalism that draws upon, is reinforced by, and reinforces, these concepts.

Funding and income intersect with the demands of enterprise culture. Not only are entrepreneurialized individuals motivated to improve their lots in life and agency work through learning and reflection, they are also motivated to cultivate, improve and protect the resources through which these improvements are facilitated. In the case of individuals receiving welfare, this phenomenon was constructed as survival on the system. Throughout our interviews, some participants living on social assistance indicated that they knew many people who 
were not strictly following the rules on welfare. In most cases, participants explained that these "indiscretions" were necessary and fair for others to undertake because these measures were only taken to ensure their survival:

Anyone that I know of that was not strictly following the welfare rules was doing it out of absolute desperation. It had nothing to do with them gaining anything financial. All they were trying to do was live... They're doing it so that they can get gas in their car so they can go to the food bank or something. These are very desperate people... These breeches are a necessity, it's a survival tactic, nobody's making a profit. People are still desperately poor and living below every line imaginable... So if I broke the rules, like they say spouse in the house, it again is only for me to maintain my apartment, keeping me off the street. (Robin)

Given that "people have to survive no matter what it takes; it's the survival of the fittest," (Sarah) it is not surprising that many of the participants expressed agreement with any move necessary to secure one's survival in the system. Participants seemed to take up understandings of the importance of independence and self-sufficiency, both notions essential to the constitution of an entrepreneurial self:

Well, it's my responsibility to make sure that I take care of myself, I don't think it's everyone else's responsibility... Maybe they should help with those problems and I would be able to stay off the system forever. Because they're throwing money at things that aren't solving anything. (Mark)

Throughout their talk, participants valourized independence and self-sufficiency, they operate under the "universal" assumption that everyone is expected to "work" (for a wage) and to be "self-supporting" (Fraser and Gordon, 324). The opposite, dependency, is demeaning: "and I also feel it very demeaning that for years I was able to have an income and independence and now I have lost the independence." (Lindsay) Their identities are linked with their production, and 
they are implicated in strategies of the responsibilization of the self, motivated by discourses of self-sufficiency used, in particular, in the social services.

\section{Responsibilizing the Self}

Although social workers are a key component in "helping" other subjects to take up these particular forms of self-governance, many workers are also wedded to older notions of welfare and social justice. Social workers can still be found to be promoting public investment programs to support unemployed or marginalized individuals in the name of social justice (Mullaly, 1997). In this way, social workers often "ride the line" between older welfare regimes and neoliberalized constructions of responsibilizing the self. This relationship is one which is complex, and often both "sides of the line" work together to create complicated subjectivities. These techniques also encourage subjects to make claims on the state, that are later used to have them mobilize subjectivities related to self-governance and commodification of the self. For example, claims to "the right to work" has since been mobilized to support workfare and rhetoric of the "end of unemployment" (Walters, 1997). In this way, we can speak of the responsibilizing of the self to be connected to Deleuzian notions of the "control society," in which we are all continuously under control, in continuous connected enclosures (Deleuze, 1995).

A key component of responsibilizing the self is adopting strategies and techniques in which investment in oneself also takes the shape of adopting "risk management as an everyday practice of the self" (Peters, 2001:61). Programs to develop professionalism and competence deploy notions of the competent worker 
- who minimizes risk, updates her skills, and takes the right courses - to engage workers in techniques of self-governance. In this way, we move away from regulating workers by legislation, although it remains at hand and is deployed when self-governance and governmentality are not "effective". Funding requirements operate in similar ways, with the end result of programs being developed in anticipation of funding requirements, and when this selfgovernance does not work, funding is pulled or not allotted. Therefore the triangle of governmentality, sovereignty and discipline are at work here, being deployed at the appropriate times to regulate the worker (Foucault, 1991:102).

Funders do not only try to mitigate risk and liability through certain governmental techniques, they also use this tool to manage their reputations. One worker spoke of having a funder direct him not to speak out because they were supposed to appear as a unit. This is clear in a quotation used in chapter two, but I will reprint it here:

It was a funder... It was a political issue in terms of not wanting us to speak because it's supposed to look as though we're cohesive, when in fact we are individuals. To be fair we have less of that problem because we're an independent charity. We're not like a transfer agency, which tends to be fairly closely tied to a political body. Whether municipally, provincially, or federally. But it has happened. (Michael)

Often, however, the reprimand is simply not necessary to encourage workers to be careful regarding their actions and reputations. PLSAs also demonstrated a measure of empathy for their employers, as good employees are wont to do, particularly with respect to protecting the reputation and legitimacy of the agency:

So anyway, we've been silenced or asked not to, and really all the organization is saying, in their defense is "don't do it in our name; do what 
you want in your own." ... I would do it all as a manager, with permission. (Elizabeth)

Governmentality, therefore, is not simply a technique deployed to ensure that citizens/workers regulate themselves in order to maximize their potential "as resources to be fostered, to be used and to be optimized" (Dean, 1999:20), but also to minimize the risk and maximize the reputation of funders and the social service agencies together. The worker is made both responsible for her own professional conduct, her own reputation, and the reputation of the agency/funder unit. The good reputation of the profession in turn allows it to maximize its influence over individuals outside of the profession, (i.e. social work's "client base") to increase the opportunity to "enable" other individuals to take up similar subjectivities.

\section{Social Workers as Experts in Enterprise Culture}

Professions are also implicated in governance and governmentality. They are not only implicated through disciplining subjects, reproducing an ethic of self-governance and constructing a particular subjectivity of citizenship but also:

The modern professions and disciplines have always been implicated in the question of government... They became implicated in governing conduct by contributing to the problem of government by virtue of their own demands, by articulating and mobilizing the demands of other social groups, and by solving problems via the expertise they provided (Isin, 2002:237).

Professions such as social work are critical in mobilizing particular subjectivities in the interest of the state. In the following section I will engage in a more indepth discussion of how social work, in particular, participates in the mobilization of the entrepreneurial self in enterprise culture, both with respect to 
the individuals whose lives social workers intervene, and social workers themselves.

With respect to governmentality, government is seen as the community of free, autonomous, self-regulating individuals with an emphasis on responsibilization of individuals as moral agents (Rose, 1999). Social workers consequently occupy a complex role in governmentality, straddling both sides of this conception of government by engaging in their own self-regulation and encouraging the self-regulation of others. Social workers, by virtue of their positions and use of "professional judgment" (Reich, 2002) use both reward and punishment to enable clients to govern themselves; they encourage clients to engage in a similar subjectivity as they do as social workers when regulating themselves through lifelong learning and the pursuit of continuing competency. Isin suggests that:

...it is very difficult to untangle strategies and technologies that professions assemble to form and govern themselves from those assembled to constitute and govern others... As the professions govern themselves, they reorient virtues that arise from governing themselves toward governing others. Thus, the virtues of being a professional gradually permeate the virtues of being a citizen and the vices of being a stranger, an outsider and an alien (2002:249).

Nowhere is this trend more prevalent than in programs like Ontario Works, which uses mandatory training and job placements to regulate those receiving social assistance, with the expressed goal of turning the "passive welfare recipient” into the active job-seeker/job-holder (Moffat, 1999).

The active job-seeker is equated with the active, productive citizen; in fact, much of the discourse around citizenship is constructed around notions of citizenship tied to productivity - specifically wage labour (Walters, 1997). Social 
workers, as well as other "helping professionals" are charged with the task of inculcating particular virtues in particular "classes." In fact, social workers' identities and citizenships are often overwhelmingly tied up in a "professional duty" to help (i.e. fix) "others." Using normalizing judgment, Isin suggests that these "disciplinary professions":

...became mediating and effective agents for articulating the virtues of bourgeois citizenship, and these virtues were deployed as yardsticks for those who lacked them...These strategies and technologies ...[are connected] up with various procedures and apparatuses of correction, inculcation and disposition...citizenship was constituted as an attainable goal...rather than as an unattainable ideal (2002:229-230).

These strategies, taken up by social workers are used both to monitor individuals receiving social assistance, as well as have subjects take up particular subjectivities in the interest of the State. The State cannot do this work on its own and so the disciplinary professions are enlisted to undertake these strategies as well. As Valverde notes:

...states may have a monopoly over the legitimate use of force, and may therefore be in a privileged position to enforce rules about behaviour, but the state can only make its citizens internalize certain values if it has the full and active cooperation of the family and of voluntary organizations (1991:23-24).

For this reason, it is essential for the state to enlist the efforts of a well-developed social services system to maintain a close eye on subjects in its respective jurisdictions, and actively work to enable subjects to take up particular strategies on their own. Professional ethics as espoused by social work are constituted as "universal norms of conduct" and citizenship, and those who "either fail or refuse to uphold these virtues...[are] subject to reformation, cure, incarceration, imprisonment and the like" (Isin, 2002:240). People are expected to maintain 
their homes in a particular way, raise their children in a socially acceptable manner, and conduct themselves at work (or at their work placement) productively. When individuals transgress these boundaries and norms, they are subject to intervention - and certainly we see some participants living on social assistance being "subjected to reform," for example by being asked to fill numerous forms detailing their finances, or being required to take on volunteer placements even when those placements conflict with a few hours of work at the factory, in the stories they tell during the interviews of this project.

Moreover, the use of normalizing judgment operating through both reward and punishment also creates hierarchies and formulations of true knowledge (Foucault, 1979). This formulation of "true knowledge," not only mobilizes status between groups, but also can create a hierarchy among different types of social workers, of knowledges, of competencies, of specializations and of rankings:

Normalizing judgment acts to formulate 'true' knowledge, to mobilize those to be afforded status, privilege and affiliation, to indicate memberships of a social group and to socially classify and distribute individuals within hierarchies across [and within] ranks (Edwards, 2002:362).

In this way, lifelong learning is generated by, and generates, a competition between workers, whereby workers vie for "legitimate knowledge" (Edwards and Nicoll, 2004). Workers attempt to identify, isolate and then undertake the "right" kinds of learning - often clinical, regularized workshops, focusing on "proper practice" with different populations in different scenarios. This particular form of engagement in professional development is not only a facet of Deleuze's "control society" but it also shapes social work in a particular manner, which at 
once constrains and enables opportunities for the practice of social work. It also reinforces certain understandings of professionalization, whereby workers shift their priorities in order to appear professional:

...in the community I worry about my reputation professionally. I don't want what I say to be used against me professionally. And in the community I sometimes don't want to speak on issues because I get too emotional about them (i.e. anti-poverty). (Julia)

Julia's comment can be understand as an illustration of the ways in which workers can to buy into the myth of the distanced and measured professional. This myth ensures that certain forms of practice and knowledge are legitimated, often in the interest of the neo-liberal state. Like Mark, Julia is a young person taking up a responsibilized subjectivity early in her life and career. In fact, as people in their twenties and thirties, they have grown up in advanced liberalism, so perhaps this early take up of an entrepreneurial subjectivity is not surprising.

\section{Constituting Ourselves: Identities and Subjectivities}

When confronting the challenges of feeling controlled, insecure and restricted in an enterprise culture, different agencies and workers take up different positions in negotiating these tensions. While some take the position that their advocacy, regardless of how intense or targeted it might be was not activism, other participants hedge on this issue a bit. Depending on the context, workers would define their interactions and approaches differently, indicating a measure of flexibility in their personal and professional philosophies. While this might look like a liberal approach to practice, their constructions seem to be more complex than that, particularly since their responses indicate an awareness 
of inequities and injustice (for the most part) and the hedging occurs predominantly when discussing targets and tactics.

One reoccurring theme is the tension between community and individual advocacy. Many of the agencies recognized the links and importance between the two, but often did not position themselves with the luxury of being able to take up both positions and forms of resistance. Most workers demonstrated a concern with social justice, empowerment and equality, for example:

I guess [that what drives me is] a bit of a passion for fair and equality and equal opportunity if that's what you mean by how I approach it. That's what drives me the, ability to sometimes when you get really lucky you can even help somebody just a little... [sometimes I can do something that] fixes something for someone. [For example, helping them to maintain their housing or secure income or food for the month.] Not that we fix it but we help them to fix it; and you feel a little bit like your work is enabling them to have something fixed. (Elizabeth)

While most of the focus on individual advocacy was set up as their "proper focus" and what agencies are "there for," many of the participants also indicated that part of their hesitation was as a result of maintaining relationships that facilitate their individual advocacy. For example, they are unwilling to sacrifice networks that help ODSP applications become fast-tracked when necessary, for community action, even when it is ostensibly meant to be supportive of ODSP applicants and recipients. Part of the social justice project is ensuring high quality services for community members. This theme came up throughout the interviews. Michael, for example, explains how he is hesitant to do anything that might negatively affect relationships or funding down the line:

...our approach just tends to be more individually focused. So if we can support an individual in their fight to get the assistance that they require because of their own personal circumstances, then we will do that. So it's more from a case-management perspective I guess... But we won't just 
jump on any social issue or action without us having some experience or direct link with that. So raising the rates kind of idea, we will comment on why people might find themselves in a [bad situation] because those rates are so low, but we're not just going to jump on that and say let's push for more rates. We would say let's push for more information to make those sorts of decisions, to help formulate those decisions. Yeah we're a bit passive that way.

And, later in that conversation:

If there's an agency that we're working with that wants to go public about something, make a statement against the government, for example, I get really nervous when I feel like I don't have enough information to feel that's true. Not to say that's not true, but we just don't want to jump on that bandwagon... Is that going to affect our funding, affect the relationship down the road? It all leads back to that relationship sort of thing. Is speaking out going to affect our relationship? Anytime there's a hot issue there's that concern. Also, that we'll be misunderstood. So for example, this is the issue, but people will take it that the criticism is against an agency, but it isn't. Same thing with the funder, they may feel like you are condemning them, but it's really a multi-faceted issue that's the problem. So you go, oooohhhhhhh, who's going to yell at me now? Be afraid, be very afraid.

Here, Michael reconstitutes group action as thoughtless and going with the flow; he also outlines why he is not inclined to act collectively with others. In this way, he and other workers expressed hesitation to speak out on issues for fear of reprisal and diminished relationship-building.

At the same time, some participants seemed willing to take stands when necessary. Workers gave examples of times when they spoke out because they felt it was absolutely necessary. But part of the challenge for workers and agencies is "picking the right battles:"

So you constantly have to find ways to work around it. Some things you do go for, but you have to hold it for those big things... You really want to reserve the big guns for the big issues. (Elizabeth) 
In these moments where agency workers have to demonstrate courage, they recognize that it is not an easy task, and seem forgiving of themselves when they are unable to take risks:

So, there's a certain comfort level because we're an independent charity, and we know we have to take risks to do the right thing. But I won't say that the other part of the gulp, and the insecurity isn't there. Because it is. I don't mean to imply that any of this is easy, but you have to keep questioning yourself, you have to keep moving (Michael).

Perhaps this attitude results from the culture and expectations of social service agencies. A certain degree of deference is expected from workers to the agency, and clients to the worker. "Good" clients and workers defer to authority, and are consequently accorded more or less autonomy based on their levels of deference. This permission-seeking and relinquishing of genuine personal autonomy is demanded to achieve "success," increase one's resources and ability to move.

While this constitution of the self may seem particularly problematic, it does provide some room to move for participants in terms of negotiating their ways through a difficult system that at once seems constraining and freeing. On the flip side, it gives a bit of room to move because it gives workers and people living on social assistance the ability to constitute themselves as "good" and useful based on what their actions are, in this case if one is doing a good job, providing the best service possible or continually looking for work, they can continue to feel good about the work they are doing. As Rose suggests:

Enterprise also provides a rationale for the structuring of the lives of individuals to become, as it were, entrepreneurs of themselves, shaping their own lives through the choices they make among the forms of life available to them (Rose 1990:226). 
In this way, the connection between the workers and the people receiving assistance is not entirely the funding/income and the concomitant feelings of being watched. Rather we can draw upon Rose's notion of the entrepreneurial self to understand the tension, the connection, is also that we are all capitalizing on ourselves all of the time, reinforced by the income (for both groups) and funding delivery mechanisms.

Participants also spoke about the desire to not be controlled. For example, Lindsay suggested that, "It's not fair that one person should have somebody on their back like that." This desire is also part of the ethos of the entrepreneurial self because it assumes that the "good" and productive person can govern herself. This person is a responsible, moral citizen and can self-govern herself as such. This ethos is not only found in the social service agency worker. The techniques of welfare try to foster this ethos in recipients, and recipients, through their talk, showed that they have been successfully mobilized in these ways. Moreover, the current business model of nonprofits further confirms this direction towards an entrepreneurial kind of social work that values markets of output and client choice. By having mobilized these notions of the self-governing individual, it is clear that these constitutions are mutually reinforcing. Even though there is some pushback against this, the culture is increasingly supportive of a marketmodel down to the clients and workers (Hough, 1999).

In this way, the operations of power are more complex than the panopticon/eye of power, which I spoke about in the introduction and first chapter. It is also more than a fear or aversion to dependency, which some authors have suggested (Fraser and Gordon, 1994). While the rhetoric around 
dependency and the protestant work ethic is an integral part of this ethos, it does not explain the whole picture. The reason why dependency is really interesting when it comes to the entrepreneurial self is that dependency seems to be the opposite of the entrepreneurial self, and is thus vilified. It serves as the shadow to reinforce the foreground through dividing practices. Fraser and Gordon (1994) see dependency as problematic in terms of its development, but this understanding of its interplay with the entrepreneurial self gives a new spin on an old concept, that again, gets mobilized when necessary. We are activated in particular ways by governmentality and particular ethos. Discipline is mobilized when governmentality does not work. While we often use discipline to think about our place in the world, there are other operations that complicate this picture. What gets really tricky is the operations of resistance in an enterprise culture. Resistance and governance techniques are in relationship with one another, and both are acts of power in power relations. Both social service agency workers and people living on social assistance spoke about everyday modes of resistance and constitutions of selves that speak out against injustice. I will explore these multiple negotiations in the next chapter.

Hitherto, I have investigated the ways in which funding and income shape the day-to-day realities of participants. I have argued that in advanced liberal societies people living on social assistance and people working for social service agencies are encouraged to take up active citizenships to maximize their potential, including maximizing their potential funding and income. I have used the entrepreneurial self as an example of the technologies available for molding citizens in governmentality. Discipline and surveillance also play an important 
role in shaping participants, and are particularly effective when governance techniques are not. In the next chapter, I will move into a discussion about resistances, specifically regarding the ways in which participants take up resistant practices in an advanced liberal society. 


\section{CHAPTER FOUR}

RESISTANCE

Up to this point I have examined some of the ways in which funding and income are distributed and managed to create certain effects and encourage people working at social service agencies and people living on social assistance to take up subjectivities that are coded as productive and useful in the neo-liberal society. I have also argued that the technique of the entrepreneurial self is mobilized to ensure that citizens take up subjectivities in the interest of advanced liberalism. I am now going to turn my attention to the manifestation and undertakings of resistance. From a Foucauldian perspective, power and resistance are intertwined and shape one another. Power can generate, produce, confront and manage resistance; resistance can also stimulate technologies of power to organize, adapt and multiply (Foucault, 1991; Knights and Vurdubakis, 1994:179). These however are not two separate operations interacting with one another - indeed acts of resistance are acts of power. This understanding of power and resistance does not erase the possibilities of the engagement in power relations for the purpose of domination, but offers a complicated look at their operations. It is the Foucauldian perspective that I will use in the discussion of techniques of resistance adopted by workers in social service agencies as well as people living on social assistance. I will argue that while the nature of governmentality has expanded and shifted with new technological operations and advances in computer and other surveillance and discipline "aides," so too have the terrain and modes of resistance (Gilliom, 1999). The interdependencies between power and resistance have enhanced the possibilities for disruptions and 
new understandings of the broad forms of resistance (Knights and Vurdubakis, 1994; O'Connell-Davidson, 1994; Gottfried, 1994; Gilliom, 1999) - both official/organized and unofficial resistance which can sometimes even manifest in playful "misbehaviour" for the purposes of resistance (Shepard, 2005).

Building upon my argument regarding the entrepreneurial self in Chapter 3 , the need to be the best citizen, the best worker or the best community member, and because of these enclosures, to engage in "bad" types of resistance is to not capitalize on oneself or to work within certain constructed codes of ethics. Because there are boundaries around different forms of resistance, and dividing practices which code them as "good" or "bad," even if the "illegitimate" forms are more useful, effective or congruent in helping us to achieve their desired effects subjects will still, more often than not, highlight their engagement in legitimate resistance and stay silent about their illegitimate forms. This can also be understood as self-protection or preservation. There is safety in the move to not perform these "illegitimate" activities because there is no chance of integrating these negative aspects into a continuous understanding of the self. Instead these are conceptualized as moves that are not consistent with the understanding of the self, and are forced by a system of injustice.

Even though individuals might engage in everyday "illegitimate" resistance, by not giving legitimacy to this resistance and not coding it as resistance, they continue to reinforce notions of what legitimate and illegitimate forms of resistance are even though they might actually be acting on both sides of that coin. 


\section{Dividing Practices}

Foucault speaks about dividing practices as discursive exclusions and boundaries that shape our ability to understand and our selves and places in context (Foucault, 1991). We all engage in dividing practices and notions of those activities and beliefs that we constitute as productive/unproductive and even good/bad. Throughout the conversations that took place in this study, it became clear that participants, while diverse in many of their beliefs, shared common notions of what are useful and less useful forms of resistance, what are more productive uses of their time, and the most effective means of getting their needs met. While these notions were commonly shared, they would shift, open up and change throughout our discussions. What became clear as I spoke with individuals about their engagement in resistance, most engaged in a dividing practice of good (official) versus bad (unofficial) resistance. Participants policed those boundaries, working to acknowledge, in particular, their engagement in official resistance (talking to one's MP, voting, writing letters to the editor) while distancing their talk from the moments in which they engaged in unofficial forms of resistance, for example moving money around in accounts, getting family members to cover for them (Lindsay), obscuring information from authorities by "doing a spouse in the house" (Robin). What is more intriguing, is that not only did participants relate these dividing practices to themselves and their constitution of their own citizenship, but also applied these practices to others in order to set themselves apart from the flock. 
Official/Good forms of resistance

When engaging in a dividing practice, participants would set apart what is perceived as good/official/legitimate resistance from bad/unofficial/illegitimate resistance. I found that in our conversations, participants and I would often define good resistance as the type of resistance represented as a marker for citizenship in the media, imbued with liberal values of engagement. For example, these activities might include lobbying one's MP or MPP, writing a letter to the editor, and speaking at a city council meeting. This type of engagement might constitute the behaviour of liberal activists. Participants would speak about what they might do if they perceived a situation to be unfair or unjust. Marie, for example, said that when something was unfair her agency would, "through written and formal requests, try to have funding from main funders increased" if they felt their funding was insufficient. Others might talk to the manager of social services if they thought that their worker was being unfair. Sarah suggested that she and her friends refused to stop at one worker, and often demanded to speak with the head of social services. Another participant illustrated her use of the official avenues of resistance: "appeal, appeal, appeal" (Robin).

Mostly, participants indicated that they found these avenues frustrating and usually ineffective. Occasionally, they will have a small success, but mostly admitted, "there's not much you can do" (Mark) and "it is an exercise in frustration and a waste of time" (Marie). However, as these are the sanctioned forms of resistance that people have access to, they are used again and again despite their perceived lack of success. I would argue that this is partially 
because these practices constitute our notion of citizenship. The active citizen participates fully in the democratic process via the channels available to her. She will go to the legal centre or write to her MP or MPP in an effort to fight for her rights. In this way, these channels are both set up and reinforced as the official ways in which to pursue fairness and social justice. Their legitimation by the State (including funding bodies and social service agencies) is reinscribed by their active use by citizens and complainants (Cruikshank, 1999).

Furthermore, these channels are not only avenues to citizenship, but are conflated with its co-virtues, pride and dignity. Participants were eager to share their active engagement in normative citizenship, particularly when they came away from that engagement with even the smallest feeling of satisfaction. Although often frustrated, participants typically have not received much in the way of punishment when pursuing justice through official channels. Where they have received negative feedback from a complaint or rights agitation (particularly with respect to the appeals process in the social assistance system), they were often met with equal congratulations and support from allies and supporters. For example, while welfare workers might make life more difficult for an individual fighting an overpayment decision, this individual does receive some measure of support and encouragement from advocates (typically with institutional legitimacy, such as a community legal centre) supporting her appeal. Additionally, the discourse of citizenship supports a notion of citizens resisting, through legitimate channels, against unjust government policies, and rights talk significantly influences this discourse. 
What was also interesting was how participants constructed individuals as active community members. Here we have the notion of the active self as a productive and useful subjectivity. Participants, in their talk, would discuss the importance of participating actively in society and fighting for one's rights (or one's client's rights) even when that agitation was not empirically effective.

Part of the importance of these official forms of resistance is that they are the types of power that all of us feel that we have access to at one point or another. We imagine that our rights of citizenship entitle us to speak up for ourselves when something is unfair. Even if these types of engagements can be frustrating, and might not yield the results that we were hoping for, they are valued in community and citizenship narratives as an appropriate use of one's energies against injustice. They support the system as legitimate and fair - as long as people participate in these legitimate channels, the organization/system is legitimated. Not surprisingly these are often liberal forms of resistance, and while raising awareness, are not too troublesome for the neo-liberal establishment, because they do not challenge notions of the active self. The citizen who continually capitalizes on herself engages in self-improvement activities wherever she can, and certainly we can see that participating actively and being a good community member in whatever form that takes as part of an active constitution of the self (Cruikshank, 1999; Rose, 1999). So, in fact, these moments of resistance, while useful and important, particularly for people who feel disenfranchised at the same time are no great challenge to neo-liberal demands for an active constitution of the self because they are seemingly productive and engaged. This constitution of active citizenship draws upon 
notions of the free and autonomous individual; citizens have the freedom to resist, thus reinforcing the myth of democracy (Rose, 1999). Even in moments that seem less productive, for example an occupation of City Hall, these types of engagements in the community are also perceived as at least agitating for justice and community. When these movements are painted as destructive it is at this moment that they become unofficial, illegitimate or "bad" forms of resistance, if they are constructed as resistance at all.

\section{Unofficial/Bad forms of resistance}

Even though individuals seemed happy to point to situations in which they engaged in fighting what they perceived to be injustice, which is something that many people do, they were also careful to distance themselves from what they perceived to be unofficial or illegitimate forms of resistance, those activities constructed as unproductive or even destructive in some situations. Not only did they distance themselves by colouring these types of activities as less than desirable survival tactics rather than resistance, and I will speak more about this later in the chapter, but they were also quick to point to other people who engaged in this type of resistance, and to frame those moments as not strategic or unproductive. This was particularly prominent with respect to social service workers.

For example, when discussing what they felt were illegitimate or unofficial forms of resistance, social service workers would characterize these moments as destructive behaviour rather than resistance. When I asked participants what they do when they think something is unfair, participants would discuss their 
official resistance, and distance themselves from unofficial resistance. This is one of the ways in which individuals can police the boundaries of resistance. Michael, in particular, suggested that while he “[doesn't] criticize people who are activists, [he] can't support them... [he] can't support activities that are just destructive." In this way, while the local coalition against poverty has very effectively put antipoverty issues on the agenda for the past number of years, Michael paints the group as destructive or ineffective, despite later articulating support for the goals of the organization.

Moreover, workers, at different points in their speech, articulate empathy with radical anti-poverty groups and their purposes. In fact, although the local anti-poverty organization had challenged most of the agencies represented in this study, workers remained supportive, if wary, of its work. As Michael suggested, "I like the name." This suggests that workers feel that a multi-pronged strategy for social justice is important, although they feel that they are not in a position to join the group in its efforts for various reasons:

It's obvious that the rates need to be raised. But in order to participate in the local initiative, you have to partner with an organization that has burnt you badly... we don't trust the organization not to speak out publicly against us like they did before without even asking us if what they were saying was correct. And it wasn't. (Elizabeth)

Organizing the political and social terrain such that those who are engaging in radical activity, in particular setting up those activities as "not really doing much" (Mark), or even "just destructive" and unproductive (Michael), differentiates the approaches used by each group from each other, creating a boundary between the tactics. These boundaries are protected by discursive shifts and characterizations. While these comments do create boundaries, they do not 
necessarily represent individuals' values. While our values inform our narratives and actions, in these types of discussion, context is also a constraining force that can limit the possibility to act in accordance with ones beliefs. The terrain is slippery, and so while participants might be understandably hesitant in aligning themselves with certain groups, these boundaries effectively shut down opportunities for imagining "acceptable" resistance outside of constructed boundaries, ultimately limiting possibilities for resistant practices.

Participants not only engage in this type of competitive discourse with respect to radical groups, or groups that they perceive to be unlike them. In fact, people who work for social service agencies and people living on social assistance also set themselves apart from those "like them." Michael discussed how his agency was "better than" other agencies:

I mean as arrogant as this may sound we are very open to that. My experience is that most agencies are not. They're very closed, very tight mouthed about things... I can tell you that this agency has been, I want to say been screwed by that, and maybe that's a little strong... I have been in a position where we have provided money for other agencies, we've put money on the table, where we've provided because it's so necessary for the community. But I don't witness that very often from other agencies. And I understand why. Everybody's in self-preservation mode ... there's a lot more competition even for the donated dollar. And with that comes some really cutthroat activities... And I'm saying about sounding a bit arrogant is because it's a fight not to play the same game. I mean it's a tendency, so I'm not criticizing anyone for doing it because I understand. We all have a natural sense of self-defense, but I think that's what puts us in the hole sometimes... But that's why if you could talk openly at a table with everybody feeling... but that's a trust issue too.

Here Michael differentiates his agency from other agencies. In this way, agencies are encouraged to compete in subtle ways that makes collaboration and coalitions difficult. This barrier is useful for a neo-liberal project as it also hinders the ability for us to be self-reflective and critical, because to do so might make us 
vulnerable to the criticism of others, which is threatening because it forces us to appear uncertain or to be critically self-reflexive. This worker is not alone in his perceptions - in fact, almost all of the individuals working for social service agencies that I spoke with indicated that they found other agencies in the community to be territorial and competitive. At times, agencies will collaborate, but these collaborations are often guarded. Interestingly, funding is being geared more and more towards partnerships, while funders are encouraging competition between agencies (because of increasingly unstable, meager and insecure funding). In this way, there are inconsistencies between funder goals and the effects of strategies. This results in inconsistencies in the ways in which agency people negotiate relationships with one another. These comments also speak to a dividing practice of more effective (often framed as legitimate) and less effective (often framed as illegitimate) activities of resistance.

Finally, people would talk about their own illegitimate resistance as nonresistance, and instead name those moves as "survival tactics." Part of this move is again about dividing practices and how we define certain aspects of our lives, the ways in which we police those boundaries by definition, and how we set ourselves apart from certain individuals and activities, goals and causes, and products by our speech and our defining of those moments and spaces.

\section{Policing Boundaries}

People engage in dividing practices by policing the boundaries around official and unofficial forms of resistance. Some scholars suggest that individuals engage in defining boundaries of resistance (Knights \& Vurdubakis, 1994:181). 
By maintaining and reinforcing beliefs about what constitutes legitimate and illegitimate forms of resistance, participants maneuver a slippery terrain of comfort and discomfort around their actions and the actions of others. Citizenship often occupies the space of these "good forms" of resistance: going to talk to your MP, writing a letter to your funder, making an official complaint to your workers; these are framed as legitimate forms of resistance against perceived injustices. They can be thought about as fighting for one's rights or engaging in legitimate forms of action - they are the sorts of actions that a legal centre or a national advocacy body might suggest that individuals take up. Even participating in a march or sit-in falls into these forms.

Moreover there are other types of actions that participants talk about hiding pockets of money away, working under the table, taking and not claiming gifts and shifting money around in their budgets. Because these are outside of the boundaries of "legitimate" forms of resistance, even though they are resistance, and people in their speech move towards thinking about these sorts of activities as resistance, but then step away from them. They frame these activities as resistant while also shying away from the words, because they are typically made to feel bad about having to do these types of things and feeling forced to undertake these everyday resistant activities. While people will say, "I have to do this to survive" or "I have to do this to keep this program afloat," it is almost as if there is an impetus to have to do it, but not a willingness to do it solely because it is the right thing to do. There seems to be a feeling of guilt associated with these movements/actions. This is resistance to the very notion of resisting. In this way resistance is conceived of as an active choice in opposition 
to injustice while survival is seen as a necessity, conceptualized as undertaken because one does not have any other options.

\section{Professionalism}

Isin suggests that the disciplinary professions (such as social work) have been "mediating and effective agents for articulating the virtues of bourgeois citizenship, and these virtues were deployed as yardsticks for assessing the conduct of those who lacked them" (2002:229). Although he speaks of this phenomenon historically, neo-liberal governmentality continues to make use of these disciplinary techniques in the control society. One of the virtues of bourgeois citizenship articulated by participants throughout the process was a notion of professionalism, however loosely defined. I found that professionalism seemed to be a continuous thread throughout our talks, and even when subtle, was a guiding principle with respect to resistance and modes of engagement. Participants working for social service agencies seemed especially concerned about appearing professional or protecting their professional reputations when engaging in or contemplating resistance. For many of us, this consideration leads us to a perpetual feeling of, in the words of one participant, not feeling "prepared to take a public position" and sometimes even a hesitation to "go for something privately" (Elizabeth). Here there is a cleavage between the personal and professional which draws on a notion of professional as dispassionate, objective, apolitical, separate and removed. Agencies often encourage their workers not to express their political views on a current event, using the agency's professionalism as being in danger if the worker becomes politicized. 
This ethos is pervasive in the social services and participants spoke of the importance of conducting oneself "professionally." Definitions of professionalism were not necessarily informed by rigid codes of conduct, enforced by the College or the law, but instead slippery notions of how one properly conducts oneself (i.e. getting "all the facts before acting," often not acting at all, speaking diplomatically, vetting permission before speaking out on an issue, using caution, and choosing one's battles very carefully). Throughout our discussions it became very clear that service workers, in particular, were less constrained by the regulation of mangers and funders, and more strictly regulating themselves through notions of professionalism. The way that an ethos of professionalism relates to policing boundaries is that as workers conceptualize themselves as distant and professional, particularly when they think of themselves as more professional than their colleagues, and they value that professionalism highly, it becomes a defining feature of their practice. Any move that does not seem to fit into that professional space (rightly or wrongly) becomes off-limit to their practices, constraining opportunities for movement. Additionally, we define boundaries between ourselves and those whom we consider to be outside of our borders of professionalism. These boundaries therefore shape opportunities for relationship and molding power relations.

Similarly, notions of caution and conducting oneself respectfully and properly shape the moves of individuals living on social assistance. Most participants spoke of using the "proper channels" to pursue justice, taking up many of the same virtues articulated by a social service mode of professionalism - "polite persistence," (Robin) careful documentation, and addressing problems 
as they arise as factually as possible. This conduct of conduct shapes possibilities for resistance, since participants are likely to restrict their activities within the boundaries of what they consider to be legitimate. At the same time when pushing the boundaries by resisting, for example obscuring information by "doing a spouse in the house" (Robin) or submitting multiple appeals within the sanctioned process, "appeal, appeal, appeal," systems further develop their technologies of surveillance (Hier, 2003). In this way, resistance and surveillance shape one another. When we regulate our behaviour within what we consider to be appropriate boundaries, boundaries are reinforced and shaped we are regulated by boundaries and we in turn regulate them. In this way, boundaries, resistance and surveillance are contingent and operate in relation to one another.

\section{Being Strategic and Following Rules}

One of these moves of setting oneself apart from others is to code one's resistance as strategic. When speaking with people working in social service agencies and people living on social assistance, participants described themselves as taking particular actions because they wanted to be strategic. Following rules and shaping one's resistance such that it falls into normalized codes of action and therefore is coded as legitimate, productive, good and useful - was one way in which to ensure that one's practices are within the legitimate bounds of resistance or avenues of having one's voice heard (i.e. the legal system, talking to one's MP, or going through the appeals process for funding or income assistance decisions). At the same time, because these notions are often complicated and 
contradictory, some participants also indicated that they take pride in "pushing the envelope" further than others. Therefore, while many participants spoke of their moves as strategic, strategy took diverse forms.

Across the board, people spoke about their moves as being strategic and the actions of others who did not necessarily follow rules in the same way as not strategic. At once practices were both coded as legitimate and productive, but they are also coded as the most appropriate in the context. People often want to feel that the actions that they take are the best possible actions in that moment and can argue that the moves made in any moment are contextually appropriate. What is interesting is that all of the participants coded each of their moves as strategic, and they often equated following rules and using the acceptable, institutionally sanctioned moves for resistance as the most strategic modes of resistance.

Following rules does not always entail following written laws, workplace policies or professional codes of conduct, but rather extends to following the directives or suggestions of an authority; for example, doing what one's boss or Board of Directors tells them to do, or listening to one's worker. For example, all of the individuals that I spoke with who work for social service agencies suggested that regardless of their resistant action, they would "obtain permission" (in various forms) from their supervisor or Board of Directors, before they took any action. They would speak about their responsibility to the Board or to the agency, and the ways in which this plays out in their ability to take action without permission. In the words of Marie, "If I were to do something for [the agency], I would talk to the Board." While this "vetting" can be framed in 
terms of expected accountability to one's employer or the community via the Board of Directors, we can also rethink these requests for permission as a way to be strategic as well. What this means is that while Marie has competing understandings of, and possibly wishes for, what she needs as a worker. On one hand she speaks of the need for autonomy and on the other hand she speaks of the importance of constantly checking with her supervisor or Board, places workers like herself in an interesting double bind, where they relinquish much of their autonomy in order to be strategic. In this way, even though one can argue that this is an important measure of accountability, workers further place themselves under the surveillance of the Board. Workers place themselves in a double bind that both removes the responsibility from themselves for radical resistance (even if they want to resist in a radical way) because Boards are often unlikely to sanction radical action, while at the same time framing this vetting as necessary in order to maintain a space in which (radical) resistance remains possible. Therefore people working for social service agencies, in particular, have a very interesting paradox that they create for themselves but that is also created for them in a variety of ways.

Marie is not alone in this feeling - certainly all of the workers expressed a desire to be autonomous while at the same time vetting everything by the Board. This desired autonomy is, after all, one of the key values of neo-liberal governmentality (Rose, 1999; Foucault, 1991). Again, it does have this interesting paradox whereby workers give up their autonomy to be "accountable" (however much we think Boards of Directors are accountable), while at the same time 
suggesting that this relinquishing of autonomy also secures the possibility for future resistance.

In this way we can see that participants use dividing practices to decide in what ways they will participate and also use those dividing practices in an effort to place and define the boundaries around their own modes of resistance. This dichotomous understanding is used to classify and partialize their own actions for justice and what kinds of spaces they fall into. This is not a neat division, under which you fall in one box or another -- this is a very slippery terrain. We see slippages in terms of people's conceptions of what is legitimate and what is illegitimate organizing and resistance. With this slippery terrain we see that there is no homogenous or continuous understanding of what resistance looks like when it is effective. This is a hard space to navigate and possibly explains some of the inconsistencies in the ways in which people will advocate for themselves and those around them, and will move throughout their lives and careers between different understandings and positions. Because the terrain and practices are slippery, the ways in which we engage in resistance are not simple and easy to define. In a lot of ways, because our conceptions are not continuous, it becomes difficult to organize a cohesive understanding of the ways in which one advocates for oneself - which also makes it difficult to solidly identify when we are taking up certain notions of ourselves and the ways in which we govern ourselves, and the ways in which we resist. These concepts work together dialectically to help us constitute ourselves, our resistance, and the ways in which we take action. 
Moreover, these moves are contextual. When we are careful about the ways in which we take action, often in order to protect ourselves, because we may be afraid of being punished (both in the case of people living on social assistance and people working for social service agencies) certainly there is a fear of making one's politics known. Here, one person living in poverty suggests that she would wear a political button:

...because it initiates discussion. But I would have to be judicial about where and when I wore it. I wouldn't want to initiate discussion with certain people. But yeah, I get political. (Robin)

This is a move to protect herself, but it also sends a message about the ways in which she make moves to resist or not resist, and the ways in which it is not simply about being overt about one's politics in order to stand up for herself. Sometimes, standing up for oneself means not wearing that political button. Therefore, when not wearing the political button gets coded as political squeamishness or apathy, these moves have to be understood as contextual. Consequently, when people are framed as dependent on certain types of income and funding, this "dependency" makes it difficult to move and resist in particular social sanctioned ways, and it also makes it difficult to resist - which may also explain some of these slippages.

It also means, in some ways, that sometimes revealing one's politics can be dangerous. In the words of Elizabeth, "you need to choose your battles." Later in the interview, Elizabeth provides context for the meaning of this statement she suggests that not only do you have to protect your spaces for resistance, you have to choose the battles that help you protect the interests of your clients and your agency - and your personal interest in maintaining a wage. Some of these 
complexities, these notions of dependency, citizenship, resistance, and productivity shapes the terrain and can make it difficult to make a move in any direction. Moreover, some of the social pressures in terms of resistance (i.e. what constitutes a good activist, what constitutes a good worker, what constitutes a good person living in poverty) are ever-present. When people talk about following rules, they are not just speaking about laws or policies, they are also talking about socially sanctioned understandings of resistance. What this means is that for some groups this might mean talking to one's MP and for others it means occupying a government building or breaking the window at the bank. Therefore, the ways in which people understand their own engagement in resistance and their moves, and what that looks like and how they are governing those moves continually, continue to conduct their conduct.

\section{Value in Unofficial Resistance}

The flip side of these dividing practices is thinking about what constitutes unofficial or "illegitimate" resistance, and how it gets constructed. I discuss a little bit earlier in this chapter what unofficial resistance might look like in terms of activities that typically get constituted as fraud in social assistance cases, for example hiding money away or working under the table - and a number of participants talk about engaging in this sort of behaviour. One of the interesting themes that emerged from our conversations was that participants spoke about unofficial resistance and the ways in which they engaged in this type of resistance, but they were less likely to constitute it as resistance. While one might think about hiding pockets of money away in order to put food on the table as 
resistant behaviour and as an acknowledgement that the "system" is set up in an unfair way, this sort of engagement gets constituted instead as survival and taking care of oneself. Therefore this engagement, which in many contexts gets named as unofficial resistance, in this context gets named as something else something that people have to do to survive. It is reshaped, not falling into the discourse of resistance, even though it can often be claimed as such. When people talk about the ways in which they "fight the system," these actions are not what they consider to be cheating, because cheating is often viewed as deliberate or unjustified.

Most participants living on social assistance that I spoke with said that they "have a responsibility to take care of [themselves]" (Mark). Their anger towards the system is not geared towards not having enough money - this was part of the problem - but a bigger part of the issue is that they are prevented from taking up active selves with an ability to be autonomous and self-sustaining. I speak a bit more about this in chapter two. In order to survive on welfare, people talked about having to deal drugs, tell lies, moving funds, and working under the table, and feel forced to be "dishonest":

There is not one person right now on welfare that is not breaking the rules, not one. It could be you, say you lost your job, you're going to go on there, and I'll tell you right now, you're going to have to tell a white lie at some point during that interview process or you ain't going to get shit. You have to lie, no matter who you are, no matter what your code of ethics, nothing. You have to play the game, or you're going to get shafted. They force you to lie, that's how they end up getting you. That's why they're always getting people for fraud, they never charge them, they just give overpayments because they know that they're the [ones] in the wrong. (Mark) 
These types of comments pop up continually throughout the transcripts. Robin spoke about her plan to use her moving allowance without actually moving. She talked about this in the context of exploiting the loopholes in the welfare system - and that is one way that people would resist:

So now I'm trying to figure out how I can utilize the money for moving without actually moving. It's kind of off topic, but I'm trying to figure out how to use the system, within the parameters, without cheating. These breeches are a necessity, it's a survival tactic, nobody's making a profit. People are still desperately poor and living below every line imaginable.

People talked about fraud throughout the interviews. First they talk about fraud as something that is separate from its context, but then go on to challenge these notions. A number of participants living on social assistance alluded to their situations as not fraud because they are not making a profit off of it. Fraud gets reshaped and contested based on the fact that people are forced to engage in behaviour that is constituted as fraud by neo-liberal regulations - people have to engage in it for survival so it gets reshaped as not fraud because it is necessary, there is an impetus for it. Mark articulated this sentiment: "I wasn't really winning anything, it wasn't fraud or nothing, I was just doing things to get things done, at a certain time." In their talk, participants living on social assistance demonstrate that nothing is separate from its context. While we often think of fraud as something in and of itself, a modern concept that can stand on its own separate from context, it is a contextual phenomenon. Like all of these concepts - resistance, fraud, survival - it is slippery, opening up new spaces for movement and resistance. 
In this chapter I fleshed out some of the implications of the constitution of participants' subjectivities with respect to resistance. The possibilities for resistance are multiple and complex. What this project seeks to achieve is an exploration of new possibilities for resistant movement. While we often conceptualize resistance as operating in collectitives, in social movements, one of the more hopeful aspects of micro-power and everyday surveillance is that they open up possibilities for micro- and everyday resistance. Mostly I hope to leave us with more questions than answers. If, as Rose suggests, the moves to shape the will, desires and identities of subjects (Rose, 1999; Knights and Vurdubakis, 1994) is much more prevalent in modern-liberal-capitalist societies than attempts at coercive domination (although we can see these acting together when related to people living on social assistance) then how does this move and shape resistance? How does this frame the moves that poor people and social service workers make? Can we trust ourselves? Moreover, are we just reinforcing governmental techniques in particular ways? While I do not have any answers to these questions, I am hopeful that the consideration of them will broaden our possibilities for movement and critical self-reflection.

In this chapter I discuss some of the ways in which resistance gets taken up by participants living on social assistance and participants working in social service agencies. In particular, I have investigated the ways in which dividing practices construct boundaries around official and unofficial modes of resistance. Participants police these boundaries in a manner consistent with characteristics associated with active citizenship and the entrepreneurial self. In this way, possibilities for resistance can be at once expanded and limited. Spaces are 
closed down by a discourse that only values official resistance associated with "acceptable" avenues of complaint, while at the same time spaces are opened for fragmented collectivities, who while agitating independently and often in their own interests, still tug at disciplinary techniques and surveillance. In the conclusion of this thesis I will describe some possibilities for resistance that attend to the styles of resistance that were explored in this chapter. 


\section{CONCLUSIONS}

Funding, income, surveillance and resistance are concepts and lived experiences that make most people feel insecure and uncertain. When we consider our livelihoods or reputations to be at stake, particularly our professional reputations, many of us go into self-preservation mode - and this is an experience that participants spoke of with respect to their income/funding strings and resistance. At the heart of most of our conversations was a deep uncertainty and insecurity about sustainable income and funding, and losing even small pockets of money by speaking out against perceived injustice.

At the same time, throughout most of my conversations with participants, a competing theme was laid bare: that of wanting to be understood as someone who speaks out against injustice, one who "fights the good fight." This theme is not surprising given the collection of people with whom I was speaking, most either living in poverty or working with/for people living in poverty - most of whom have trouble making ends meet on their meager incomes, most of whom face difficult circumstances every day of their lives. It is into these complexities and difficulties that I begin to make some observations about the ways in which we might consider future directions with respect to funding, income assistance and resistance.

I have attempted to outline some of the reasons for this concurrent reticence and resistance throughout the pages of this thesis, in the spirit of poststructural and critical social work analytics. This project was not developed in such a way as to suggest sweeping recommendations or solutions to the problems 
it poses; my aim was more modest. I hoped to unpack some of the stories of a small group of participants in order to develop a deeper understanding of the many complex issues facing them with respect to income, funding, surveillance and resistance. In chapter one I looked at some of the ways in which social service agency workers and managers negotiate daily tensions of their work, specifically with respect to funding strings, accountability, autonomy and surveillance. Throughout our conversations, people working in social service agencies illustrated these tensions, and some of the specific challenges facing their agencies and them as workers. One of the particularly interesting themes that came out of our discussions was a sense that issues facing agencies and workers are much more complicated than minimal resources and increasing demands on those resources. Therefore, demands for increased funding and more local control over that funding, while often the idyllic "left-wing" answer to such problems is not sufficient, and indeed reproduce some of the challenges articulated by most participants.

In chapter two, I investigated some of the themes I saw emerge from my conversations with participants living on social assistance. Here a number of the issues raised by participants working in social service agencies were echoed, but some new issues were also brought to the fore. In particular, participants living on social assistance articulated a complex understanding of the challenges they face while living on welfare, including multiple reasons for which that experience is shaming. What was especially striking during these conversations was the implications on the citizenship of people living on social assistance. Not only is the experience of accessing welfare demeaning, but also in advanced liberalism 
where the citizen is an autonomous, free and self-regulating subject, discourses around the dependency of the "welfare recipient" attack the freedom and autonomy of people living on assistance. While participants living on assistance articulate themselves as productive and contributing citizens, there is a shadow of rhetoric that follows their everyday moves, and governmental techniques employed at multiple sites encourage them to understand themselves as not fulfilling their potential to be free and self-sufficient. Therefore, the creativity and survival techniques that people living on welfare employ daily gets reconstituted as less useful than participating in menial wage labour. These concepts have consequences for the ways in which people live and resist in their daily lives.

To begin to pull together some of these themes, I employed the notion of the "entrepreneurial self" (Rose, 1996; Rose, 1999). In chapter three, I explored the articulation of enterprise culture and the continual capitalization of the self to understand the connections between the experiences of people working in social service agencies and people living on social assistance. I found this formation of subjectivity particularly useful because it allowed me to develop a more nuanced understanding of the active self and the ways in which subjects take it up in the advanced liberal society. It also helped me to understand how, regardless of the political convictions of the participants with whom I spoke, most (at least at some point in our conversations) seemed to buy into notions of the free and autonomous subject as the ideal formation of the self. This principle extends to the social service agency, where principles of freedom, self-sufficiency and continual improvement of services was situated as the pinnacle of success. This 
formation of the ideal has implications for the ways in which participants engage in resistance.

Finally, in chapter four, I investigated resistance, particularly with respect to the articulations and understandings of participants with an eye to the continual capitalization of the self. I began to sketch some of ways in which participants constructed their resistances and the dividing practices used to understand those movements. I also attempted to unpack how notions of professionalism affect resistance, particularly with respect to the notion of the professional as removed, dispassionate and apolitical. These values are not specific to people working in social service agencies, they are also woven into the ways in which people living on social assistance negotiate bureaucracies. The "professional," loosely defined, is also strategic and follows rules. Finally, I used chapter four to reflect upon the value in unofficial resistance, that is misbehaviour for the purposes of disrupting power relations. I unpacked these concepts to provide some hopeful reflections on possibilities for broader understandings of resistance, which rely upon notions of micro-power and everyday resistance.

The everyday resistance and misbehaviour investigated in chapter four offers some significant possibilities with respect to the themes outlined in this project: "the evocation of Foucauldian motif has allowed us to think about resistance in new and broader ways that do not rest solely upon the nomenclature of dialectics, true interests and overt antagonism" (Fleming, 2002:194). I want to take a few pages of this conclusion to begin to speak to the possibilities of resistance that I see this analysis pointing towards. While these modes of 
resistance were not clearly articulated in the data, I think that within the project itself lays the foundation to consider these strategies as possible mechanisms to resist the relations that I explored.

In response to the imperative for active citizenship and the constitution of an entrepreneurial self, I would suggest that resistance-mischief, that is playful misbehaviour for the purposes of resistance, might be a useful construct. Organizational misbehaviour, for example, offers workers an opportunity to resist in unconventional and creative ways (Ackroyd and Thompson, 1999). Misbehaviour is important not only for people working in social service agencies, but also for people living on social assistance, because it potentially interrupts the moment when subjects are being regulated by governmental techniques. In this space subjects can break, momentarily, their entrepreneurial selves. Moreover, as Shepard suggests:

Playing gets us out of our theoretical ruts. While creative social workers can still find themselves stifled in organizations that fail to appreciate their ideas, play nevertheless helps social actors to move outside of their conceptual cul-de-sacs" (2005:50).

While resistance/mischief does not fix the funding problem, it does give us a way to think about funding controls - and that is part of the reason why "fun" activism works, because it breaks the entrepreneurial self up a bit, and opens new possibilities for movement. If one reflects back on this project, we can begin to imagine spaces where participants begin to move towards play in their resistant talk, for example through humour in alleviating some of the tension in relaying their experiences. Robin's contemplation of sending her worker's note to MAD 
magazine or National Lampoon is one way to think about possibilities for playful misbehaviour as a mode of resistance.

However, it is not enough to say that if we just break out of our entrepreneurial selves and we play as resistance, then we can exit from relations of power, or eliminate dominant power relations:

This Foucauldian sensibility seems to have shifted our attention away from class politics to those subtle micropractices that do not necessarily aim for 'revolution' but nevertheless allow subordinates to construct counterspheres within forms of domination, change trajectory of controls and quietly challenge power relations without necessarily leaving them (de Certeau, 1984 in Fleming, 2002:194).

It is therefore not sufficient to set resistance-mischief up as a mode of resistance to get outside of governmentality because as long as we are trying to get outside of it or break free of governmental techniques, we are in them. By engaging in resistance, whatever form it takes, we are acting upon ourselves in ways that we think are productive. For this reason, it is too simplistic to conceptualize play as an efficient means of resistance that avoids some of the pitfalls associated with other activities consistent with the values of advanced liberalism, for example, active participation in democratic processes or efficiency in waged labour. Therefore, while play can be reclaimed as a "useful tool for social work practice" and resistance (Shepard, 2005:65), it is still embedded in power relations.

Thus, my discussion of play in the conclusion of this project is not meant to suggest that we should play and engage in resistance-mischief as a way to escape the hold of governmental techniques. There is no way to escape power relations. No amount of agitation for rights or funding, or engagement in resistance can relieve us from power in advanced liberal societies. Even when we 
are consciously trying to be unproductive, the conscious effort to be unproductive for political purposes is productive. We can only find a way to negotiate through them -- but even these tools of reflection are tools of capitalizing on ourselves (Gilbert, 2001). In this way, while we can think about resistance-mischief as a way to think through new terrains for resistance, there is no way to exit power relations and the advanced liberal demand for self-governing citizens. Even the most innovative resistant practices cannot escape from the web of power or eliminate its technologies.

Given the problematics raised in this thesis, particularly with respect to enterprise culture and governmentality, it is tempting to suggest that we just do away with such techniques altogether. If such a thing were even at all possible, it would not necessarily be advisable. While these techniques certainly get taken up by neo-liberalism, "this does not mean that there is an intrinsic relation between the techniques and the politics, such that they must be discarded by those who seek an alternative art of government" (Barry et al, in Reich, 2002). Therefore, eliminating such techniques is not an effective or feasible strategy particularly since, not only does it have some good effects, but also notions of the reflective and entrepreneurial self are not easily or usefully rooted out. Moreover, as Rose suggests, discourses of the autonomous, free-choosing, responsible individual as the political ideal have become taken for granted notions which infuse political mentalities of the "West" (Rose, 1996:51) and will not simply evaporate with an overhaul of a political system or change in government. It is particularly important that social work continue to struggle with this challenge as a result of social workers' dual role with respect to encouraging and taking up "technologies 
of the self" which require us all to the entrepreneurial and efficient lifelong learner/workers. Healy suggests:

The field has yet to adequately explore the opportunities provided by major contemporary social thinkers whose critical engagements with postmodern and poststructural ideas in relation to power, subjectivity, and social citizenship are of relevance to the ongoing transformation of critical social work (2000: 145).

While there has been a good deal of literature taking up Healy's challenge since 1999, I found that the literature did not adequately confront questions about resistance, and the different forms that it could take given new understandings of power as minute and relational. I have attempted to sketch some possibilities for micropractices of resistance in this project.

While collective struggles for more community control, increased autonomous funding and increased social assistance rates are valuable, they are also problematic. If the problem is that governmentality and power are productive of the types of resistance that agencies and clients are performing, if it is the funding itself that produces us in particular ways, then fighting for a return to pre-1994 social assistance levels and increased funding might not be the answer to the challenges presented by participants. Targeting the amount of income or funding does little to change the mechanism of its delivery, which is just as troublesome for participants in this project. There might not be a way out of governance techniques and an imperative for active citizenship. Looking at the way power operates and the ways in which it is productive in relationship means that we also have to rethink the ways in which we engage to shift those relations.

At the same time, it would be foolish to suggest that neo-liberal forms of governance are doing us any favours by cutting funding and developing new and 
innovative techniques to shape the conduct of people living on social assistance and social service agency workers. From these reflections I am left grasping for solutions. Despite the fact that this thesis presents a number of complications with respect to surveillance, funding, ties and the ways that we are produced as entrepreneurial selves, I would also suggest that there are spaces of hope in this picture. Discipline is not simply manufactured, and power is not simply "top down." While power is pervasive in all social relations, and while this thesis suggests that the battles we have been fighting up hitherto cannot be won the way they have been fought, it also suggests that power relations are much more complicated than a righteous battle between those who work to control the poor and the poor and those who aim to "help" them. While we can no longer "race to innocence" (Razak and Fellows, 1998), what we can do is acknowledge that these complexities open up new spaces where we can act. Therefore while we can no longer imagine ourselves outside oppressive relations when resisting repressive funding or income models, we can exploit these new spaces and try new forms of resistance and ways of movement. We can negotiate our relationships in new ways, given the manner in which they are already starting to form.

Additionally, there is pressure to be wholly congruent and consistent in the ways in which we engage. These new understandings begin to take the pressure off being the "heroic activist" (Healy, 1999). The concept of the heroic activist, as explored by Healy (1999) and others (Rossiter, 2001; McBeath and Webb, 2005) is problematic. I worry a great deal about congruency, about engaging in activities that are progressive, in ways that are perceived as the "right" politic, in the right way. Different types of organizations and approaches, 
charity, activist, welfare state and market, are often perceived as mutually exclusive, although they often work together and reinforce one another (Kenny, 2002). We find safety in trying to operate within the correct framework, for example, if I consider myself an activist, any action that I undertake which deviates from that framework is considered off-limits, and incongruent with my approach. At the same time, when we do something resistant, there is always some part of us that wishes that we could fit within the norm, and therefore this can be a conflicted location. There are very few of us that can take up resistant (or normative) identities without any doubt. None of us are pure, innocent or perfect, and none of us are wholly congruent all of the time. None of us can claim to be always "fighting the good fight;" in fact there is doubt that there is a singular good fight to be fought in a singular way. What this does, then, is open up new spaces for movement; "we [can] reconfigure [our approach] as a kaleidoscope, where every intervention shifts the pattern and creates a whole new vision of possibilities" (Mizrahi, 2001:185). For example mischief and resistance play an integral part in the ways in which we understand talking back to funding and income regimes that do not work. When resistance takes playful shapes we are liberated to take risks, to try new things, to not worry so much about doing exactly the right thing as the heroic activist.

We need to think about how we can recover a sense of play in our resistance (Shepard, 2005). Critical social work often tends towards seriousness - it attends to the complexities of power relations seriously - and injustice is serious business. I wonder, however, if in reflection on the talk in the interviews if there is a space for joyful mischief and misbehaviour in the ways in which we 
push the limits and resist, in the ways in which we break, if we can, the capitalization of the self and, even for a moment carve a space in surveillance and the ways it works upon us.

In finishing these pages, I am struck with the reality that these musings cannot be wrapped up in a neat package of perfectly constructed reflections on the nature of surveillance and resistance in funding and income regimes. In fact, no musings on resistance are ever neat or simple (or at least, not when well attended to). There are, however, some moments in these chapters that I wish to be hopeful; there are some moments in which we can transform our engagements. Perhaps the picture on funding and income is not so bleak. Certainly there are problems, certainly the cuts over the last decades have had tragic consequences, but at the same time with those consequences come possibilities. I hope to leave us with the question of what those possibilities are and what those spaces can be. Only through negotiating through those possibilities and spaces can we hope that they will become clearer to us and continue to bring us hope. 


\section{REFERENCES}

Ackroyd, Stephen. and Thompson, Paul. (1999). Organizational Misbehaviour. London: Sage.

Adams St. Pierre, Elizabeth (2004). "Deleuzian Concepts for Education: The subject undone." Educational Philosophy and Theory. 36(3): 283-295.

Alexander, Jennifer Renee Nank and Camilla Stivers. (December 1999). "Implications of Welfare Reform: Do nonprofit Survival Strategies Threaten Civil Society?” Nonprofit and Voluntary Sector Quarterly. 28(4).

Anheiner, Helmut K., Stefan Toepler and S. Wojciech Sokolowski. (1997). "The Implications of Government Funding for Non-profit Organizations: Three Propositions.” International Journal of Public Sector Management. 10(3).

Arendt, Hannah. (1964). Eichmann in Jerusalem: A Report on the Banality of Evil. New York: The Viking Press.

Babbie, Earl and Lucia Benaquisto. (2002). Fundamentals of Social Research: First Canadian Edition. Scarborough: Thompson Nelson.

Cain, Roy. (1993). "Community-Based Services: Formalization and Depoliticization." International Journal of Health Services 23 (4): 66584.

Cain, Roy. (1994). "Managing Impressions of an AIDS Service Organization: Into the Mainstream or Out of the Closet?" Qualitative Sociology 17 (1): 43-61.

Camilleri, Peter. (1999). "Social Work and its Search for Meaning: Theories, Narratives and Practices." Transforming Social Work Practice: Postmodern and Critical Perspectives. Bob Pease and Jan Fook, (Eds.) New York: Routledge. 25-39.

Cruikshank, Barbara. (1996). 'Revolutions within: self-government and selfesteem'. Foucault and Political Reason. A. Barry et al (Eds). Chicago: University of Chicago Press. 231-251.

Cruickshank, Barbara. (1999). The Will to Empower: Democratic Citizens and Other Subjects. Ithaca: Cornell University Press.

Dean, Mitchell. (1999). "Chapter 1: Basic Concepts and Themes." Governmentality: Power and Rule in Modern Society. London: Sage. 
Deleuze, Gilles. (1995). "Postscript on Control Societies." Negotiations 19721990. New York: Columbia University Press. Retrieved from http://www.watsoninstitute.org/infopeace/vy2k/deleuze-societies.cfm, on January 20, 2006.

Deleuze, Gilles and Felix Guattari. (1987). A Thousand Plateaus: Capitalism and Schizophrenia. Brian Massumi (Trans.) Minneapolis: University of Minnesota Press.

de Montigny, Gerald. (2005). "A Reflexive Materialist Alternative." Social Work: A Critical Turn. S. Hick, J. Fook \& R. Pozzuto (Eds.) Toronto: Thompson Educational Press. 121-136.

Dobbin, Murray. (1998). The Myth of the Good Corporate Citizen: Democracy Under the Rule of Big Business. Toronto: Stoddart.

Drummond, John. (2003). "Care of the Self in a Knowledge Economy: Higher education, vocation and the ethics of Michel Foucault." Educational Philosophy and Theory. 35(1): 57-69.

Dybicz, Phillip. (2004). "An Inquiry into Practice Wisdom." Families in Society: The Journal of Contemporary Social Services, 85(2): 197-203.

Edwards, Richard. (2002). "Mobilizing lifelong learning: governmentality in educational practices." Journal of Education Policy. 17(3):353-365.

Edwards, Richard and Katherine Nicoll. (2004). "Mobilizing workplaces: actors, discipline and governmentality." Studies in Continuing Education. 26(2): 159-173.

Ferguson, Kathy E. (1984). The Feminist Case Against Bureaucracy. Philadelphia: Temple University Press.

Fleming, Peter. (2001). "Beyond the Panopticon?" Ephemera: Critical Dialogues on Organization. 1(2): 190-194.

Fook, Jan. (1999). "Critical Reflectivity in Education and Practice." Transforming Social Work Practice: Postmodern and Critical Perspectives. Bob Pease and Jan Fook, (Eds.) New York: Routledge. 150-157.

Fook, Jan. (2000). "Deconstructing and Reconstructing Professional Expertise." Practice and Research in Social Work. B. Fawcett, B. Featherstone, J. Fook \& A. Rossiter (Eds.) London: Routledge. 104-119.

Fook, Jan. (2002). Social Work: Critical Theory and Practice. London: Sage. 
Fook, Jan and Christine Morley. (2005). "Empowerment: A Contextual Perspective." Social Work: A Critical Turn. Steven Hick, Jan Fook and Richard Pozzuto (Eds). Toronto: Thompson Educational Publishing. 6786.

Foucault, Michel. (1977). Discipline and Punish: The Birth of the Prison. Harmondsworth: Penguin.

Foucault, Michel. (1978). The History of Sexuality, Vol. 1: An Introduction. New York: Vintage Books.

Foucault, Michel. (1979). Discipline and Punish: The Birth of the Prison. Harmondsworth: Penguin.

Foucault, Michel. (1982). "Technologies of the Self." The Essential Foucault. P. Rainbow \& N. Rose (Eds.) New York: The New Press. 145-169.

Foucault, Michel. (1988). "Technologies of the Self." Technologies of the Self: A Seminar with Michel Foucault. L. Martin, H. Gutman and P.H. Hutton (Eds.), Amherst: The University of Massachusetts Press. 16-49.

Foucault, Michel. (1991). "Governmentality." The Foucault Effect. G. Burchell et al. (Eds.) Harvester.

Foucault, Michel, Jacques Donzelot, Paul Virilio, Philippe Meyer, and Jean-Rene Treanton. (1999). "Social Work, Social Control, and Normalization: Roundtable Discussion with Michel Foucault." Reading Foucault for Social Work. Adrienne S. Chambon, Allan Irving and Laura Epstein, (Eds.) New York: Columbia University Press.

Fraser, Nancy. (1989). Unruly Practices: Power, Discourse and Gender in Contemporary Social Theory. Minneapolis: University of Minnesota Press.

Fraser Nancy and Linda Gordon. (1994). "A Genealogy of Dependency: Tracing a Keyword of the U.S. Welfare State." Signs: Journal of Women in Culture and Society, 19(2).

Froelich, Karen A. (September 1999). "Diversification of Revenue Strategies: Evolving Resource Dependence in Nonprofit Organizations." Nonprofit and Voluntary Sector Quarterly. 28(3): 246-268.

Frost, Nick. (2001). "Professionalism, Change and the Politics of Lifelong Learning." Studies in Continuing Education. 23(1): 5-17. 
Frumkin, Peter and Alice Andre-Clark. (2000). "When Missions, Markets, and Politics Collide: Values and Strategy ion the Nonprofit Human Services." Nonprofit and Voluntary Sector Quarterly. 29(1): 141-163.

Gilbert, Tony. (2001). "Reflective practice and clinical supervision: meticulous rituals of the confessional." Journal of Advanced Nursing. 36(2): 199205.

Gilliom, John. (2001). Overseers of the Poor: Surveillance, Resistance and the Limits of Privacy. Chicago and London: University of Chicago Press.

Gottfried, Heidi. (1994). "Learning the Score: The Duality of Control and Everyday Resistance in the Temporary-Help Service Industry." Resistance \& Power in Organizations. John M. Jermier, David Knights and Walter R. Nord (Eds.) London: Routledge. 102-127.

Gregory, Marilyn and Margaret Holloway. (2005). Language and the Shaping of Social Work. British Journal of Social Work, 35:37-53.

Healy, Karen. (1999). "Power and Activist Social Work." Transforming Social Work Practice: Postmodern and Critical Perspectives. Bob Pease and Jan Fook, (Eds.) New York: Routledge. 115-134.

Healy, Karen. (2000). Social Work Practices: Contemporary Perspectives on Change. London: Sage.

Hick, Steven and Richard Pozzuto. (2005). "Introduction: Towards 'Becoming' a Critical Social Worker." Social Work: A Critical Turn. Steven Hick, Jan Fook and Richard Pozzuto (Eds). Toronto: Thompson Educational Publishing. ix-xviii.

Hier, Sean P. (2003). "Probing the Surveillant Assemblage: on the dialectics of surveillance practices as processes of social control." Surveillance \& Society. 1(3): 399-411.

Hooper, Anthony. (2001). "In the Eye of the Storm: Community Development Responses to Enterprise Culture." Critical Social Work. 2(1).

Hough, Gary. (1999). "The Organization of Social Work in the Customer Culture." Transforming Social Work Practice: Postmodern and Critical Perspectives. Bob Pease and Jan Fook (Eds.) New York: Routledge. 4056 .

Hurtig, Mel. Pay the Rent or Feed the Kids: The Tragedy and Disgrace of Poverty in Canada. Toronto: McLelland and Stewart, 1999. 
Isin, Engin F. (2002). Being Political: Genealogies of Citizenship. Minneapolis: University of Minnesota Press.

Kenny, Sue. (2002). "Tensions and Dilemmas in Community Development: New Discourses new Trojans?" Community Development Journal, 37 (4): 284299.

Kinsman, Gary. (1997). "Managing AIDS Organizing: "Consultation," "Partnership," and "Responsibility" as Strategies of Regulation." Organizing Dissent: Contemporary Social Movements in Theory and Practice. $2^{\text {nd }}$ Ed. William K. Carroll (Ed.) Toronto: Garamond Press. 213-239.

Kirby, Sandra and Kate McKenna. (1989). Experience Research Social Change: Methods from the Margins. Toronto: Garamond Press.

Knights, David and Theo Vurdubakis. (1994). "Foucault, Power, Resistance and All That." Resistance \& Power in Organizations. John M. Jermier, David Knights and Walter R. Nord (Eds.) London: Routledge. 167-198.

Lee, Marc. Snakes and Ladders: A Policy Brief on Poverty Dynamics. Ottawa: Canadian Centre for Policy Alternatives, 2002.

Leonard, Peter. (1997). Postmodern Welfare: Reconstructing an Emancipatory Project. Thousand Oaks, CA: Sage.

Little, Margaret. (1998). No Car, No Radio, No Liquor Permit: The Moral Regulation of Single Mothers in Ontario, 1920-1997. Toronto: Oxford University Press.

Loconte, Joe. (1997). "Seducing the Samaritan: How Government contracts are Reshaping Social Services.” Pioneer Institute for Public Research. (abstract).

Lundy, Colleen. (2004). Social Work and Social Justice: A Structural Approach to Practice. Peterborough: Broadview Press.

Margolin, Leslie. (1997). Under the Cover of Kindness: The Invention of Social Work. Charlottesville: University Press of Virginia.

McBeath, Graham and Stephen Webb. (2005). "Post-Critical Social Work Analytics." Social Work: A Critical Turn. Steven Hick, Jan Fook and Richard Pozzuto (Eds). Toronto: Thompson Educational Publishing. 167188. 
McFarlane, Susan and Robert Roach. (September 1999). "Strings Attached: Nonprofits \& their Funding Relationships with Government." Canada West Foundation. 4.

Mizrahi, Terry. (2001). "The Status of Community Organizing in 2001: Community Practice, context, Complexities, Contradictions and Contributions." Research on Social Work Practice, 11(2): 176-189.

Moffatt, Ken. (1999). "Surveillance and Government of the Welfare Recipient." Reading Foucault for Social Work. Adrienne S. Chambon, Allan Irving and Laura Epstein (Eds.) New York: Columbia University Press.

Mosher, Janet, Patricia Evans, Margaret Little, Eileen Morrow, Jo-anne Boulding and Nancy VanderPlaats. (2004). Walking on Eggshells: Abused Women's Experiences of Ontario's Welfare System.

Mullaly, Bob. (1997). Structural Social Work: Ideology, Theory and Practice. $2^{\text {nd }}$ ed. Toronto: Oxford University Press.

O'Connell Davidson, Julia. (1994). "The Sources and Limits of Resistance in a Privatized Utility." Resistance \& Power in Organizations. John M. Jermier, David Knights and Walter R. Nord (Eds.) London: Routledge. 69-101.

Oliphant, Michael and Chris Slosser. "Targeting the Most Vulnerable: A Decade of Desperation for Ontario's Welfare Recipients." The Ontario Alternative Budget 2003. Ottawa: Canadian Centre for Policy Alternatives, 2003.

Parenti, Christian. (2003). The Benevolent Gaze: Dossiers and the Helping Professions. New York: Basic Books.

Parker, Stephen, Jan Fook and Bob Pease. (1999). "Empowerment: The modernist social work concept par excellence." Transforming Social Work Practice: Postmodern and Critical Perspectives. Bob Pease and Jan Fook, (Eds.) New York: Routledge. 150-157.

Parton, Nigel. (2003). 'Rethinking Professional Practice: The Contributions of Social Constructionism and the Feminist "Ethics of Care." British Journal of Social Work. 33: 1-16.

Peters, Michael. (2001). "Education, Enterprise Culture and the Entrepreneurial Self: A Foucauldian Perspective." Journal of Educational Enquiry. 2(2): 58-71.

Piven, Frances Fox and Richard A. Cloward. (1979). Poor People's Movements: Why They Succeed, How They Fail. New York: Vintage. 
Piven, Frances Fox and Richard A. Cloward. (1993). Regulating the Poor: The Functions of Public Welfare. New York: Vintage Books.

Rainbow, Paul and Nikolas Rose. (1994). "Introduction." The Essential Foucault: Selections from Essential Works of Foucault, 1954-1984. Paul Rainbow and Nikolas Rose, (Eds.) New York: The New Press. vii-xxxv.

Ralph, Diana S., André Régimbald and Nérée St-Armand (eds). (1997). Open for business : closed to people : Mike Harris's Ontario. Halifax, N.S.: Fernwood.

Razak, Sherene and Mary Louise Fellows. (1998). "Race to Innocence: Confronting Hierarchical Relations Among Women." Journal of Gender, Race and Justice. 2: 335-352.

Reich, Ann. (2002). "Learning Organizations and Child Protection Agencies: post-Fordist techniques?" Studies in Continuing Education. 24(2): 219232.

Reinharz, Shulamit. (1992). Feminist Methods in Social Research. Oxford: Oxford University Press.

Rice, James J. and Michael J. Prince. (200o). Changing Politics of Canadian Social Policy. Toronto: University of Toronto Press.

Riordon, Michael. (2004). An Unauthorized Biography of the World: Oral History on the Front Lines. Toronto: Between the Lines.

Rose, Nikolas. (1990). Governing the Soul: The Shaping of the Private Self. London: Routledge.

Rose, Nikolas and Peter Miller. (1992). "Political Power Beyond the State: Problematics of government." British Journal of Sociology. 43(2):173205.

Rose, Nikolas. (1996). Inventing Ourselves: Psychology, power and personhood. Cambridge: Polity Press.

Rose, Nikolas. (1999). Powers of Freedom: Reframing political thought. Cambridge: Cambridge University Press.

Rossiter, Amy. (2001). "Innocence Lost and Suspicion Found: Do we Educate for or Against Social Work?" Critical Social Work. 2(1).

Rossiter, Amy. (2005a). "Discourse Analysis in Critical Social Work: From Apology to Question." Critical Social Work, 6(1). 
Rossiter, Amy. (2005b). "Where in the World Are We? Notes on the Need for a Social Work Response to Global Power." Social Work: A Critical Turn. S. Hick, J. Fook \& R. Pozzuto (Eds.) Toronto: Thompson Educational Press. 189-202.

Scott, Katherine. (2003). Funding Matters: The Impact of Canada's New Funding Regime on Nonprofit and Voluntary Organizations. Ottawa: Canadian Council on Social Development.

Shepard, Benjamin. (2005). Play, Creativity, and the New Community Organizing. Journal of Progressive Human Services, 16(2): 47-69.

Smith, Dorothy E. (1987). The Everyday World as Problematic: A Feminist Sociology. Toronto: University of Toronto Press.

Swanson, Jean. (2001). Poor-Bashing: The Politics of Exclusion. Toronto: Between the Lines.

Valverde, Mariana. (1991). The Age of Light, Soap and Water: Moral Reform in English Canada, 1885-1925. Toronto: McClelland \& Stewart.

Walters, William. (1997) 'The "Active Society": New Designs for Social Policy'. Policy \& Politics, 25(3): 221-34. 


\begin{abstract}
APPENDIX A
Interview Guide for People Living on Welfare

This is a semi-structured interview. Before posing the questions, thank the participant for agreeing to meet with you. Review the information letter in detail. Review the consent form in detail, then ask him/her to sign it. Explain that he or she may decline to answer any questions, or may choose to remove him/herself from the process at any time. Explain that anonymity will be guaranteed and that information will not be used against you in any way. Ask if s/he has any questions before we get started.
\end{abstract}

1. What does getting welfare feel like for you? Are there good things about welfare? Bad things about welfare?

2. How do you feel about having to deal with welfare workers? What is that like for you?

3. When you first went on welfare, what kind of information did they need from you?

4. How did you feel about them asking for this information?

5. Why do you think they need this information?

6. Have you ever been asked to look for work or have a "work placement" while on welfare? Did you feel like you had a choice? How do you feel about that?

6. Have you ever been told that you couldn't access resources because of job requirements? What was that like for you?

7. Many people say that it is difficult to make ends meet while living on welfare. Tell me about how you manage on welfare.

8. Are you aware of any situation where welfare rules are not strictly followed? How do you feel about that? Please do not disclose names. (Probe for reporting income, rent etc.)

9. Is there anything you feel you can't do because of where you get your money?

10. Do you ever talk to other folks on welfare and share information about "the system?" 
11. Some people feel monitored on welfare. Have you ever experienced this? What was that like for you?

12. Many people have been accused of doing things on welfare, even though they might be innocent. People have also been cut off of welfare for not "checking in" (for example, not submitting rent receipts or a resume every 3 months). Have you ever been investigated on welfare? Ever been cut off or assessed an overpayment? Did you fight this decision? Why/why not?

13. Did your worker ever tell you about legal/advocacy resources you could use to fight a decision you disagreed with?

14. Have you ever used the Legal Centre or the Coalition against Poverty to help you fight welfare? Why/why not?

15. Are there things that you think are unfair about welfare? What do you do or say when you think something is unfair?

16. Would you ever: sign a petition, join a protest, talk to your MP/MPP, write a letter, wear a button, vote in an election, join PCAP? Why or why not?

17. Is there anything you would like to talk about that we haven't covered?

Thank the participant for his/her time. Give him/her a list of resources, and talk to him/her about the resources/events happening in his/her community. 


\section{Interview Guide for Social Service Workers}

This is a semi-structured interview. Before posing the questions, thank the participant for agreeing to meet with you. Review the information letter in detail. Review the consent form in detail, then ask him/her to sign it. Explain that he or she may decline to answer any questions, or may choose to remove him/herself from the process at any time. Explain that anonymity will be guaranteed. Ask if s/he has any questions before we get started.

1. First, I'd like you to tell me the story of how you started working in the social service sector.

2. Tell me a bit about how you approach your job.

3. How does your funding help you? Is there anything you feel you can't do because of where you get your funding?

4. Are there things that you like about your funding? Are there things that you think are unfair about your funding? What do you do or say when you think something is unfair?

5. Do you ever talk to social service workers from other agencies and share information about how to access more funding/get around funding strings?

6. How do you deal with controversial issues in the workplace? (i.e. Welfare regulations, local advocacy campaigns)

7. How does your agency actualize your mission statement or make it concrete? How does your agency not do this? How are these moves shaped by funding requirements?

8. Has your agency changed in the time that you have been there? How has it changed? Why do you think it has changed? How do you feel about the change? (Probe for changes in funding regime with respect to agency changes.)

9. Have you ever been directed by a superior not to speak out on an issue that negatively affects the people you are supposed to be helping? Why? What did you do? How did you feel about that?

10. Some people feel monitored in the workplace? Have you ever experienced this? What was that like for you? (Probe for: not informing supervisor of action to avoid consequences.) 
11. When, if ever, are you afraid to speak out in your workplace, and/or in the community? Why are you afraid to speak out? How do you feel about that?

12. Would you ever: sign a petition, join a protest, talk to your MP/MPP, write a letter, wear a button, vote in an election, join PCAP? Why or why not?

13. Is there anything you would like to talk about that we haven't covered?

Thank the participant for his/her time. Give him/her a list of resources, and talk to him/her about the resources/events happening in his/her community. 


\section{APPENDIX B}

\section{ARE YOU ON WELFARE?}

Are you frustrated with the social assistance system?

Are you tired of not being listened to?

Would you like to share your experiences?

I am hoping to talk to people receiving welfare about their experiences with the social assistance system. The interviews are anonymous and confidential.

The findings will be used for a research project, as well as for community organizing.

If you are interested, please contact Marisa at 705-868-2521.

This research project has been approved by the Carleton University Research Ethics Committee.

\section{DO YOU WORK AT A SOCIAL SERVICE AGENCY?}

Are you frustrated with feeling that your funding sources affect your ability to advocate on behalf of clients?

Are you tired of not being listened to?

Would you like to share your experiences?

I am hoping to talk to individuals working for social service agencies about their experiences with advocacy. The interviews are anonymous and confidential.

The findings will be used for a research project, as well as for community organizing.

If you are interested, please contact Marisa at 705-868-2521.

This research project has been approved by the Carleton University Research Ethics Committee. 


\section{APPENDIX C}

\section{Funding/Income Support and Its Impacts: Letter of Information}

My name is Marisa Barnhart. I am a student at Carleton University's School of Social Work. I am currently working on a research project, which looks at how people receiving welfare or working in not-for-profit agencies are affected by the realities of their "funding arrangements." For example, some people are afraid to fight welfare because they are worried about getting "cut off". I would like to talk to 6 social service workers and 6 welfare recipients about their experiences in receiving money from government, for-profit and notfor-profit agencies.

\section{What happens if I participate?}

If you decide to participate in this project, you would be asked to take part in one interview that would last between 60-90 minutes. There is no compensation for participation. I will book a room where we can meet. I can give you bus tickets if you need help with transportation.

I have attached an interview guide to this letter, so you know a bit about what the interview would be like. You have the right to refuse to answer specific questions if you do not feel comfortable answering them.

If at any time before, during or after the interview you have any concerns, questions or you don't want to participate anymore, you can contact:

o me at 705-868-2521 (I am the only one who will have access to my messages on this line),

- my supervisor Professor Sarah Todd from the Carleton University School of Social Work at 613-520-2600 x. 4498,

- or the Carleton University Ethics Committee Chair, Professor Antonio Gualtieri at 613-520-2517 who will try to answer any questions you may have and address any of your concerns.

You can stop participating at any time, without any consequences. You can also decide not to answer certain questions during the interview.

\section{How Will Interviews Be Used?}

Interviews will be taped and written down by someone I hire who will not know who you are. I am the only person who will know your name. Your name will not appear on the recording or transcript, and therefore your identity will remain confidential and anonymous.

If you use any identifying information in your interview, this will be removed from the transcript in the research paper. Recordings and transcripts will be stored in a locked cabinet in my home, and I am the only one who has a key to that cabinet. I will also destroy them at the end of the research project (approximately September 2006).

\section{Will Anything Happen to me if I Participate?}

While there are not very many risks in participating in this project, because other people will not know that you are participating, it is possible that other people (for example, someone 
from the welfare office) could read this report and respond in a way that is either negative or positive. For this reason, I will remove any identifying information that might let people know who you are from the final paper. Also, even though I will be using direct quotations from our interview, I will remove any references to your identity, types of things that you do, and any other identifying information. Therefore, there should not be any risks if you participate.

\section{How Will I Know What Happens with the Research?}

I will give you a written copy of the interview. I would also be happy to give you a summary of my findings when the research is completed. The information will be used in the final research project. I might also use the information in conference presentations and articles.

I'd also like to share the project with the community, through the local anti-poverty advocacy organization, so that we can use this information to help our community.

This project has been approved by the Carleton University Research Ethics Committee. If you have any concerns or questions about your involvement in the research process, you may contact the Chair of the Committee, Prof. Antonio Gualtieri. You can call him at 613-5202517 or email the ethics committee at ethics@carleton.ca.

If you would like to participate in this project, please read and sign the attached consent portion. I appreciate your interest in this project, and I look forward to the opportunity to work together.

Sincerely,

\section{Marisa Barnhart}

Name of Person Giving Consent:

Telephone or Other Contact:

Name of Researcher: $\quad$ Marisa Barnhart marisabarnhart@gmail.com 705-868-2521

Date of Research Activity:

I, the undersigned, have read the attached letter of information, and voluntarily agree that the researcher may use the information and quotations from our interaction.

Signature of Person Giving Consent

Signature of the Researcher
Date

Date 